$10 / 213-94850$

SAND93-7043

Unlimited Release

Printed April 1993

UC-276

\title{
Photovoltaic Power As A Utility Service: Guidelines For Livestock Water Pumping
}

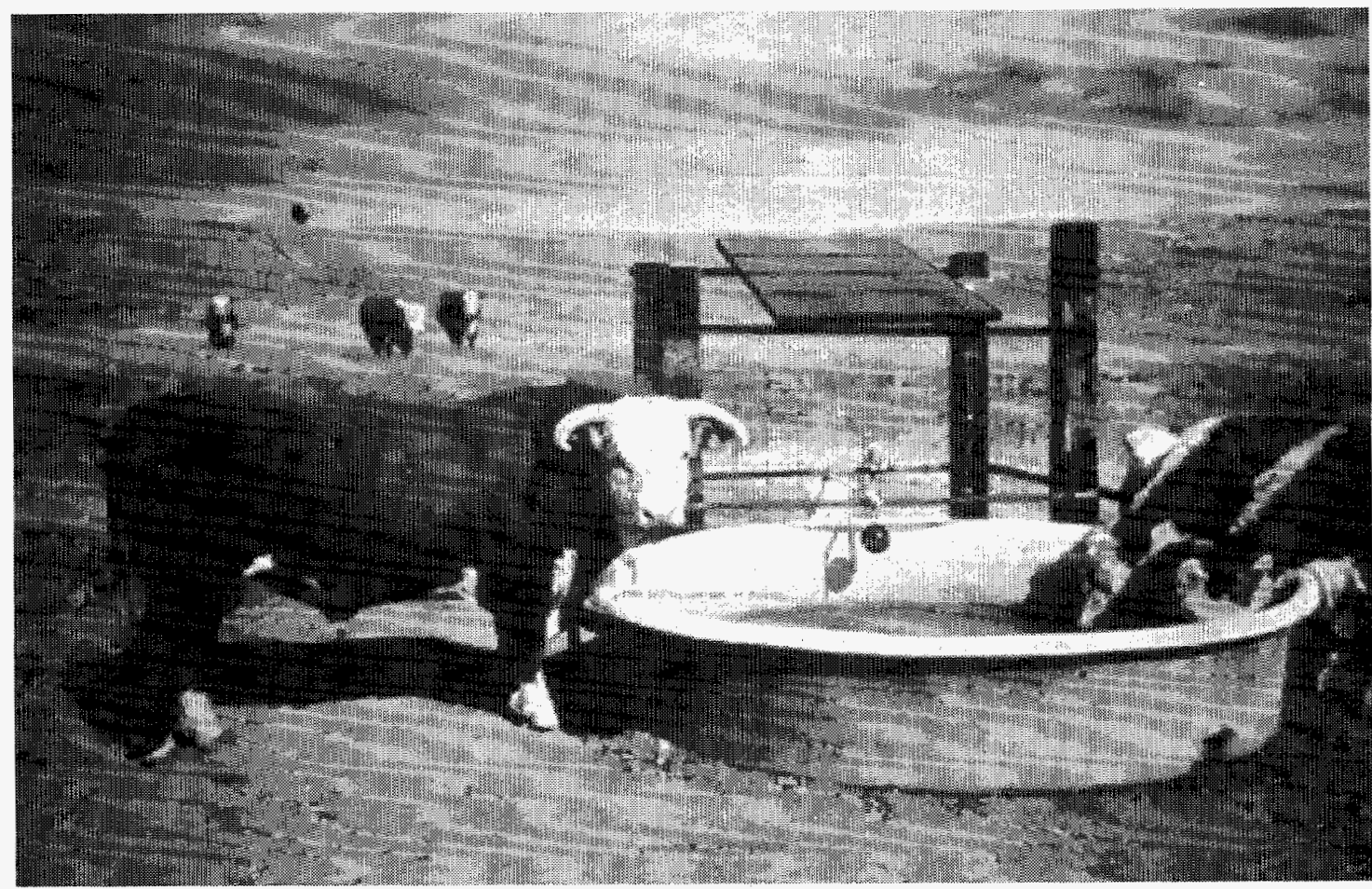

Prepared by Sandia National Laboratories Albuquerque, New Mexico 87185 and Livermore, California 94550 for the United States Department of Energy under Contract DE-AC04-76DP00789 
Issued by Sandia National Laboratories, operated for the United States Department of Energy by Sandia Corporation.

NOTICE: This report was prepared as an account of work sponsored by an agency of the United States Government. Neither the United States Government nor any agency thereof, nor any of their employees, nor any of their contractors, subcontractors, or their employees, makes any warranty, express or implied, or assumes any legal liability or responsibility for the accuracy, completeness, or usefulness of any information, apparatus, product, or process disclosed, or represents that its use would not infringe privately owned rights. Reference herein to any specific commercial product, process, or service by trade name, trademark, manufacturer, or otherwise, does not necessarily constitute or imply its endorsement, recommendation, or favoring by the United States Government, any agency thereof or any of their contractors or subcontractors. The views and opinions expressed herein do not necessarily state or reflect those of the United States Government, any agency thereof or any of their contractors.

Printed in the United States of America. This report has been reproduced directly from the best available copy.

Available to DOE and DOE contractors from

Office of Scientific and Technical Information

PO Box 62

Oak Ridge, TN 37831

Prices available from (615) 576-8401, FTS 626-8401

Available to the public from

National Technical Information Service

US Department of Commerce

5285 Port Royal Rd

Springfield, VA 22161

NTIS price codes

Printed copy: A10

Microfiche copy: A01 


\section{DISCLAIMER}

Portions of this document may be illegible in electronic image products. Images are produced from the best available original document. 
SAND93-7043

Unlimited Release

Printed March 1993

Distribution

Category UC-276

Contractor Report

\title{
PHOTOVOLTAIC POWER AS A UTILITY SERVICE: GUIDELINES FOR LIVESTOCK WATER PUMPING
}

\author{
Prepared for \\ Mark Reineke \\ of \\ Sandia National Laboratories \\ Co-Sponsors \\ Electric Power Research Institute \\ Western Area Power Administration \\ Prepared by \\ Kirk Stokes, Pat Saito, and Cheryl Hjelle \\ of \\ NEOS Corporation
}

\begin{abstract}
Several utilities in the western U.S. have recently begun testing photovoltaic (PV) service programs. To transfer information from these utilities to others that might be interested, Sandia National Laboratories, in collaboration with the Electric Power Research Institute and the Western Area Power Administration, is addressing five primary objectives: (1) identify utilities that presently offer PV as a service option for isolated utility loads, such as livestock water pumping; (2) gather information on program implementation procedures and constraints; (3) assess utility and customer attitudes toward PV-powered systems; (4) document the cost, performance, and reliability of any PV-powered systems installed by these utilities; and (5) compile all "lessons learned" into a document describing PV as a utility service option for livestock water pumping.

This document provides electric utility staff (e.g., planning, marketing, engineering, etc.) with general guidelines for implementing PV services for pumping livestock water. The first part of the document provides general PV service guidelines based on the experiences and observations of utilities that have begun to consider these services. The second part is intended to provide implementation guidelines for water pumping projects, ranging from site selection to installation and troubleshooting. Throughout this document, the utility "lessons learned" are used to substantiate the PV service and water pumping guidelines.
\end{abstract}

The goal of the PV water pumping project has been to assess the suitability of PV as a utility service for livestock water pumping customers because this particular load occurs frequently in the western and mid-western U.S. and the cost of serving this load using traditional utility methods can be excessive. However, the "lessons learned" from utility PV-powered water pumping services are applicable to other off-grid PV service applications as well. 


\section{ACKNOWLEDGMENTS}

Thanks to Mark Reineke of Sandia National Laboratories, John Bigger of the Electric Power Research Institute, and Peggy Plate of the Western Area Power Administration. They have provided the leadership necessary to make PV power a viable service option for electric utilities.

Thanks to all the utilities that have participated openly in the PV water pumping projects sponsored by Sandia, EPRI, and Western. Without their enthusiasm and cooperation, this document would not have been possible.

Finally, thanks to Tim Ball and Mike McGoey of Solar Engineering Services for their valuable contributions to the development of this document. The PV system design, installation, and maintenance expertise that they and other PV suppliers provide is a resource utilities should consider when implementing PV services. 


\section{CONTENTS}

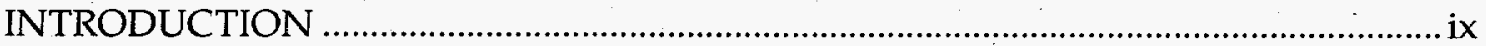

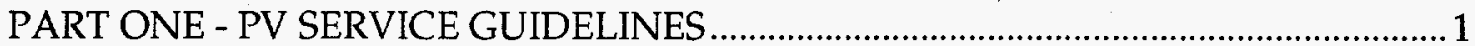

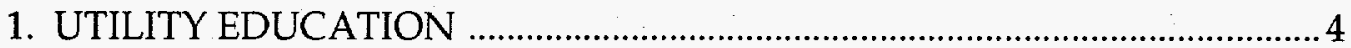

Goals and Objectives ....................................................................... 4

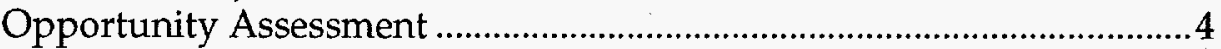

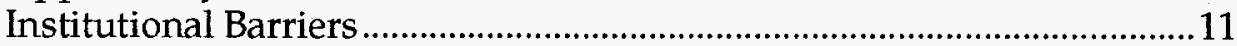

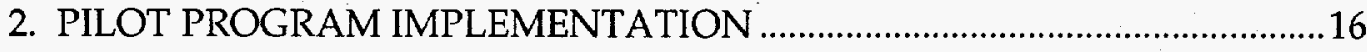

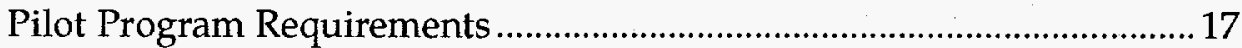

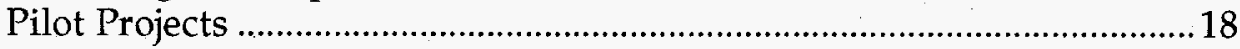

3. FULL-SCALE PROGRAM DESIGN AND IMPLEMENTATION .................22

Design PV Service Program ................................................................... 22

Implement Full-Scale Program ........................................................... 30

PART TWO - PV-POWERED WATER PUMPING GUIDELINES ….................................33

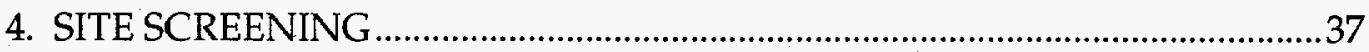

How to Use the Cost-Estimation Chart .................................................38

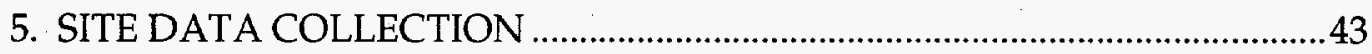

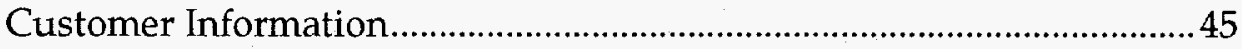

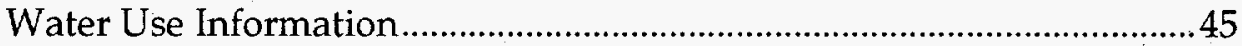

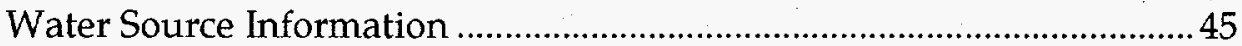

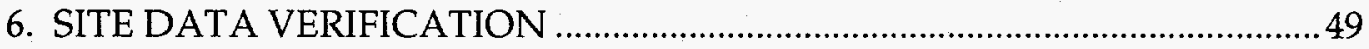

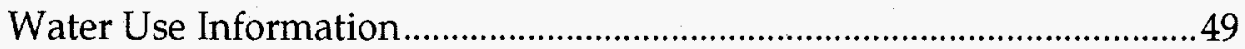

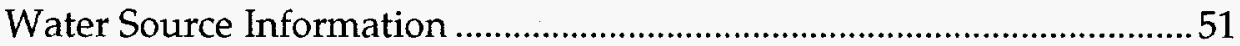

7. PV PUMPING SYSTEM COMPONENTS ................................................5

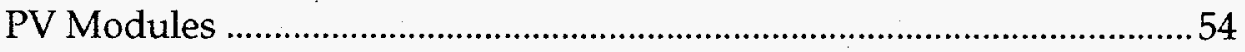

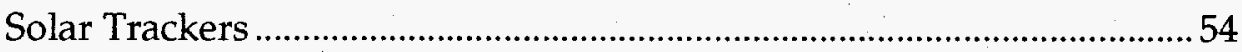

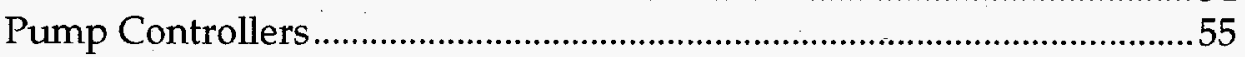

Batteries and Charge Controllers ...........................................................56

Water Level Sensors and Float Switches ...................................................5 57

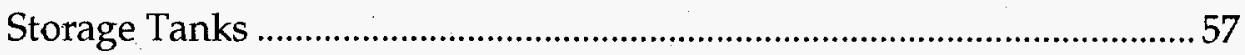

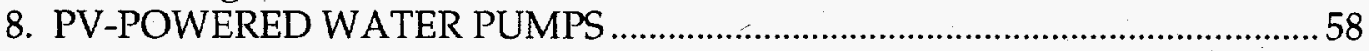

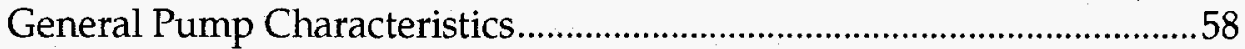

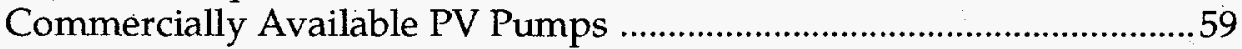

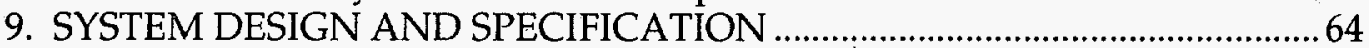

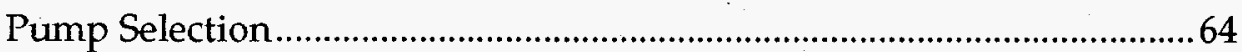

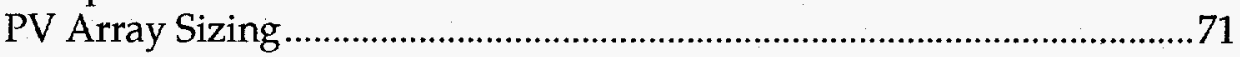

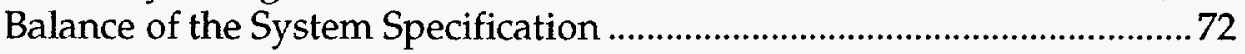

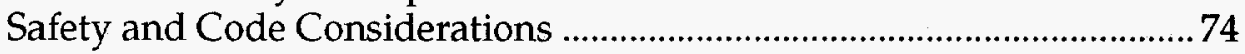

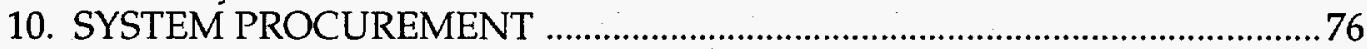

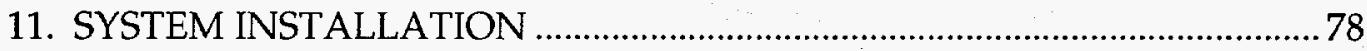

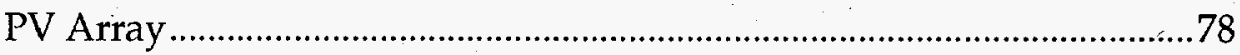

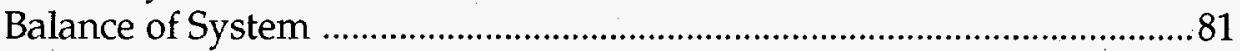

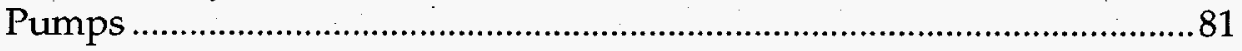

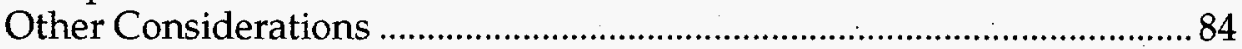

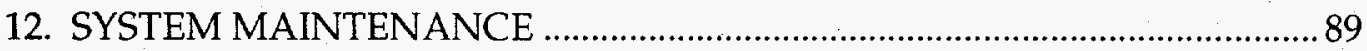

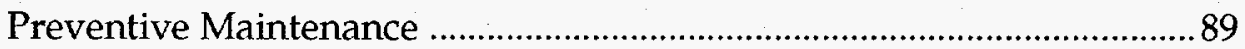

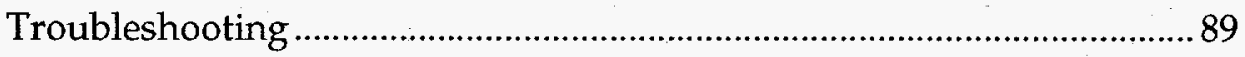




\section{CONTENTS (Continued)}

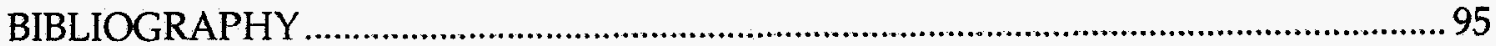

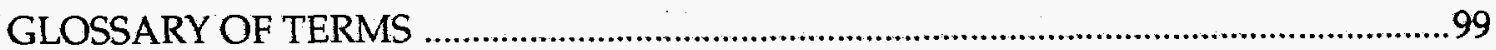

APPENDIX A Resource List for PV Information .............................................................. 103

APPENDIX B List of Pump Manufacturers and Equipment Suppliers ...........................107

APPENDIX C Wiring Sizing Guidelines from PV Stand-Alone Handbook ...................111

\section{FIGURES}

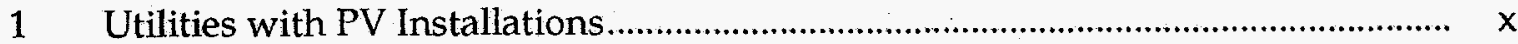

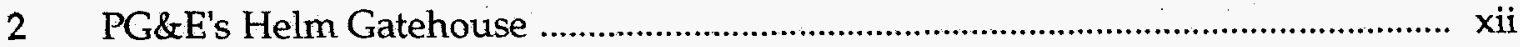

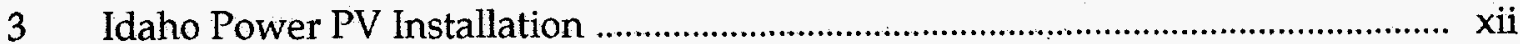

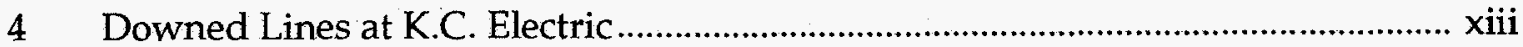

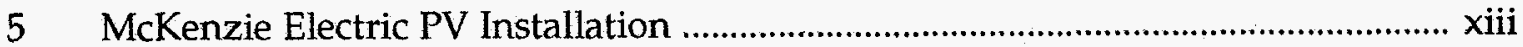

6 San Isabel's Trailer-Mounted System ................................................................... xiv

$7 \quad$ Pumping System in Northwest Rural's Territory .................................................... Xv

$8 \quad$ Northwest Rural Installing PV System .................................................................. 1

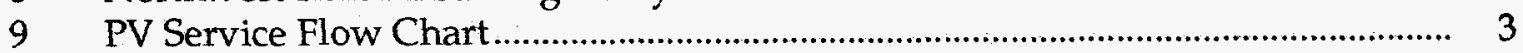

10 Utility Education Flow Chart .............................................................................. 5

11 Typical REC Service Costs for Livestock Water Pumping Customers .................. 7

12 Typical Livestock Water Pumping System ............................................................. 10

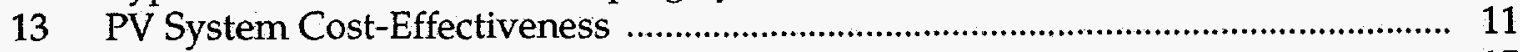

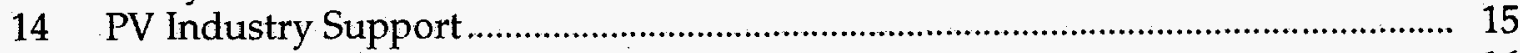

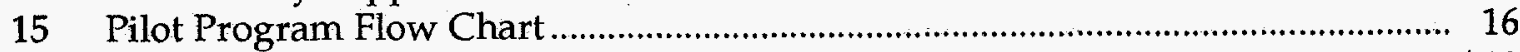

16 Trailer-Mounted Systems ...................................................................................... 19

17 Full-Scale Program Flow Chart ............................................................................ 22

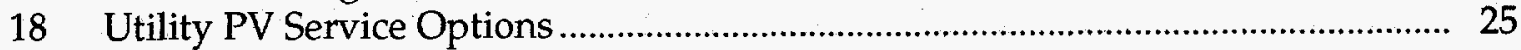

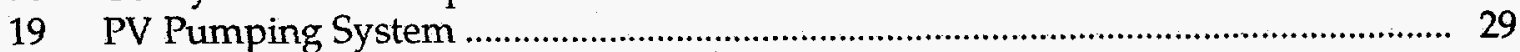

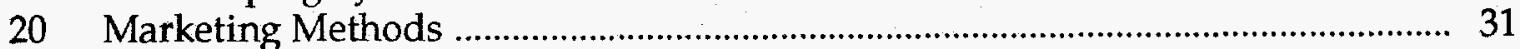

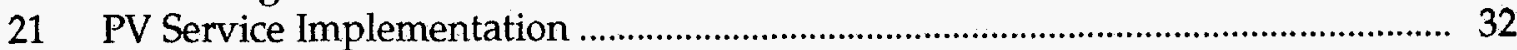

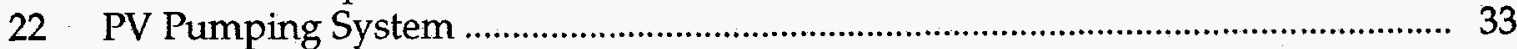

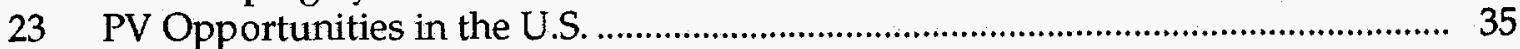

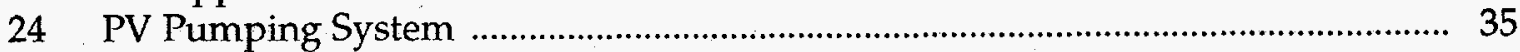

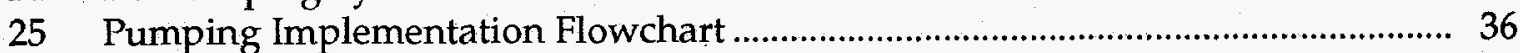

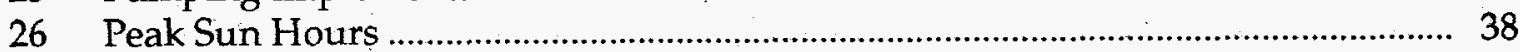

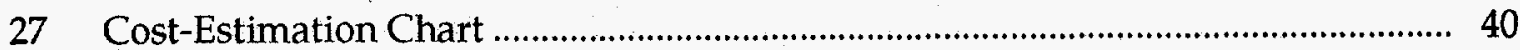

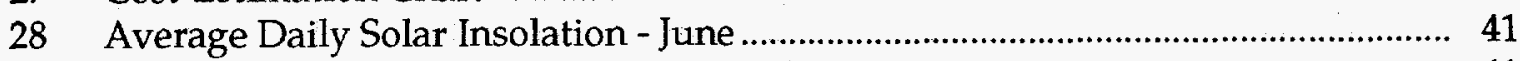

29 Average Daily Solar Insolation - September .................................................. 41

30 Average Daily Solar Insolation - December ......................................................... 42

31 Average Daily Solar Insólation - March................................................................ 42

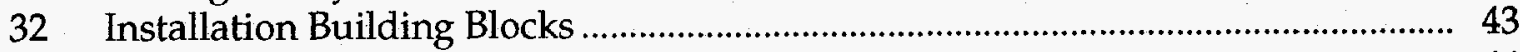

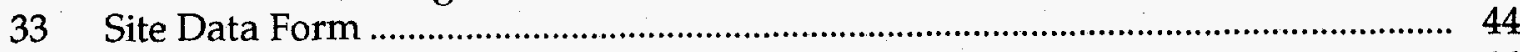

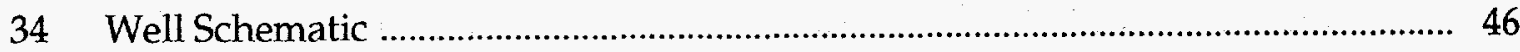

35 Crumbling Installation Building Blocks ............................................................. 49

36 PV Pumping System ..................................................................................... 50 


\section{FIGURES (Continued)}

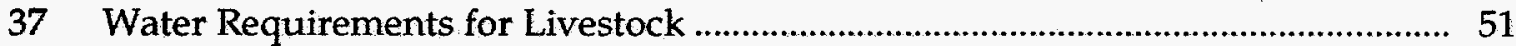

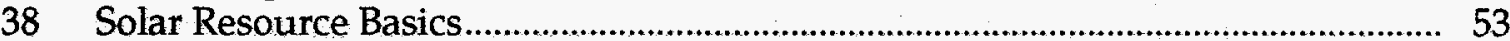

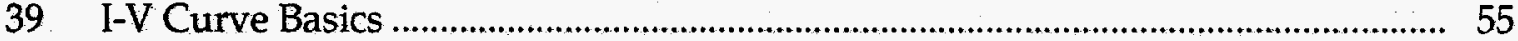

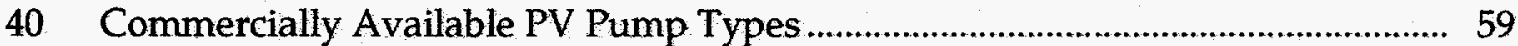

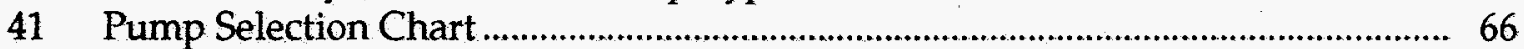

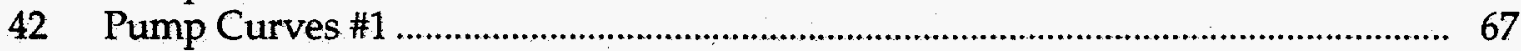

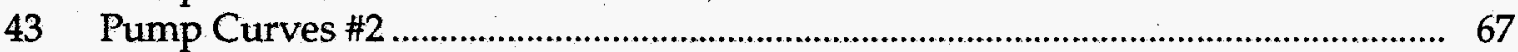

44 Commercial PV Pump Types with Manufacturers ............................................... 70

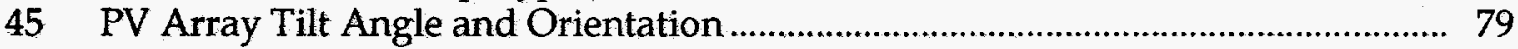

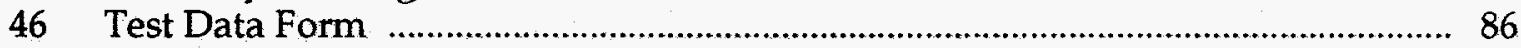

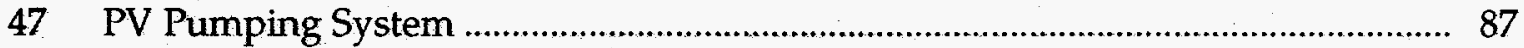




\section{PHOTOVOLTAIC POWER AS A UTILITY SERVICE: GUIDELINES FOR LIVESTOCK WATER PUMPING}

\section{INTRODUCTION}

This document is intended to provide electric utility staff (e.g., planning, marketing, engineering, etc.) with general guidelines for implementing photovoltaic (PV) services to livestock water pumping customers. To transfer information from existing utility PV service programs to others that might be interested, Sandia National Laboratories (Sandia), the Electric Power Research Institute (EPRI), and the Western Area Power Administration (Western) have collaborated closely to document systems. These experiences are used throughout this document to substantiate the PV service and water pumping guidelines.

Why are electric utilities offering PV power as a customer service, as well as using it within their own operations?

- Reduced installation, operation, and maintenance costs!

- Extended customer service options!

- Improved customer relations!

- More affordable utility service in remote areas!

- Stronger local economies due to reduced costs and the use of local resources!

In fact, the recognition of these benefits has become widespread in the utility industry today. Small and large; publicly owned and privately owned; and rural and municipal utilities are recognizing that $\mathrm{PV}$ power can significantly reduce the cost of service to small outlying or difficult-to-serve loads (e.g., lighting systems, livestock water pumping, and cathodic protection, etc.) without compromising service reliability or customer satisfaction.

\section{Overview}

At last count, over 70 utilities in 28 states throughout the country have installed PV-powered systems for numerous applications in their service territories. Additionally, 15 of these utilities have implemented pilot PV service programs to solve line extension problems and create new customer service options. 


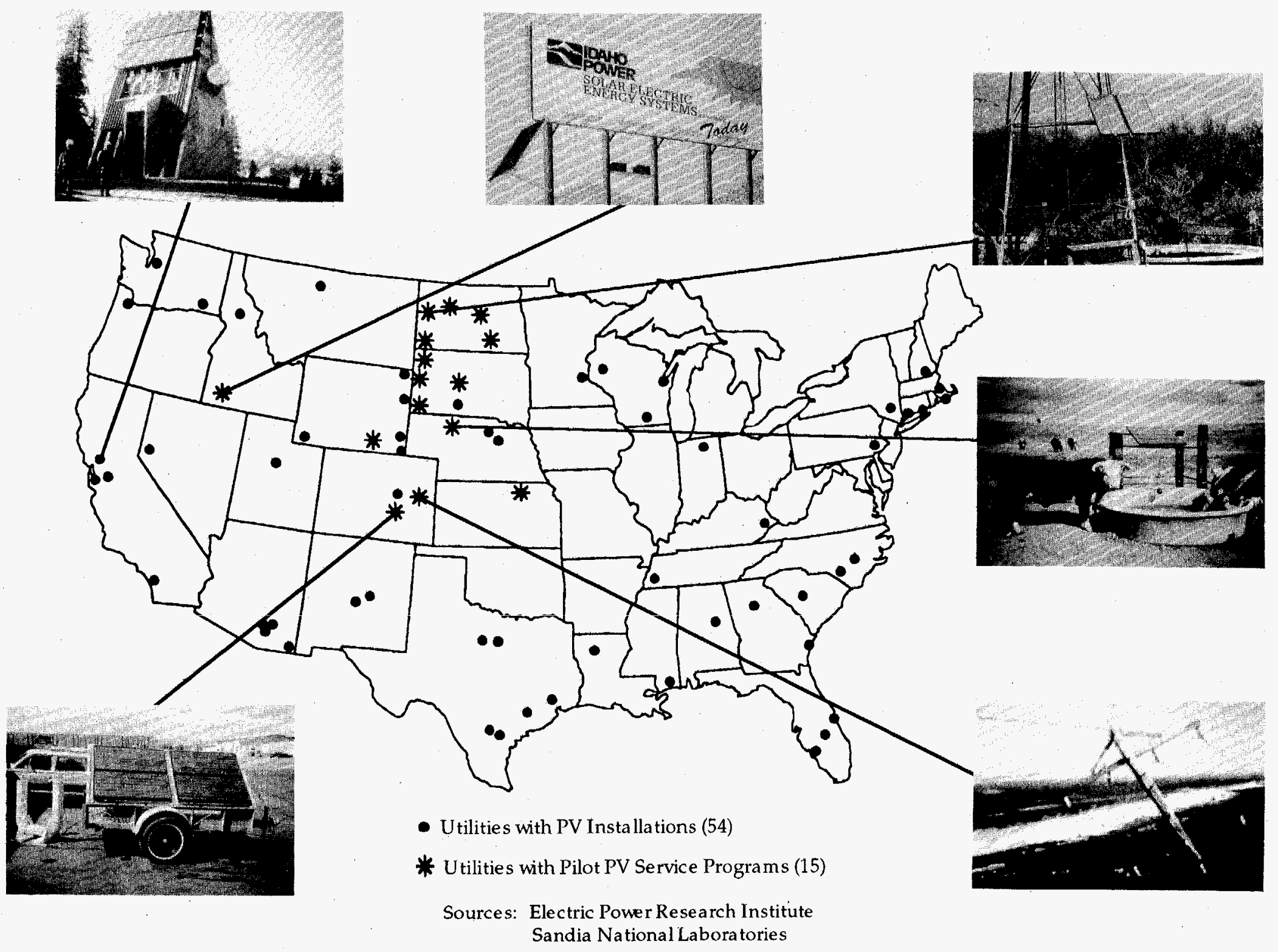


At the end of 1992, over 1,000 cost-effective PV systems had been installed within PG\&E's operations for numerous applications including remote monitoring, cathodic protection, and communications. In most cases, these electric loads have been characterized by their relatively small power requirements, remote locations, and high costs of service. In all cases, the PVpowered system was the least expensive solution for the particular application.

\section{Idaho Power Company}

In January 1993, Idaho Power became the first investor-owned utility in the country to provide PV power as a service to its customers. Under the pilot program tariff, the utility will not sell PV systems but rather will design, install, own, and maintain the systems to provide electric service at the point of use. The three-year pilot program, which has a $\$ 5$ million total budget and a $\$ 50,000$ maximum cost per installation, is intended primarily to provide service to off-grid residences and livestock water pumping systems.

\section{K.C. Electric Association}

As with many rural electric cooperatives, K.C. Electric is responsible for operating and maintaining a distribution system that serves many remote ranching and farming loads. The cost of maintaining this system was staggering in March 1989 when a winter storm destroyed over 1,000 poles that cost nearly one million dollars to repair. Additionally, many of the rebuilt lines from this storm serviced only small remote pumping loads. K.C. Electric has subsequently identified over 60 grid-connected stock well pumping systems (accounting for 90 miles of utility line) that will be replaced with PV-powered systems should the line require repair in the future.

\section{McKenzie Electric}

McKenzie Electric is a rural electric cooperative with nearly 900 grid-connected livestock wells in its service territory. Due to the age of much of its system, the utility will need to rebuild line to many of these wells in the next few years at an estimated cost of nearly $\$ 10$ million. McKenzie Electric's PV service program will address these problems by replacing gridconnected pumping systems with PV-powered ones as required. To date, a partially completed system survey has identified 110 replacement sites that would eliminate over 72 miles of line and save the utility over $\$ 500,000$ in reconstruction costs.

\section{San Isabel Electric}

San Isabel Electric is a rural electric cooperative interested in using PV power to extend the utility's service options. San Isabel has built its program on the flexibility of PV-powered systems by purchasing six trailer-mounted pumping systems that will be leased to its customers. By leasing trailer-mounted systems, the utility has the flexibility to move each PV- 
Introduction

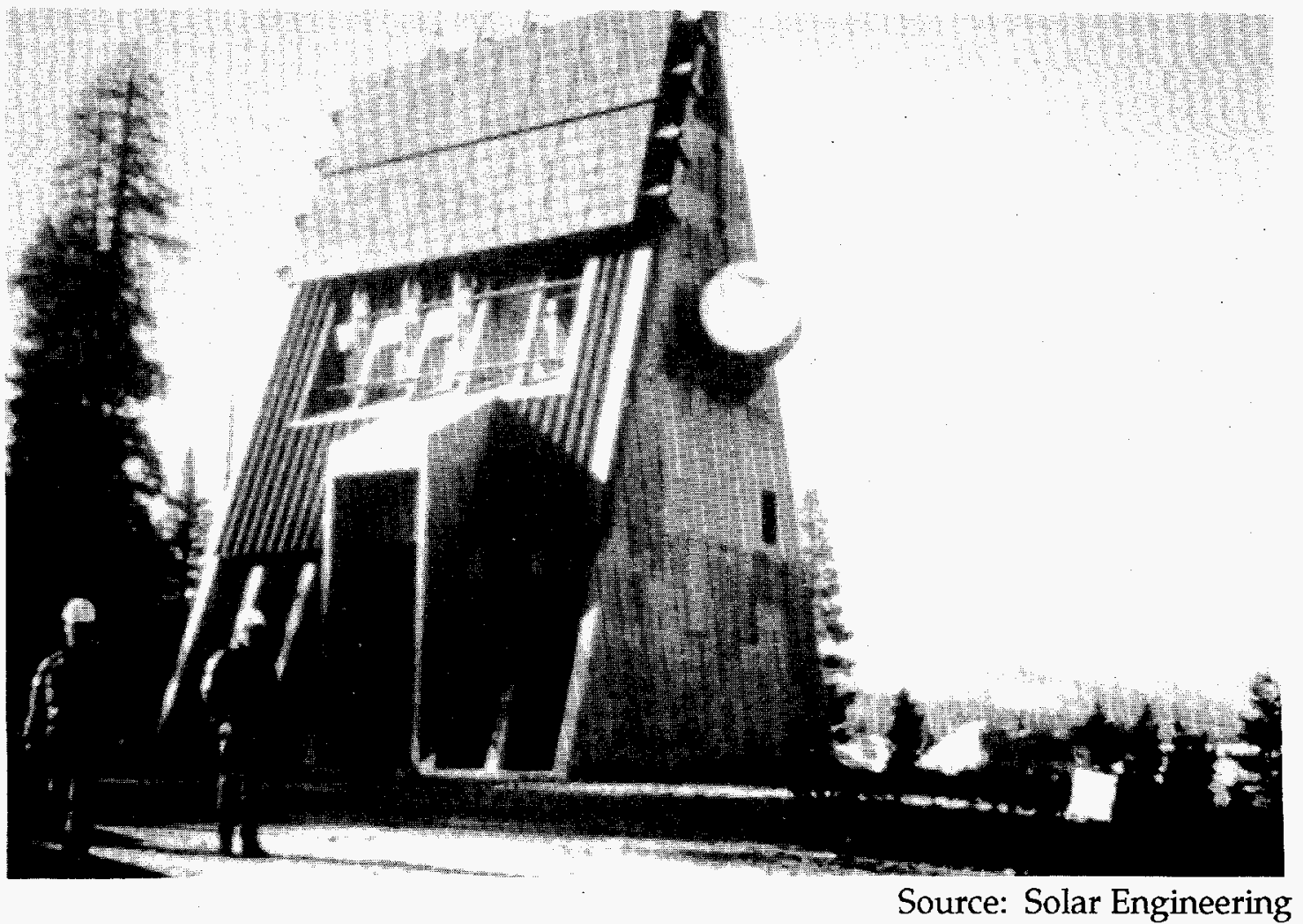

Figure 2. PG\&E's Helm Gatehouse

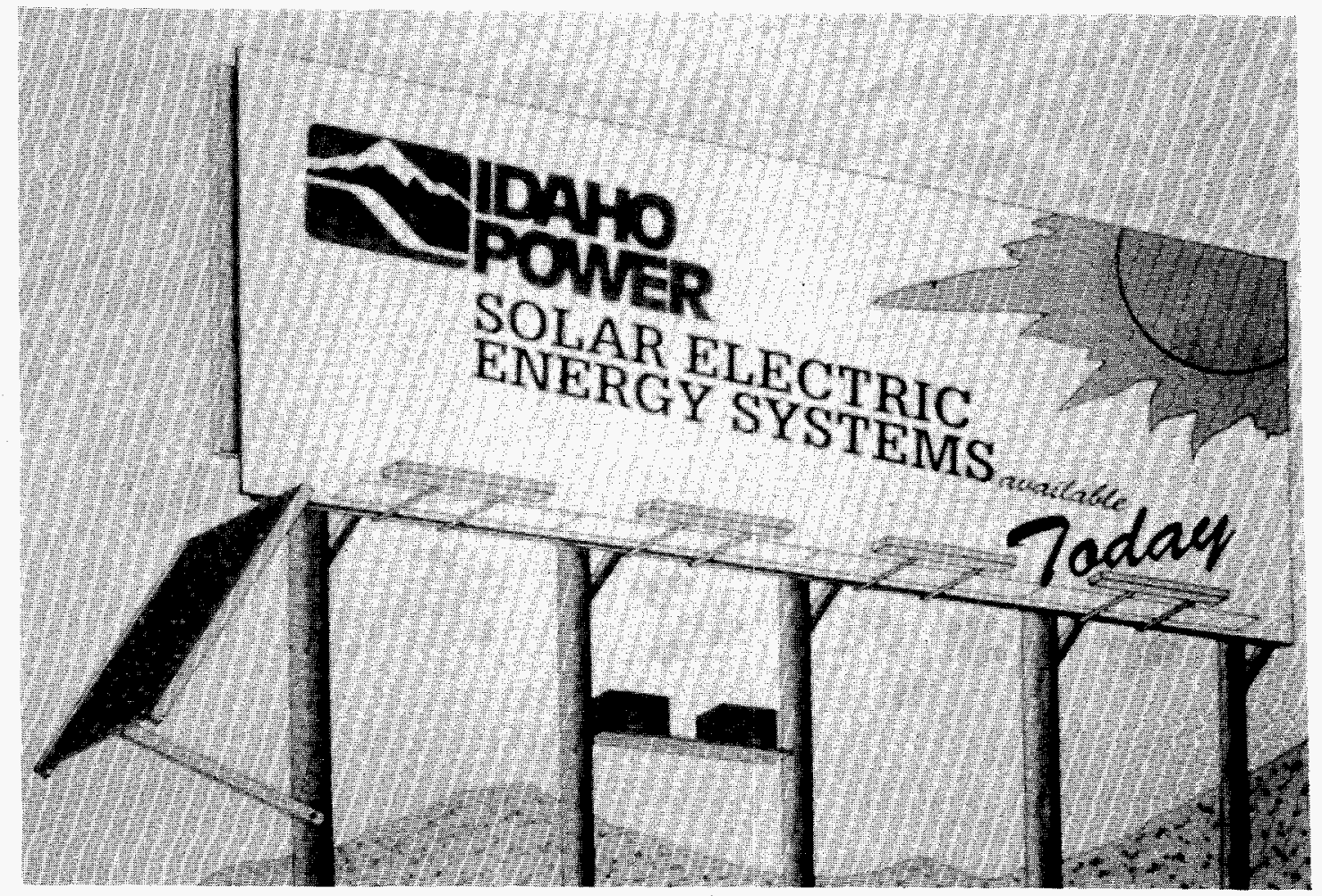

Figure 3. Idaho Power PV Installation 


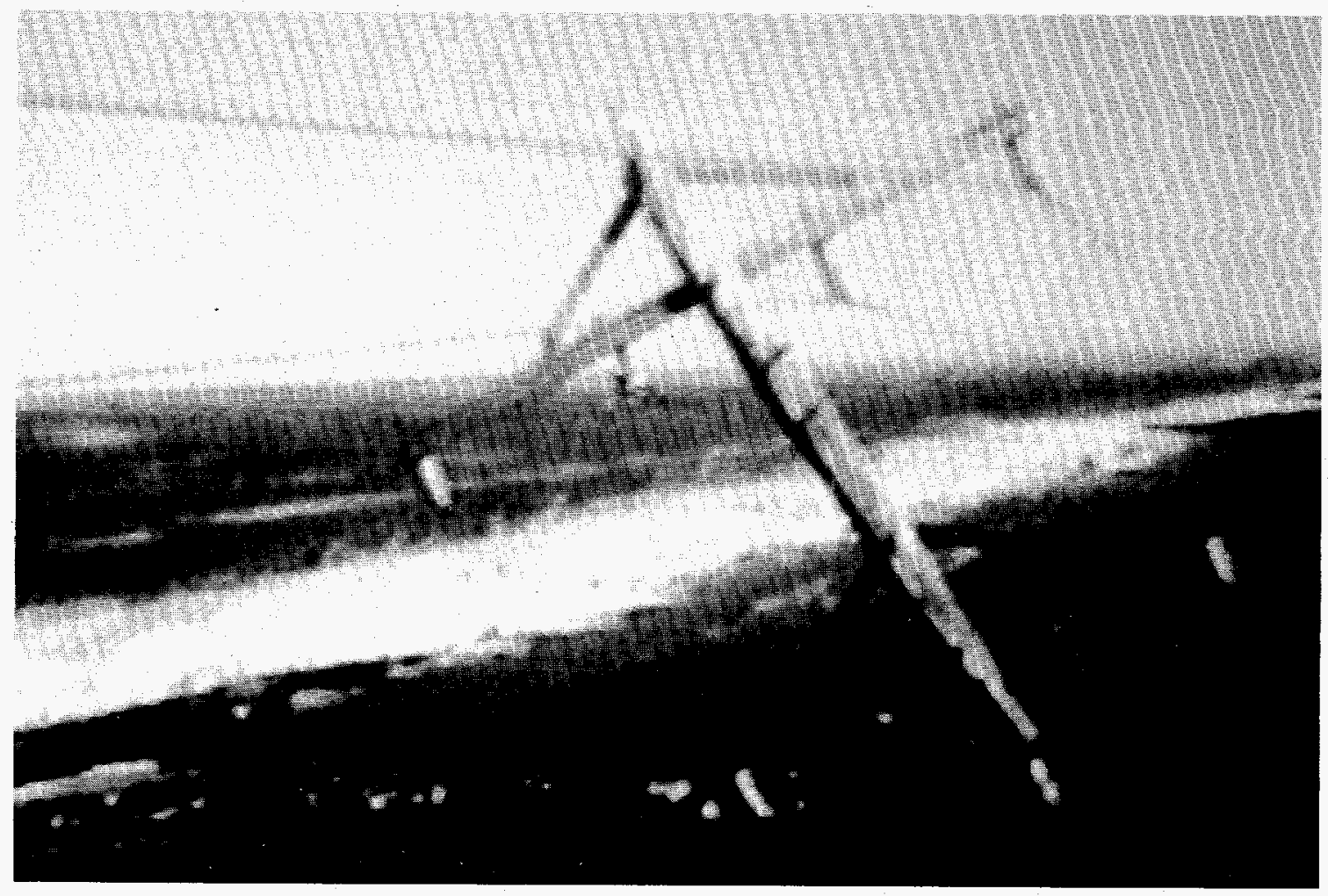

Figure 4. Downed Lines at K.C. Electric

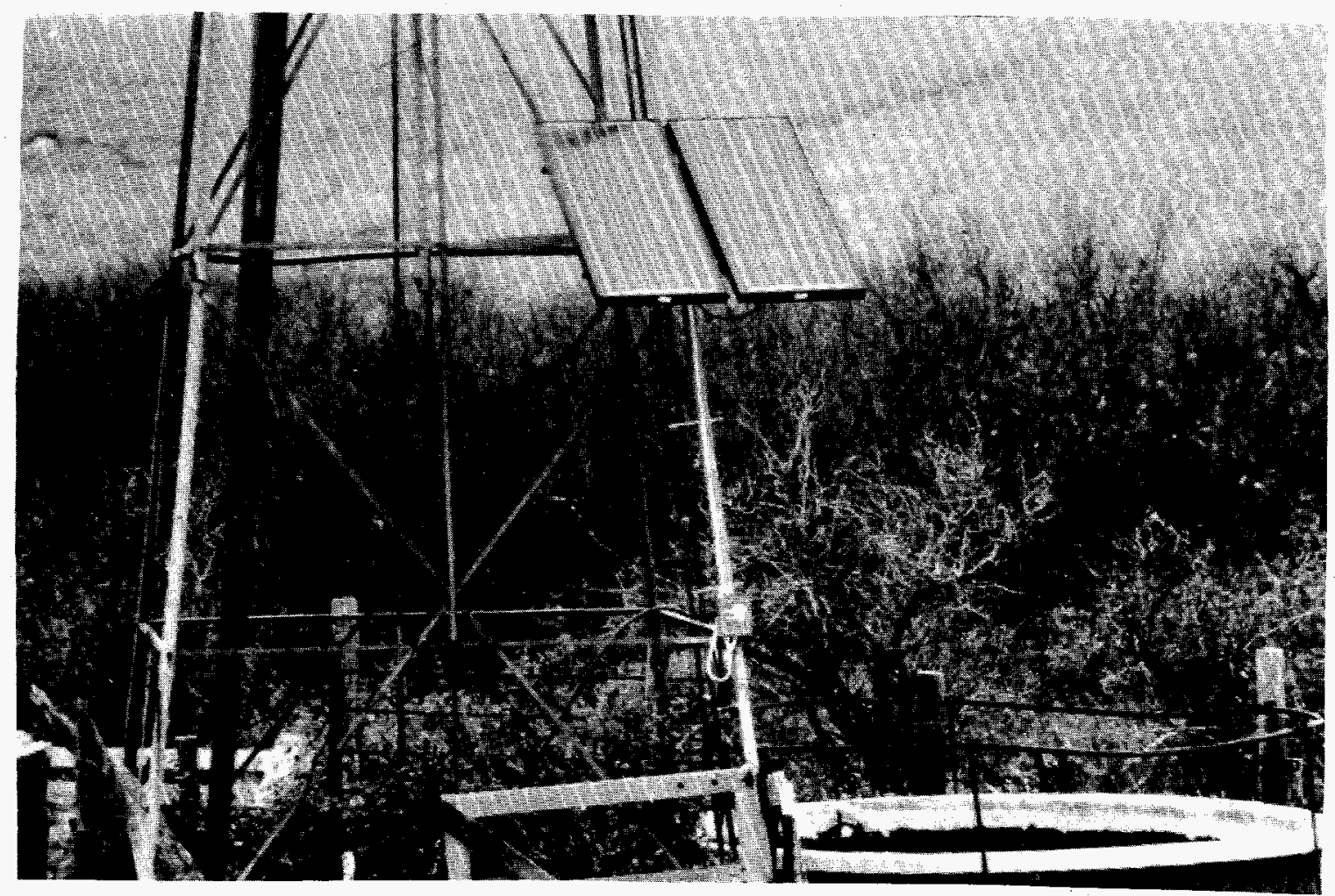

Figure 5. McKenzie Electric PV Installation 


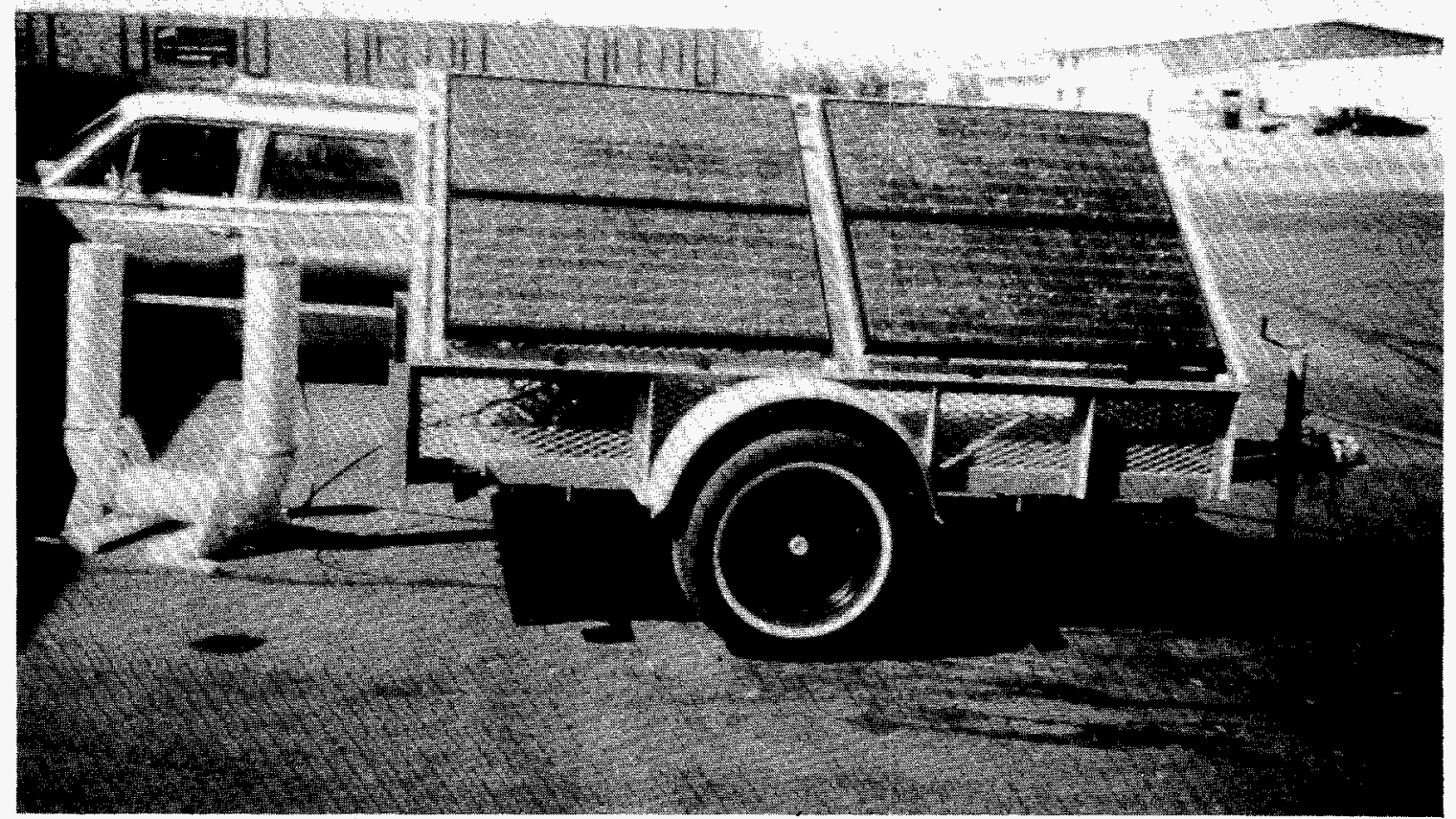

Source: Remote Power

Figure 6. San Isabel's Trailer-Mounted System

powered pumping system to different pastures depending on the customer's need. Additionally, the water delivered to each site can be adjusted to particular needs simply by adding or subtracting PV modules from the trailer. In this way, San Isabel's ranching customers benefit by receiving service tailored to their needs and by not paying for a "fixed" installation that is useless when cattle are moved out of the pasture.

\section{Northwest Rural Public Power District}

Northwest Rural initiated its pilot PV service program in April 1990 in an effort to provide less costly service to its ranching customers. Not only does the utility have reconstruction problems similar to other rural electric cooperatives, but it regularly receives line extension requests for service to new well sites. One reason for these requests is that grazing regulations on federal lands, which are significant in the area, are changing to require more frequent pasture rotation. This rotation in turn requires more water sources, and line extension requests result. Another unique attribute of Northwest Rural's program has been the utility's desire to foster local economic development by working closely with a rancher who expressed interest in starting a PV business. 


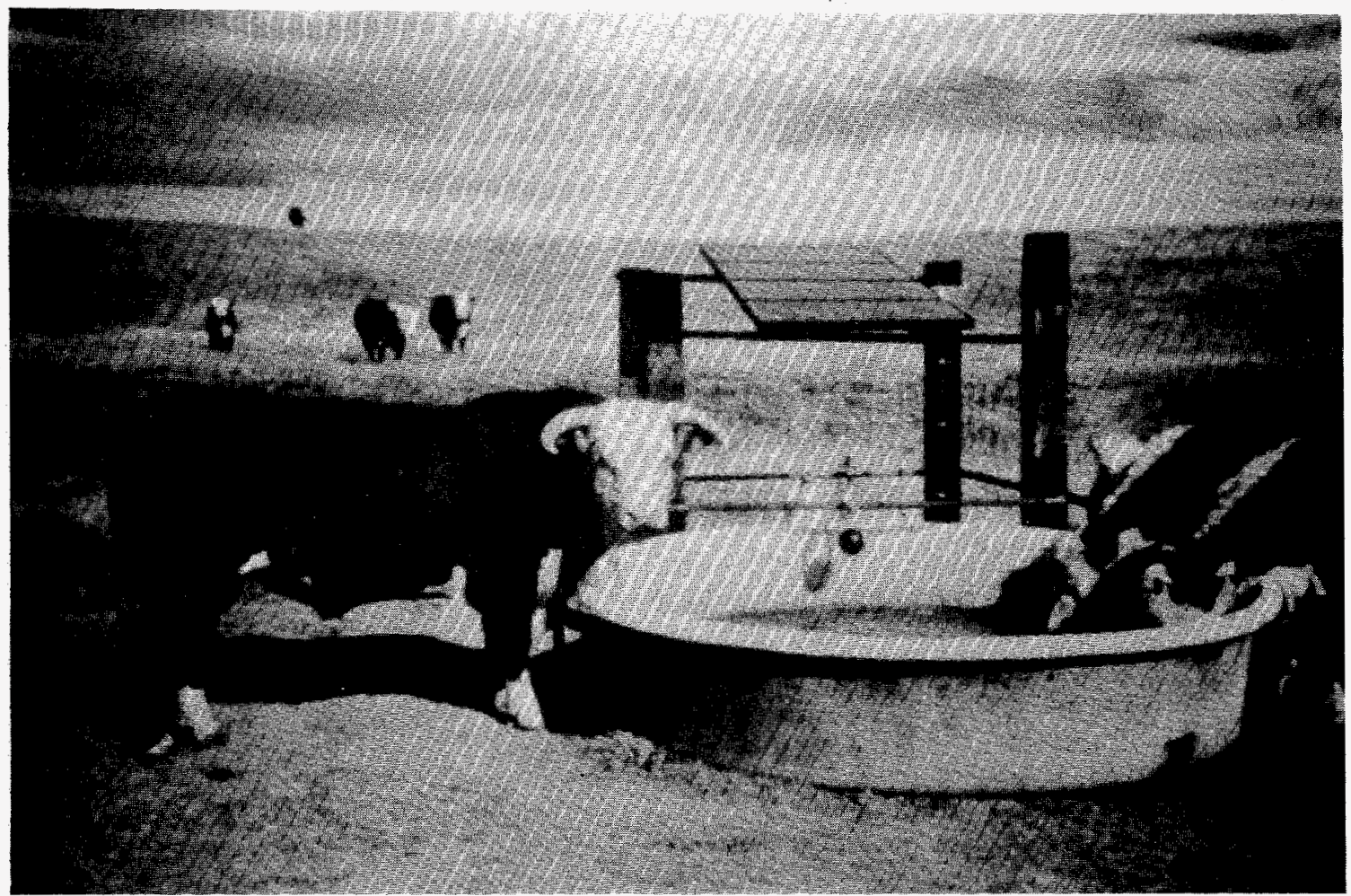

Figure 7. Pumping System in Northwest Rural's Territory

As is evident, the two primary reasons that utilities offer PV services are reduced operation and maintenance (O\&M) costs and extended service options. However, other reasons identified by utilities include benefits such as PV system flexibility (i.e., both mobility and modularity) and opportunities to improve customer relations by lowering electric service costs in remote areas. These PV services can also foster local economic development and reduce environmental impacts by using a renewable energy resource to eliminate line extensions.

\section{Utility Resources}

When utilities recognize these benefits and decide to implement PV services, they already have the resources necessary for establishing successful PV services. These resources include financial resources, staff expertise, business stability, and an existing market. First, the financial resources required to implement a PV service program are essential, since nearly all the costs for a PV-powered system occur initially as a capital investment. Second, supplying customers with energy services is a business the utility knows well, and the utility's existing staff expertise (e.g., technical, marketing, procurement, etc.) will be necessary to support the new customer service. Third, the utility's inherent business stability will encourage customer confidence that PV technology is reliable and that the utility's customer service will be available when needed. 
Finally, the utility's service territory is an existing market that is easily accessed for new energy service opportunities like PV.

Everyone wins when electric utilities provide PV services. Obviously, the utility wins by reducing its service costs, extending service options, and improving customer relations. Utility customers win because of more affordable remote electric service, improved local economies, and reduced environmental impacts. PV equipment manufacturers and vendors win when the utility creates a wider market, lends credibility to the PV technology, and provides long-term stability to the relatively new PV industry.

\section{Guidebook Description}

The goal of this document is to provide electric utility staff (e.g., planning, marketing, engineering, etc.) with general guidelines for implementing PV services to livestock water pumping customers. To achieve this goal, the document has been divided into two parts, $P V$ Service Guidelines and PV-Powered Water Pumping Guidelines. The first part is intended to provide general PV service guidelines based on the experiences and observations of utilities that have begun to consider these services. The second part is intended to provide water pumping project implementation guidelines, ranging from site selection to installation and troubleshooting. Throughout this document, the utility "lessons learned" are used to substantiate the PV service and water pumping guidelines. 
PART ONE - PV SERVICE GUIDELINES

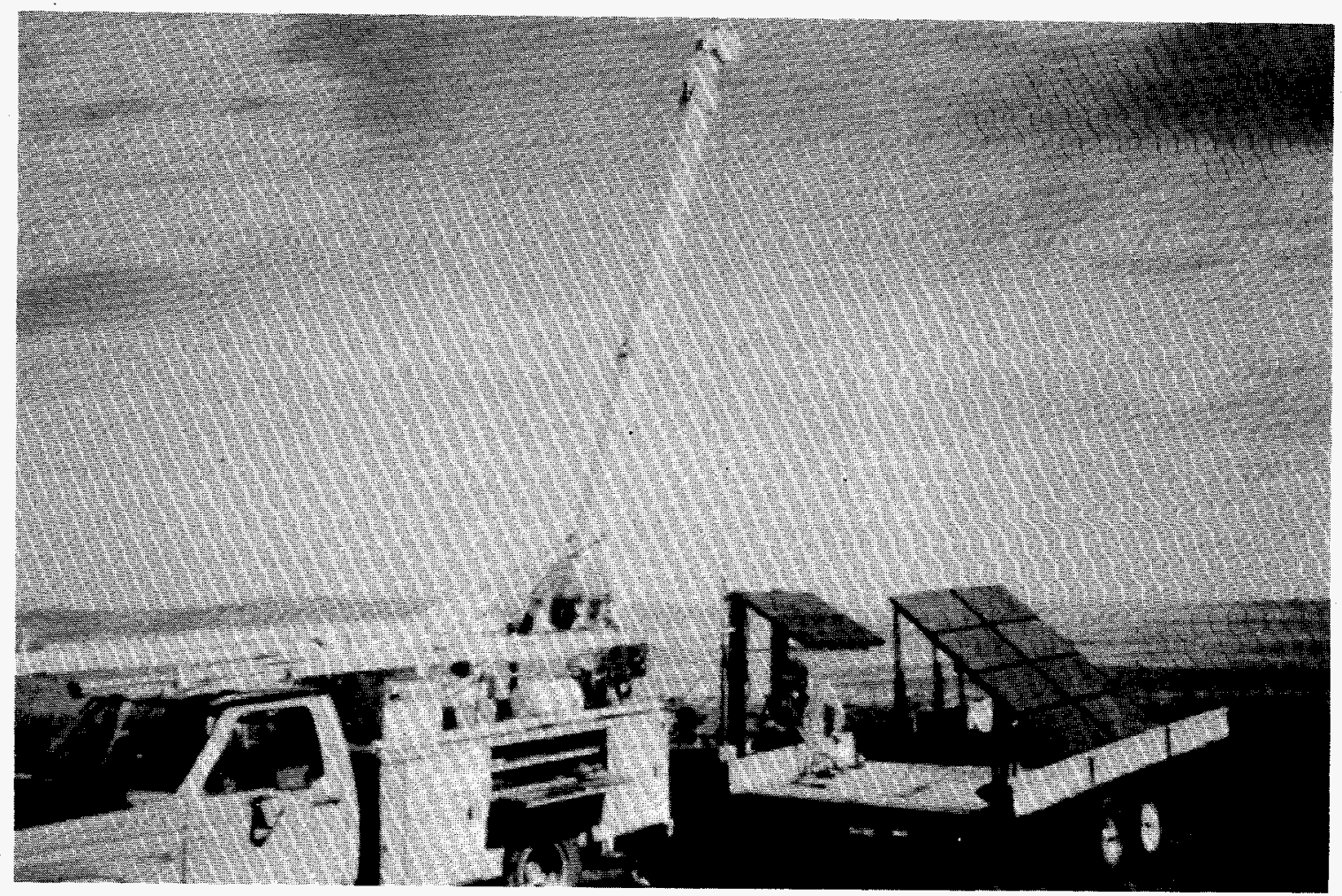

Figure 8. Northwest Rural Installing PV System 
During the past few years, much discussion has occurred regarding the use of PV power by electric utilities. One particular concept, developed by Pacific Gas and Electric, for introducing PV into the utility industry, suggests that PV cost-effectiveness for particular "niche" markets will be the driving force behind its introduction. The concept clearly suggests how PV-powered applications might "diffuse" into the utility market. Specifically, utility involvement with PV likely will begin with small "stand alone" (i.e., not grid-connected) applications, ranging in size from a few watts to a few kilowatts. As utility experience grows with these applications, the model implies that other cost-effective niches will develop, such as distributed grid-support applications or customer-sited, demand-side management applications.

However, the PG\&E concept does not offer (nor was it intended to offer) suggested methods for initiating this utility market penetration within any particular market niche. As a result, the information presented in this part of the guidebook suggests a sequence of utility activities that can result in utility PV services for remote, stand-alone applications, such as livestock water pumping. The sequence includes three primary phases: utility education, initiation of a PV service pilot program, and design and implementation of a full-scale program. The transition between each step in this sequence involves considering whether PV services will actually solve a perceived problem or address a perceived opportunity within constraints (e.g., cost, performance, and reliability) established by individual utilities.

The following discussion is divided into three sections, utility education, pilot program implementation, and full-scale program design and implementation. In each section, a flow chart is presented that suggests a possible process for implementing the activities in each phase. For each activity, a specific statement is made that summarizes the particular activity. Each specific statement is then supported by a description of actual utility experiences and observations related to that activity. As described previously, many of the supporting utility experiences and observations are drawn from PV services for livestock water pumping customers. However, many of the lessons learned from this application are relevant to other remote, stand-alone applications as well.

The intent of this information is to provide electric utility staff (e.g., planning, marketing, engineering) with general guidelines for implementing PV services for off-grid applications like livestock water pumping. The specific activities related to PV service development will undoubtedly vary from utility to utility. 

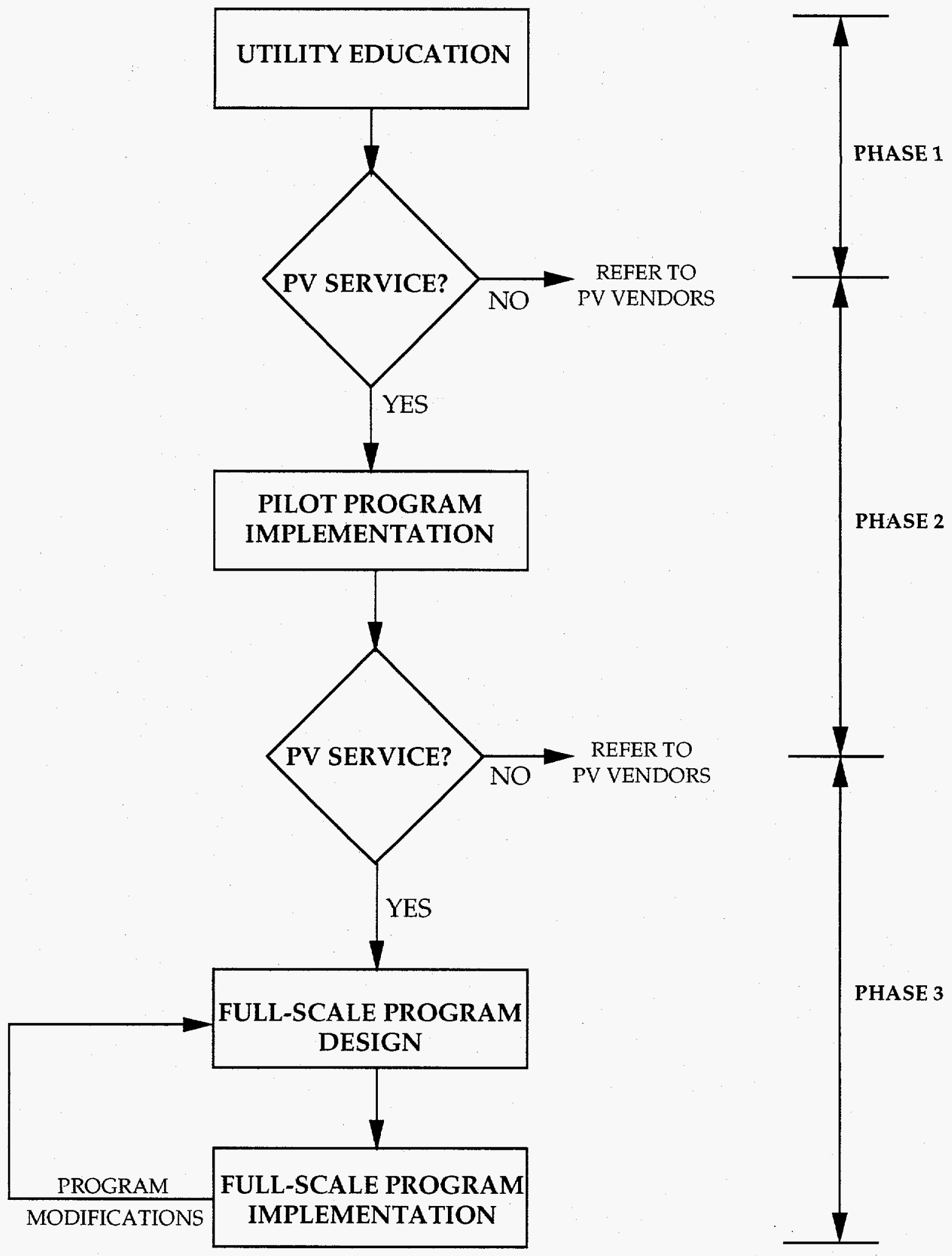

Figure 9. PV Service Flow Chart 


\section{UTILITY EDUCATION}

As is evident in the following flow chart, providing utility education with regard to PV services can be an iterative process. This process involves three primary activities: identifying PV program goals and objectives, conducting an opportunity assessment within the utility's service territory, and evaluating any institutional barriers that might exist. Utility education in this context is wide-ranging and includes education for utility staff, management, and board members.

Prior to initiating this phase, however, preliminary education should occur that can include reviewing the PV opportunities identified by other utilities or utility organizations (as documented in published literature), attending seminars on PV topics, and joining industry associations whose aim is to support utility PV activities. The bibliography and appendices developed for this document can be used as a starting point for these initial efforts. In particular, numerous remote, stand-alone applications have been documented by EPRI, Sandia, and PG\&E, providing excellent examples of a wide range of cost-effective applications.

\section{Goals and Objectives}

Whether PV program goals and objectives are simple (e.g., "learn about PV") or involved (e.g., "establish PV service guidelines within one year"), one of the first activities should be to establish initial PV service objectives related to parameters such as program scope, financial requirements, and implementation schedule. As evident from the flow chart, the utility education process allows for re-evaluation and modification of these goals and objectives as necessary.

\section{Opportunity Assessment}

After establishing preliminary goals and objectives, an opportunity assessment can be conducted by the interested utility. The assessment can include tasks such as implementing a service territory audit; conducting a preliminary market investigation; reviewing PV system costs, capabilities, and limitations; and evaluating preliminary PV system cost-effectiveness with an economic assessment. 


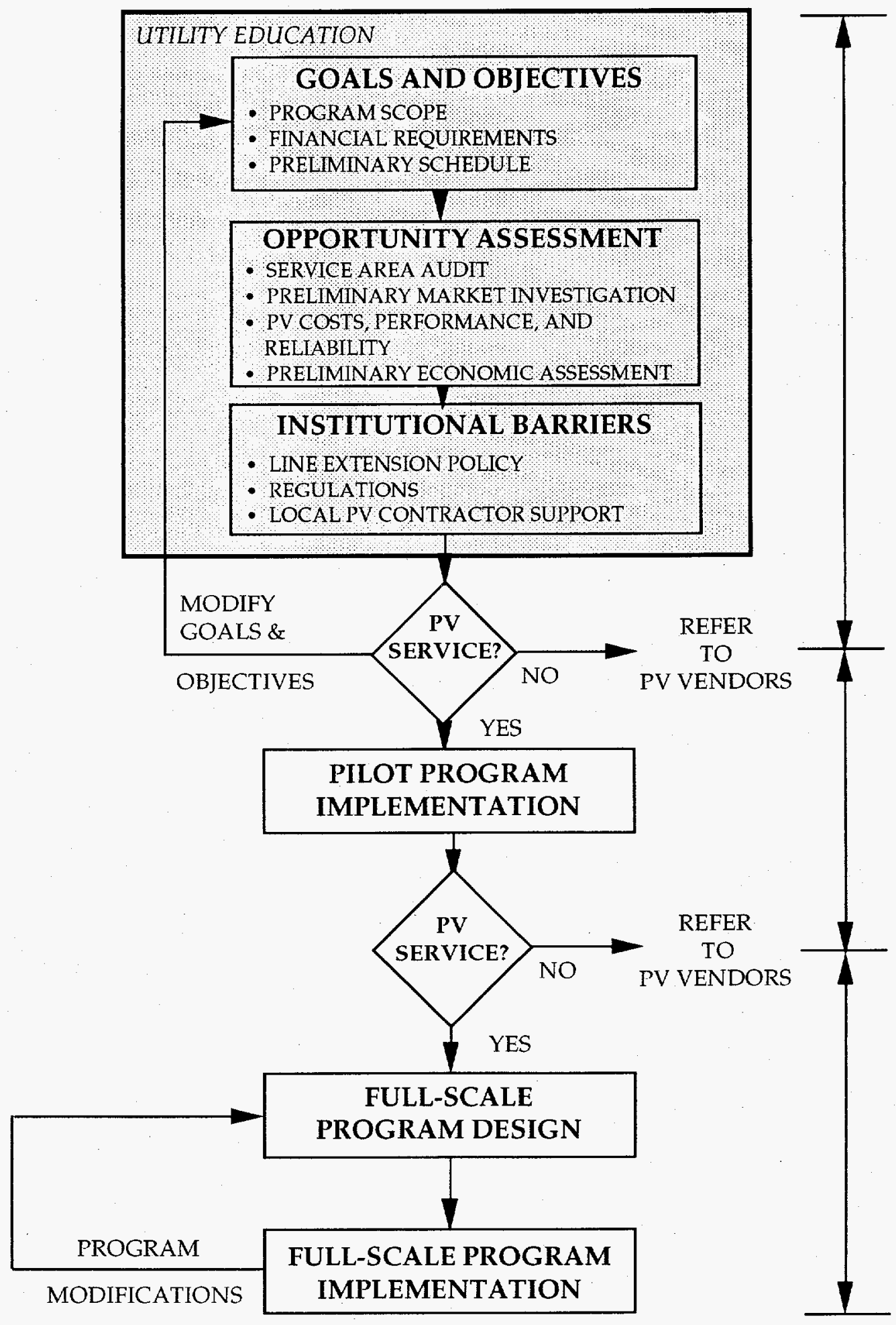

PHASE 1

PHASE 2

PHASE 3

Figure 10. Utility Education Flow Chart 
Opportunities for PV services can exist either within the utility or as a customer service. Using methods ranging in difficulty from billing record screening to cost of service studies, assessing opportunities for PV services should be an initial step of any interested utility.

A service area audit to identify cost-effective PV applications can have two objectives, either identifying opportunities for PV applications within the utility or identifying potential customer service applications. In both cases, the load characteristics include high service costs and little or no revenue. For example, in 1989 PG\&E's Department of Research and Development conducted an internal survey to identify PV systems installed by company personnel. Employees were contacted to identify existing and planned cost-effective PV installations within PG\&E's service territory. It was determined that PG\&E had over 400 utility-owned installations, ranging in size from $10 \mathrm{~W}$ to $7,200 \mathrm{~W}$, for a total of $32,000 \mathrm{~W} .1$ The applications included 17 different end uses, including water level sensors, gas flow meters, lighting systems, and cathodic protection. Today, the number of applications is estimated to be over 1,000 totaling approximately $80 \mathrm{~kW}$.

Additionally, since little or no revenue characteristically means low energy consumption, an easy initial step for identifying potential customer service opportunities is to search for low energy consumers in the utility's billing system records. McKenzie Electric conducted this type of search and identified nearly 900 grid-connected livestock wells in its service territory, many of which consumed less than 1,000 kWh per year. A cost of service study was then conducted for these consumers, and it was determined that the existing rate would have to increase over five times (from $\$ 10 / \mathrm{mo}$. to $\$ 55 / \mathrm{mo}$. service charge) for the services to pay for themselves.

A detailed system survey was then conducted by McKenzie to provide utility management with more specific information about these grid-connected loads. The location of each consumer was identified, and the installation was surveyed to assess distribution feeder characteristics and pumping system requirements (i.e., customer provided. well depth and water requirements). Therefore, McKenzie Electric personnel could determine whether the grid-connected pumping system was a candidate for replacement by a PV-powered system. To date, a partially completed system survey has identified 110 replacement sites that would eliminate over 72 miles of line and save the utility over $\$ 500,000$ in reconstruction costs.

${ }^{1}$ C. Jennings, "PG \& E's Cost-Effective PV Installations," Pacific Gas and Electric Co., Report No. 007.3-89.5, August 1989. 
Similar results are likely within many utilities in the western U.S. Recently, nearly 50 RECs in this region were surveyed to assess the opportunities for PV services to livestock water pumping loads. ${ }^{2,3}$ The trends evident in the following table indicate that an average of 400 (and as high as 2,000) grid-connected livestock pumping systems exist in each utility territory. The number of new line extensions constructed annually varies from zero to over 100, and the annual average is approximately 15.

\begin{tabular}{|c|c|c|c|c|c|}
\hline \multicolumn{2}{|c|}{ 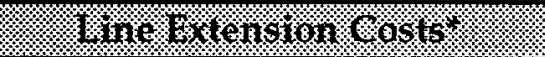 } & \multicolumn{4}{|c|}{ 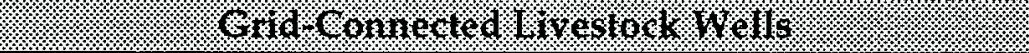 } \\
\hline Construction** & $\begin{array}{c}\text { Annual } \\
\text { Operation*** }\end{array}$ & $\begin{array}{l}\text { Total } \\
\text { No. }\end{array}$ & $\begin{array}{c}\text { Annual } \\
\text { Extensions } \\
\text { Built }\end{array}$ & $\begin{array}{l}\text { Annual Energy } \\
\text { Consumption per } \\
\text { Well (kWH) }\end{array}$ & $\begin{array}{c}\text { Annual } \\
\text { Revenue per } \\
\text { Well**** }\end{array}$ \\
\hline$\$ 15,000$ & $\$ 500$ & 400 & 15 & 1,000 & $\$ 260$ \\
\hline
\end{tabular}

Notes:

* - Costs for one mile of single phase overhead line.

* - Minimum cost ranged from $\$ 10,000$ to $\$ 20,000$ with cost increases up to $40 \%$, depending on the terrain.

** - Costs include $O \& M$, insurance, taxes, and depreciation.

$* * *$ - Revenue based on $\$ .08 / \mathrm{kWh}$ and $\$ 15 / \mathrm{mo}$. service charge.

Figure 11. Typical REC Service Costs for Livestock Water Pumping Customers

Also evident is the fact that these particular loads consume little energy (approximately 1,000 $\mathrm{kWh}$ each) on an annual basis, which provides little annual revenue (approximately $\$ 260$ ) for the utility. When construction costs and the estimated annual operating costs are added, it becomes clear that these loads rarely pay for the cost of service or provide any return for the utility.

\section{Preliminary Market Investigation}

Knowing whether the PV service will solve the customer's problems is essential for implementing a successful service, but these problems cannot be solved unless they are first understood.

A preliminary market investigation is another task that can provide essential information regarding "candidate" PV applications, such as water pumping and cathodic protection, in a utility's service territory. The primary objective of this task is to understand the customer's

2 K. Stokes et al., "Early Applications of PV in the Electric Utility Industry: Livestock Water Pumping," Electric Power Research Institute, Report No. RP1975-07, May 1990.

3 K. Stokes and G. Churchill, "Photovoltaic Power as a Utility Service: Lessons Learned from 15 PV Service Programs," Sandia National Laboratories, Interim Report, October 1992. 
needs with regard to the candidate application, including what traditional alternatives are used to fulfill those needs and reasons PV-powered systems might be preferred.

According to the National Cattleman's Association, ${ }^{4}$ over 80 percent of all open-pasture livestock grazing occurs in roughly 15 western states. There are nearly 21 million cattle on the range in these states, and these cattle consume over 75 billion gallons of water per year. In all of these states, a significant portion of this water is pumped with power from electric utilities. However, utility power for water pumping is often an expensive luxury for consumers when compared to either a windmill or engine generator system. Line extensions can cost the customer thousands of dollars, while windmills and engine generators cost much less. However, the reliability of these traditional alternatives is also less in many cases. ${ }^{5}$

In addition to technical and cost issues that encourage the use of PV-powered systems, several recent regulatory developments are influencing the grazing practices (and the corresponding need for water pumping) in the western U.S. These developments include changing federal grazing regulations and weather patterns in the last several years. First, grazing regulations on federal lands, which are a significant portion of the grazing lands available in the region, are changing and now require more frequent rotation of cattle on federal land. This increased pasture rotation preserves the grassland ecosystem by preventing overgrazing, but as a result requires more water sources.

Another recent regulatory change requires the elimination of livestock grazing in riparian areas (i.e., highly vegetated areas next to streams and rivers). To prevent livestock from damaging the riparian area, ranchers are required to fence the area and provide alternative water sources. In many cases, this means pumping water from the stream to a nearby tank.

Finally, the weather can be a significant reason for new water sources. For example, many areas in the western U.S. have experienced frequent drought conditions in the last several years, and utility personnel in this region have indicated that line extension requests can increase by a factor of five in a "dry" year.

PV Cost, Performance, and Reliability

An important part of utility education will be reviewing the findings of other organizations relative to the cost, performance, and reliability of specific PV applications.

The objective of this particular task is simply to review existing literature to obtain an initial understanding of PV system cost, performance, and reliability for the particular candidate

\footnotetext{
4 National Cattleman's Association, Denver, Colorado.

${ }^{5}$ Both windmills and engine generators require significant annual maintenance (including engine maintenance and fuel hauling), while the lack of significant wind reduces windmill reliability during the summer, when water requirements for many users (e.g., ranchers) reach a peak.
} 
application(s). Recent studies, funded by EPRI and Sandia, would be useful to review because they focus on the performance and reliability of PV-powered water pumping systems.

In particular, a project was initiated by EPRI in 1991 to obtain cost, performance, and reliability information on PV-powered pumping systems installed within the last five years. ${ }^{6}$ A survey was developed and mailed to 251 owners of PV-powered water pumping systems installed in the western and mid-western U.S. The survey results, which were documented in an EPRI report, included system installation characteristics, system performance trends, and system reliability trends.

As presented in the EPRI report, over 60 percent of the installations were relatively small pumping systems with installed costs of approximately $\$ 2,000$. This typical pumping system consisted of two PV modules $(100 \mathrm{~W})$ direct-coupled through a maximum power controller to a 24-volt submersible diaphragm pump (see component and design descriptions in Part 2 of this report). Depending on the site specifications, the season, and the mounting configuration, the system delivered from 400 to $900 \mathrm{gal} /$ day. Furthermore, no battery storage was included in this typical system, as water was stored in a tank.

Overall, the pumping system installations identified in this survey required little daily energy (i.e., $1 \mathrm{kWh} /$ day to $8 \mathrm{kWh} /$ day), and the system owners were satisfied with the performance nearly 90 percent of the time. The largest reason (nearly 70 percent of the complaints) for performance dissatisfaction was due to cloudy weather. ${ }^{7}$ A small portion of this dissatisfaction was due to system failures, and the most reliable system components were the PV modules. Only four module failures (out of nearly 500 installed modules) were identified, and these "failures" were due to wiring problems and vandalism.

Literature should be reviewed for various applications to assess costs, capabilities, and limitations. In most cases, the information can be obtained from the organizations and manufacturers listed in Appendices A and B, respectively.

6 K. Stokes and P. Saito, "Reliability, Cost, and Performance of PV-Powered Water Pumping Systems: A Survey for Electric Utilities," Electric Power Research Institute, Report No. RP3258-02, April 1992.

7 Since any PV-powered system should be designed to account for local weather patterns, this reason could indicate a lack of adequate storage capacity (either water or battery storage). 


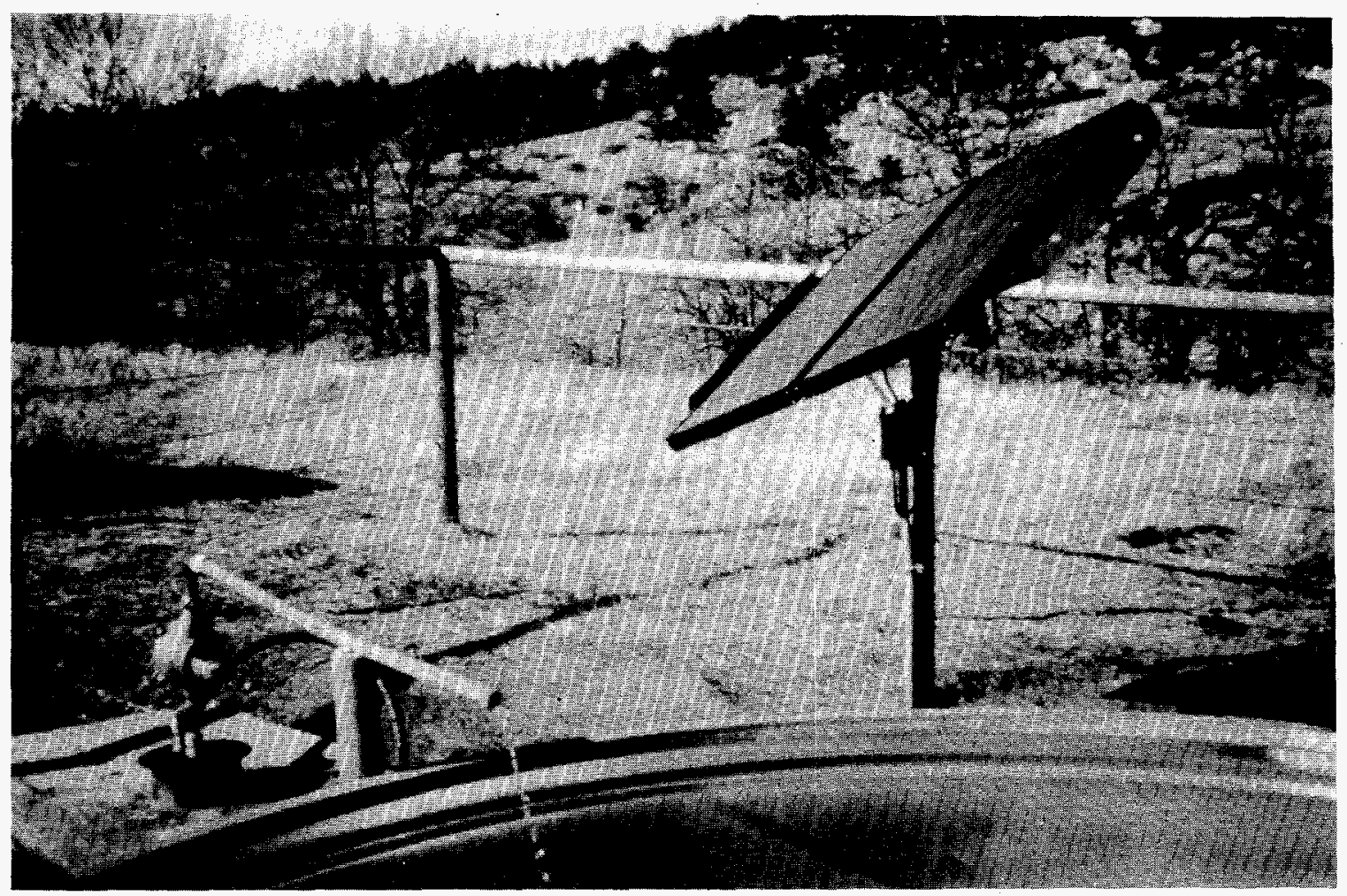

Source: Tri-County Electric, WY

Figure 12. Typical Livestock Water Pumping System

Preliminary Economic Assessment

Once PV system costs have been identified, they should be compared to corresponding utility line extension costs to assess preliminary PV cost-effectiveness.

A preliminary economic assessment can be conducted to compare PV system costs with line extension costs. The PV system costs, which include estimates for the installed equipment and O\&M, should be available from the literature reviewed in the previous task. The line extension costs include the initial cost of construction plus such annually recurring costs as O\&M, insurance, property taxes, and depreciation. When these costs are compared, the utility will have a PV cost-effectiveness indicator similar to the one shown below. 


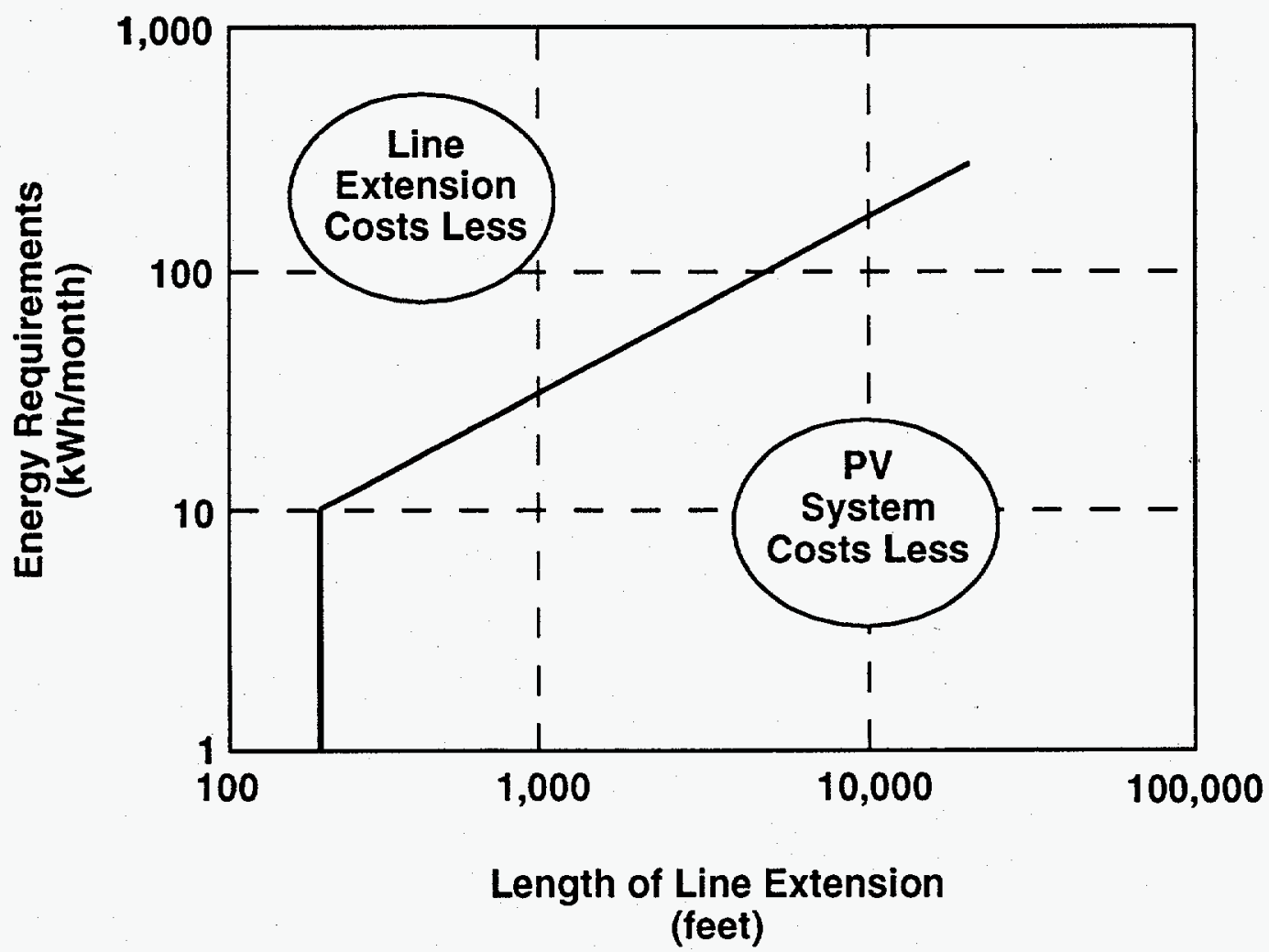

Source: Electric Power Research Institute

Figure 13. PV System Cost-Effectiveness

In this particular case, the PV system costs, which vary proportionally with the required monthly energy, were compared to the average line extension costs for six EPRI member utilities. The comparison provided an initial indication of when PV-powered systems were more cost-effective than utility line extensions.

Institutional Barriers

The final activity suggested in the iterative utility education process is identifying possible institutional barriers that might influence the program goals and objectives. Such institutional barriers could include the utility's line extension policy, applicable state or federal regulations, and availability of local PV supplier support. 
Line Extension Policy

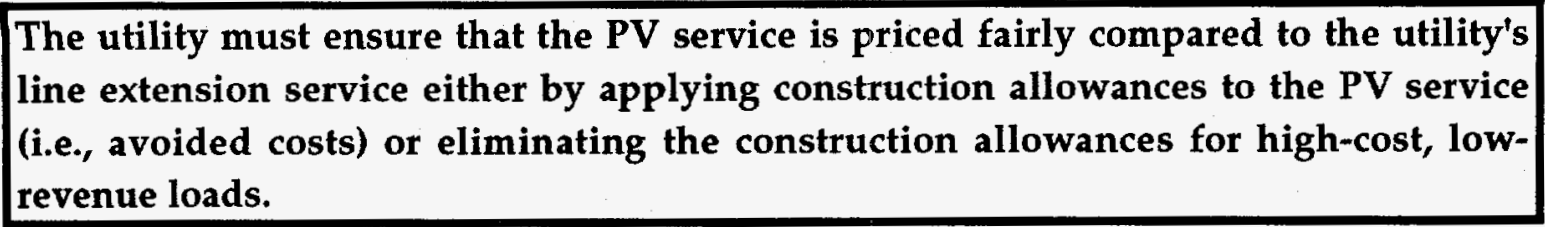

The objective of this task is simply to recognize the total costs of providing traditional service to remote customers. In the past, utility line extensions have been the only utility option available for serving small remote loads like livestock water pumping. Additionally, for the rural electric cooperatives (RECs), the construction of these lines was financed in large part by the Rural Electrification Administration (REA). The line extension policies established by these utilities reflected this outside funding by providing generous "construction allowances" to each customer. Today, however, the federal funding is disappearing, yet generous construction allowances persist in many cases. For example, of the 15 utilities implementing PV services, only four of the utilities require the customer to assume all the initial construction costs for water pumping line extensions, despite the fact that cost recovery from these loads is nearly impossible.

For many of these utilities, the PV service option has been implemented to discourage certain line extension customers (i.e., water pumping) from having the line built. However, under present circumstances at many of these same utilities, the cost of the PV service is more expensive than the line extension service (from the customer's perspective) due to the construction allowances applied to line extensions. Specifically, the average construction allowance given by the 14 RECs (included in this group of 15 PV service utilities) is approximately $\$ 2,700$, and the allowances range as high as $\$ 6,500$. In terms of distance, the average allowance covers approximately 0.2 miles, while the most lenient allowance covers nearly 0.6 miles. Unless this construction allowance is either reduced or applied to the PV service as well, the alternative service will not solve this line extension problem.

However, the policies are difficult to change for two main reasons. First, consumers of the member-owned RECs are accustomed to the policy, and, second, policy changes for regulated utilities mean approval by state utility commission, a time-consuming and costly process.

\section{Regulations}

All utilities, whether regulated or not, should inform state regulators of proposed utility PV services to learn of possible barriers or incentives regarding these services.

To date, regulated utilities (including RECs in some states) have received nothing but encouragement from regulators for their PV service programs. However, the objective of this task is to review all regulations that might pertain to $P V$, as they will vary from state to state. $A$ 
good example is Idaho Power Company's application to the Idaho and Oregon Public Utilities Commissions for a PV service tariff. In both cases, the commission approved the application and supported the company's PV program as an "important step in providing innovative service."

In Colorado, the state Public Utilities Commission has provided an excellent example of emerging regulatory activity that encourages consideration of PV services. In March 1991, the Colorado commission recommended ${ }^{8}$ that $\mathrm{PV}$ power be evaluated as a cost-effective alternative for all new line extensions. In other words, the commission has encouraged regulated utilities to consider PV services when that service is the least cost option.

For regulated and unregulated RECs, two other (and probably more relevant) forms of regulation are the "all requirements" contracts each utility has with its wholesale power supplier (i.e., typically a generation and transmission (G\&T) cooperative) and the regulations imposed by the REA. The all-requirements contract essentially requires that the REC purchase all of its energy and capacity requirements from the G\&T. A good example of this relationship exists between Tri-State G\&T in Colorado and its 34 REC members. Initially, utility personnel (specifically K.C. Electric) investigating PV services from several of these utilities were concerned that their PV installations might violate their all-requirements contracts. However, during the course of their PV activities, Tri-State modified its all-requirements contracts to allow for renewable energy projects owned and operated by REC members for up to $25 \mathrm{~kW}$ per project.

The REA regulates RECs primarily by establishing guidelines under which the utilities can borrow low-interest money for construction. To date, the REA has not allowed funds to be borrowed to offset PV costs for two main reasons. First, REA loan funds are intended for distribution plant expenses only. Since PV power "generates" electricity (though it offsets distribution plant expenses when used by the RECs), it is not eligible under present guidelines. Second, REA loans are amortized over a 35-year period, which is the rated life of most distribution plant equipment. Since PV modules do not have a 35-year lifetime (most experts agree that a 25-year life is more reasonable), PV equipment could not be financed using present methods, even if it was eligible for the loans.

Despite many regulatory endorsements for PV services, some concerns have been expressed with regard to regulated utilities providing PV services. In a paper developed by the California Energy Commission ${ }^{9}$ and others, several possible regulatory barriers were identified for California utilities. The paper suggests that any PV services offered by regulated utilities in the state "must aid PV implementation, be in the ratepayer's best interest, not have anti-competitive effects on the PV industry, not compromise quality and universality of service," and that any utility affiliate's involvement in PV receive consent from the Public Utilities Commission. It is

\footnotetext{
${ }^{8}$ The Commission's amendment to Rule 31, the line extension rule, provides the PV service guideline.

${ }^{9}$ M. DeAngelis et al., "California PV for Utilities: Commercialization Strategy," Prepared for the PV for Utilities Working Group, December 1992.
} 
unclear how these regulations will be interpreted in the case of utility PV services, since no regulated utility has proposed a PV service in California to date.

Finally, for Carbon Power and Light, a regulated REC in Wyoming, the state Public Service Commission has been responsive to its interest in PV services and has encouraged "pilot program" activities to continue. The only regulatory "barrier" that exists for Carbon is the fact that making their PV service formal requires a rate hearing before the Commission, and a rate hearing requires significant personnel time and cost to prepare the proper documents. As a result, Carbon likely will wait to make their request for a PV service rate until their next scheduled rate hearing.

\section{Local PV Supplier Support}

PV supplier support of design, installation, and maintenance activities will be desired by many utilities, and determining whether qualified local PV suppliers exist will be an essential first step for these utilities.

The primary objective of this task is to assess possible options for PV supplier support. For the utilities with PV service programs initiated, PV vendors have provided valuable support with system design, installation, and maintenance activities. However, many have chosen to install and maintain the PV-powered systems using utility personnel. One reason for this choice was that the utilities simply wanted full responsibility for these activities, as their customers will hold the utility accountable for the PV service regardless of any PV supplier support. Another reason was the fact that local PV suppliers do not exist in many utility service territories. To remedy this situation, qualified regional or national PV system suppliers have been used to provide design assistance and training with installation and maintenance procedures. As qualified local contractors become available in the future, the installation and maintenance support could be provided by these contractors.

For the RECs in particular, local PV supplier support will be essential to the success of their PV service programs, and the lack of local PV supplier support is a limitation. The RECs typically are small organizations with limited resources and, generally, the member services personnel are committed to other full-time responsibilities. In many cases, a successful new program within an REC can benefit from outside support initially to provide design guidelines and to train both utility personnel and local electrical or pumping contractors. Then, as more activity surfaces for the utility, more utility resources can be devoted toward service support.

However, the difficulty with this situation from the PV industry's perspective is that the industry also has resource limitations. Individual PV vendors, which are typically no larger than 10-person companies, may not have the resources to provide rapid on-site support to emerging PV service programs, as the utility may be hundreds of miles away. Design support can easily be provided over that distance with phone calls and a facsimile machine, but providing quick installation and maintenance support may be difficult. 


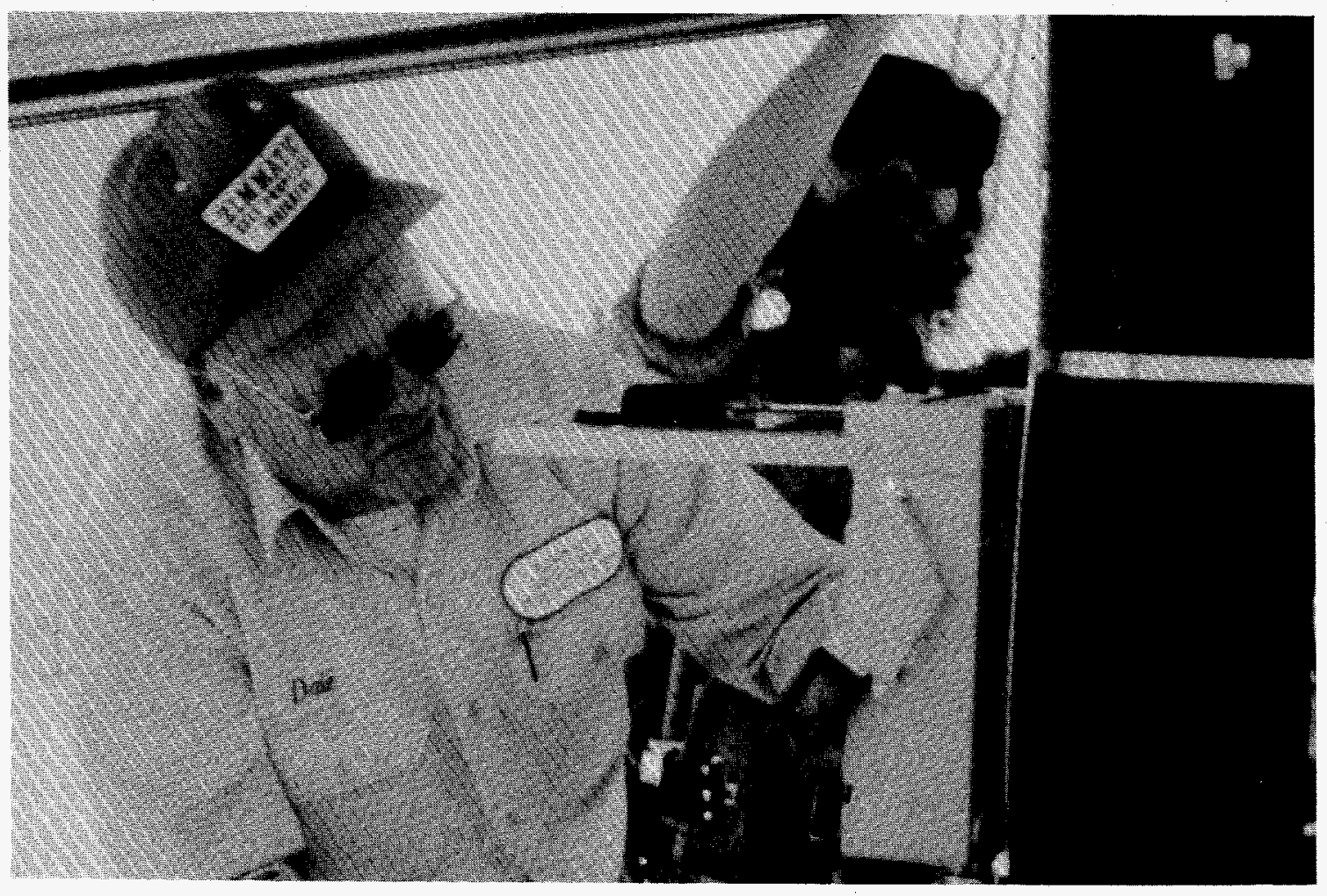

Source: WY

Figure 14. PV Industry Support 


\section{PILOT PROGRAM IMPLEMENTATION}

Once utilities feel comfortable with PV service goals and objectives resulting from the utility education process, a pilot PV service program can be initiated for Phase 2 of the PV service process. As shown in the following flow chart, pilot program implementation is intended to validate the information gathered through the utility education process through direct (i.e., hands on) experience with PV installations. In this way, the utility can systematically gather information relevant to the PV service program (i.e., technical, economic, and logistical issues and customer acceptance) and determine whether development of the full-scale PV service program is justified.

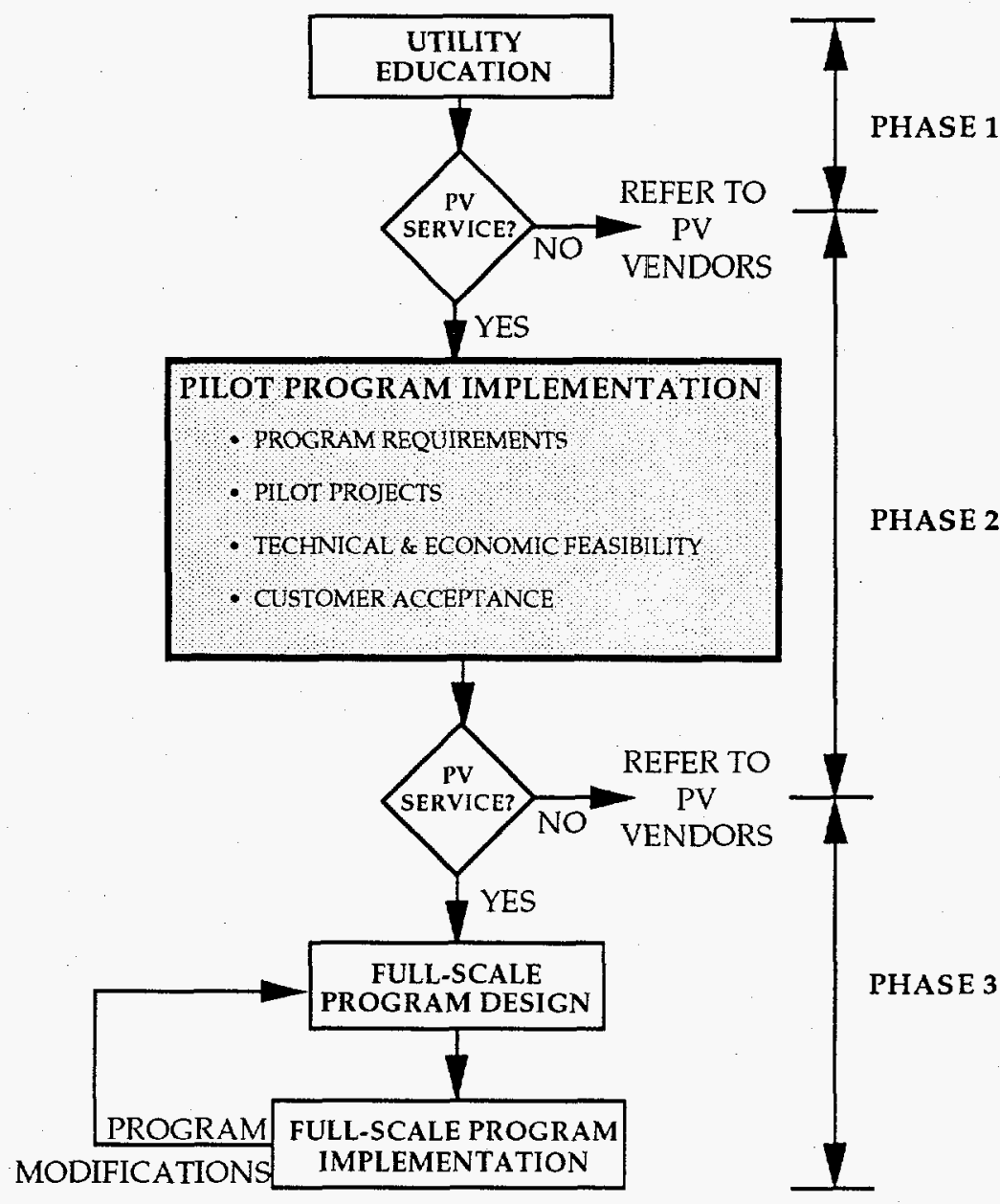

Figure 15. Pilot Program Flow Chart

To implement the pilot program, four activities have been identified: estimating pilot program requirements; installing pilot projects; assessing technical and economic feasibility; and evaluating customer acceptance. In this context, most utilities have defined the pilot program to be a "controlled experiment" in which prospective participants are carefully screened to allow for a close utility/participant relationship through the various pilot program activities. 
Implementing a pilot program will require personnel and financial resources that should be evaluated prior to initiating pilot installations.

The objective of this activity is to simply consider the pilot program scale (e.g., how many systems will be installed), the schedule, and the resources (both financial and human) required for implementing the proposed pilot program.

The PV service activities at Northwest Rural Public Power District provide a good example of the resources required to implement a small-scale pilot program for livestock water pumping customers. As described previously, Northwest Rural implemented its PV pilot program in April 1990 to provide lower cost service to remote ranching customers. During the next two years, eight PV-powered pumping systems were installed and monitored for selected customers at an average installed cost of approximately $\$ 2,500$ per system. As shown in the following table, over $20 \%$ of one person's time (i.e., approximately 435 hours per year) was required to coordinate these activities, and the causes of this implementation time included utility education ( $8 \%$ ) providing direct support to the eight pilot program customers $(3 \%)$, responding to inquiries for information from other interested utilities (3\%), and delivering presentations at seminars and conferences $(7 \%)$.

\begin{tabular}{|lcc|}
\hline Item & Annual Hours & $\begin{array}{c}\text { Person-Year } \\
\text { Fraction (\%) }\end{array}$ \\
\hline \hline Education \& Training & 175 & \\
$\begin{array}{l}\text { Direct Support } \\
\text { Design \& Installation Support }\end{array}$ & 50 & $8 \%$ \\
$\quad$ Maintenance Support & 10 & $2 \%$ \\
Inquiry Response & 60 & $1 \%$ \\
Presentations & 140 & $3 \%$ \\
TOTAL & 435 & $7 \%$ \\
\hline
\end{tabular}

During these first two program years, the majority of time spent was for utility education and training, as utility personnel needed to learn about PV system design, installation, and maintenance requirements. At Northwest Rural, direct support for system design and installation required only a moderate amount of time, since they relied on a local PV system vendor to design and install the systems. For system maintenance, utility personnel were the first to receive customer calls regarding problems with the PV pumping system. However, utility personnel were called out to only five sites during the two-year period, so little repair time was actually required. 


\section{Pilot Projects}

Implementing successful pilot projects requires careful selection of project
participants and sites prior to developing standardized PV application packages for
the installations. Additionally, PV industry support in developing these standardized
packages can significantly eliminate design uncertainty.

The objective of this activity is to install the pilot projects. Several steps are possible for initiating this activity, including establishing customer (and site) selection criteria, developing PV system specifications, and initiating trade ally relations.

As mentioned previously, the participant for each pilot project should be carefully selected to establish a close working relationship through the various pilot project tasks. Some participant characteristics could include an interest in new solutions to old problems; an ability to provide accurate site data; a willingness to allow frequent site access; and a willingness to assist with performance monitoring. Furthermore, in the past "early adopting" customers have been given incentives by the utility, such as no-cost use of the PV system during the pilot program activities.

In addition to establishing customer selection criteria, establishing site selection criteria is essential for successful installations as well. For water pumping installations in particular, not all water sites are appropriate for PV-powered pumping systems. As described in Part 2 of this guidebook, the suitability of a site for PV-powered pumping is determined by many factors, such as the customer's end use and water requirements, the well specifications, and the site's solar access. The selection of suitable sites is essential to the success of the pilot program, as the impression these initial PV installations have on customers and utility management will be lasting.

Once customers and sites have been selected, system specifications can be developed for the pilot installations. For all PV applications, the development of "packaged" (or standardized) systems can contribute to the program's success. The advantages of standardized systems can include reduced design costs and increased service reliability. The primary disadvantage of standardized systems is that the PV-powered "package" will perform in a relatively narrow operating range and will not fulfill the exact needs of all customers. As a result, an important objective of the pilot installations will be to evaluate equipment for use in the standardized packages, though this determination may require some trial and error initially.

Another objective that should be considered while developing these standardized packages is initiating contact with local trade allies. Many qualified PV designers exist who have years of experience specifying equipment for a variety of applications. Incorporating these experiences into the specification development process can significantly eliminate design uncertainty. Additionally, many utilities have expressed interest in collaborating with local PV vendors for two reasons. First, supporting local businesses stimulates the local economy, and, second, the 


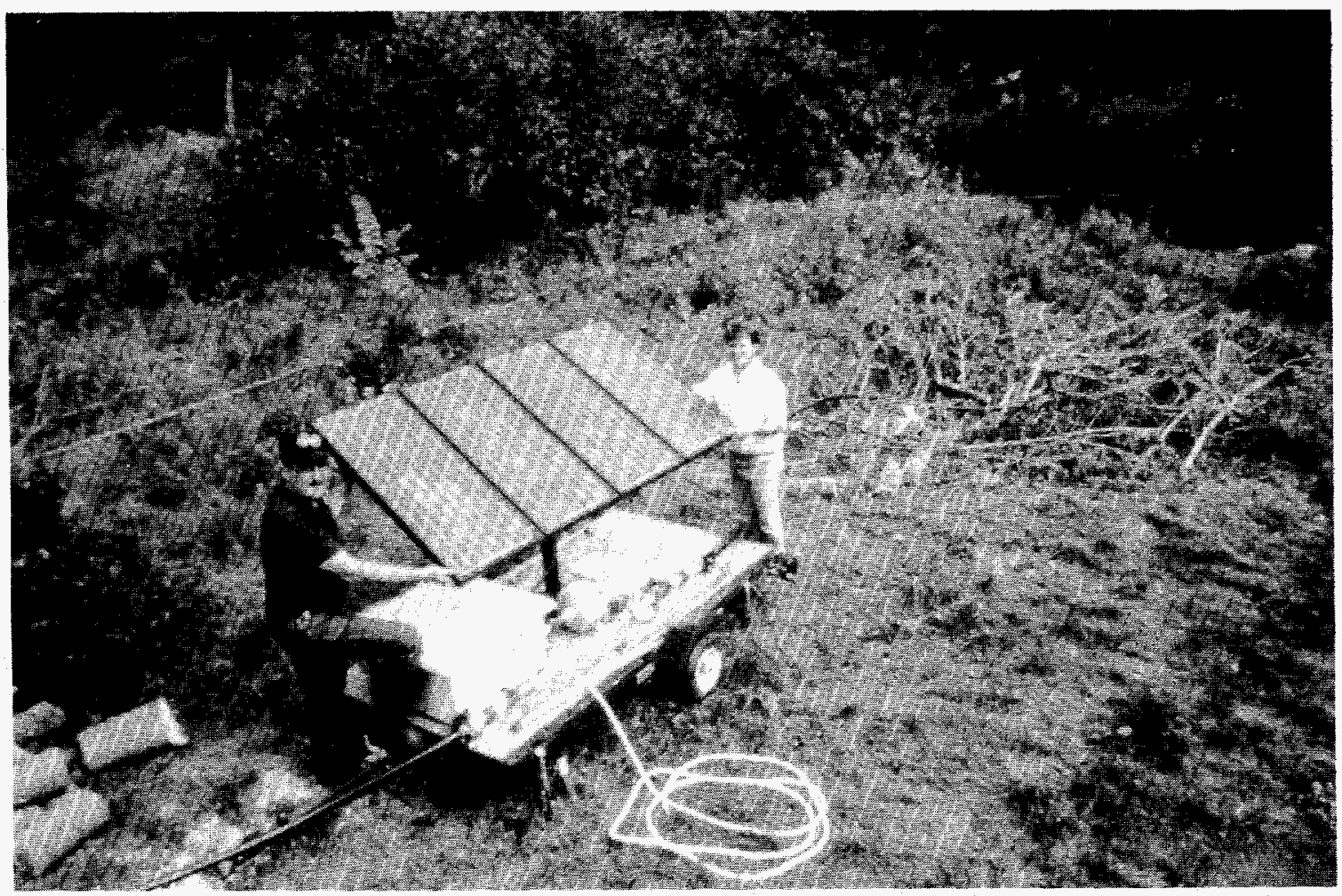

Source: Wisconsin Public Service

Figure 16. Trailer-Mounted Systems

local PV vendor can provide service support (e.g., design, installation, maintenance, etc.) as required by the particular utility.

For livestock water pumping, two utilities (Norton-Decatur and San Isabel) are standardizing the pumping systems they offer to customers with the help of qualified PV industry vendors. First, Norton-Decatur has identified a reliable pump from one manufacturer that can be powered with either two or four PV modules. Depending on the customer's well requirements, the Norton-Decatur personnel provide an estimate of water output (i.e., a water "rating") that varies from site to site. In this way, the equipment installed by the utility personnel becomes standardized. Second, a similar approach is being used by San Isabel with the added feature of a trailer-mounted PV power supply. Six identical trailers were purchased recently by the utility, so the equipment installed at any customer's site is standardized. Only the water output "rating" varies for the particular site. 


\section{Technical and Economic Feasibility}

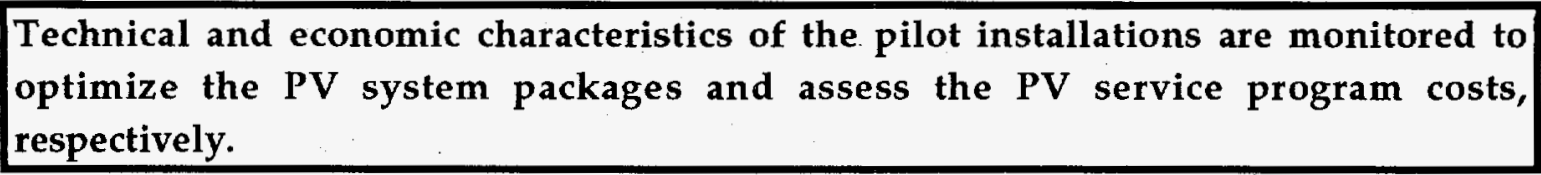

The objective of this activity is to evaluate the technical and economic feasibility of the PV service during the pilot program phase. Technical details (i.e., performance and reliability information) are gathered to optimize the PV system equipment used in the "packages," while economic details (i.e., installation costs and operating expenses) are gathered to support the service pricing efforts during the PV program development phase.

For PV-powered water pumping, evaluating the pumping equipment available on the market, as described in Part 2 of this guidebook, will require some time. An understanding of each component's technical specifications and limitations will be important for standardizing the pumping system packages appropriate for each utility service area. Furthermore, each pump will have different maintenance requirements that may affect the final equipment choices.

For Northwest Rural, evaluating these technical details was difficult because critical information was not available from the PV manufacturers or local vendors. Specifically, the lack of information regarding required pump maintenance was an initial problem. Northwest Rural personnel believe that the diaphragm pumps used in their systems require annual preventative maintenance to replace the diaphragm(s). However, this maintenance requirement was not emphasized by the PV manufacturers or vendors that Northwest Rural consulted. This knowledge is important because ranchers are accustomed to submersible pumps that last 10 years or longer (based on the rancher's experience with AC pumps).

Another important technical detail to consider during pilot projects is that installation practices should be standardized to avoid unsafe or unreliable systems. Again, the lack of sufficient information from a local PV supplier created problems for Northwest Rural, as their initial systems installations included several problems (e.g., wiring connections, ${ }^{10}$ connector compatibility, ${ }^{11}$ etc.) that could have been avoided had detailed methods been available. These personnel felt (in retrospect) that they had "re-invented the wheel" in many cases. Information regarding installation practices and the National Electric Code were available, ${ }^{12}$ but similar information describing proper components and wiring practices particularly for water pumping systems would have been useful as well.

Finally, utilities may want to consider monitoring the solar resource, as the availability of solar energy can vary due to local weather patterns. Solar resource monitoring is important when

10 Inadequate wire splices for moist down-hole environment.

11 Insufficient space in junction box for proper wiring technique.

12 J. Wiles, Photovoltaic Power Systems and the National Electric Code: Suggested Practices, Southwest Technology Development Institute, Draft Report, November 1992. 
larger (i.e., tens of kilowatts) installations are being considered in order to optimize the installation design with respect to cost. However, for relatively small stand-alone installations, such as livestock water pumping, published solar data are sufficient for successful system designs.

By implementing these pilot projects and evaluating the technical details mentioned, PV. program costs for equipment and services will become evident. These costs include the capital cost of the standardized PV packages and service support costs such as design, installation, and maintenance (both preventive and troubleshooting). Additional costs that should be considered during these pilot installations are insurance and administrative costs. Identifying these costs will provide the necessary information for establishing the PV service price required to meet the utility's financial goals.

\section{Customer Acceptance}

Performance monitoring to assess participant satisfaction should include periodic system testing, as well as regular contact with the participant.

Finally, the objective of this activity is to determine whether the pilot program participants are satisfied with the performance of the PV installation. To achieve this objective, performance monitoring should be included for all pilot installations to assess both system performance and customer satisfaction. For livestock water pumping, the performance monitoring should include periodic system testing (see Part 2 of this guidebook), as well as regular contact with the participant. At a minimum, tracking water delivery (with "spot" checks or with an "in-line" water meter) can provide the information necessary to quantify the customer's satisfaction (or dissatisfaction).

At K.C. Electric, this type of performance monitoring was quite successful in documenting customer satisfaction with livestock water pumping systems. By monitoring the water output on one system, it was obvious that the system was delivering less water than expected. However, the relatively low average output was due to the fact that more water was being pumped than the owner's distribution system could handle. During much of the daylight time when the PV system could be pumping, the system's storage tank was full. When the tank was full, the pumping system was automatically turned off. To the owner's satisfaction, this increased capacity allowed him to install an additional water pipeline from the well site to another holding tank, and the water was then distributed through gravity-fed pipelines to other pastures.

Another method used to measure customer acceptance has included utility personnel attending local grazing association meetings and discussing the pilot project results with non-participants. In this way, utility personnel can begin to confirm whether the desire for this particular PV service is widespread in the local community. 


\section{FULL-SCALE PROGRAM DESIGN AND IMPLEMENTATION}

Once the pilot program has been evaluated, the full-scale PV service program can be designed and implemented according to the flow chart sequence shown below. In this final phase, initiating the full-scale PV service program is an iterative process, where the program design can be modified as required after the program is begun.

\section{Design PV Service Program}

To initiate this final phase, the full-scale program should be designed by implementing such tasks as identifying PV service options, evaluating procurement options, establishing a service pricing method, assessing liability issues, designing customer education materials, and developing a marketing plan.

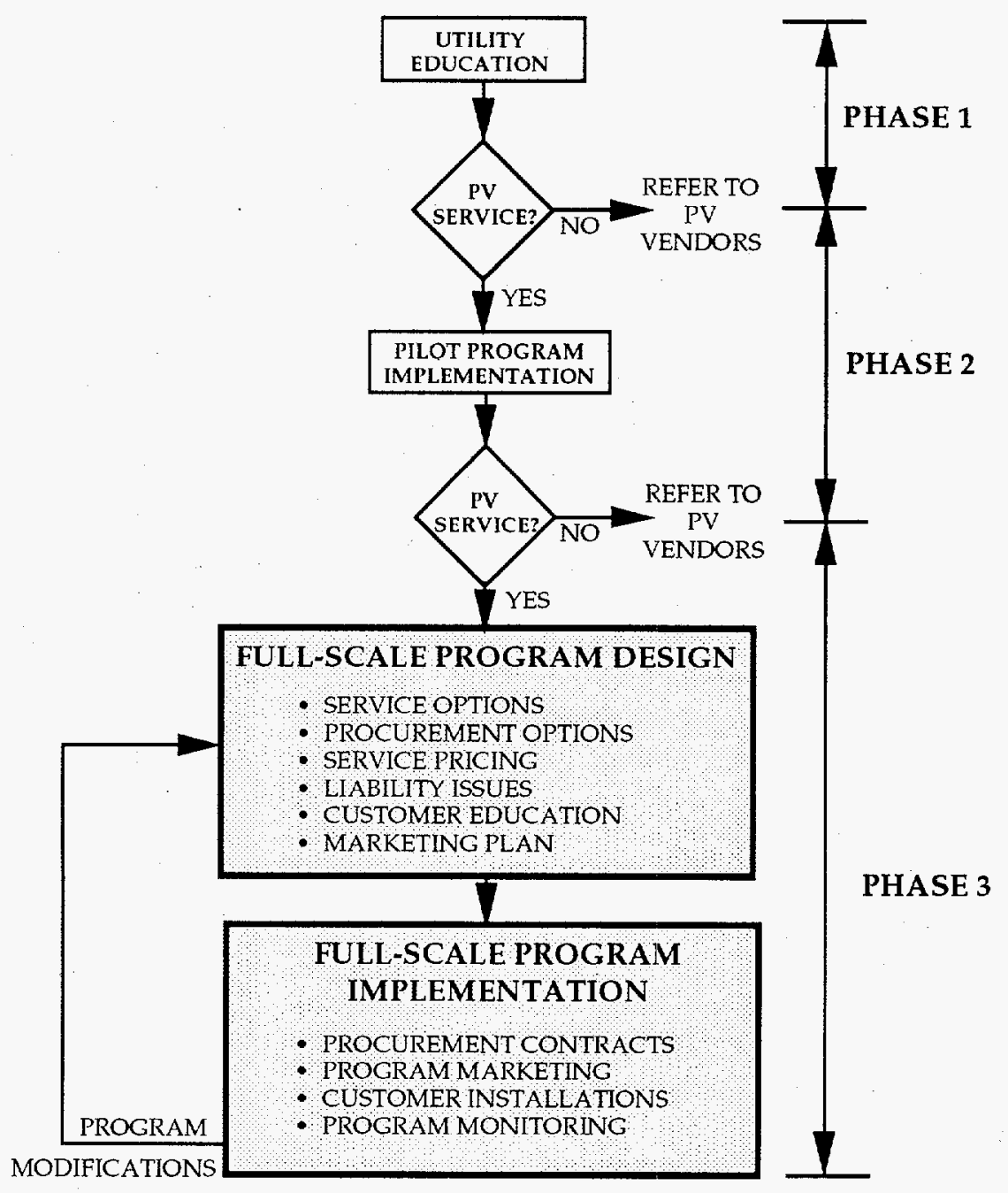

Figure 17. Full-Scale Program Flow Chart 
When implementing PV services to either avoid reconstructed service lines or to expand customer service options, utilities will be held accountable for system design, installation, and maintenance whether or not these services are provided by utility personnel or PV suppliers.

Whether the utility finances only the PV power supply or the entire system (e.g., pump equipment too), offering standardized PV packages will help ensure successful installations by limiting the use of unproved equipment.

The objective of this task is to identify PV service options and assess the roles and responsibilities of utility personnel, local trade allies, and customers relevant to each option. The service options can include assessing the circumstances under which PV services would be provided, which PV system equipment to provide, as well as which services (i.e., design, installation, O\&M, etc.) to offer.

Assessing the circumstances under which PV services will be provided should be an initial priority. As described previously, two PV service opportunities arise from the traditional problem of extending line to high-cost, low-revenue loads. The first opportunity simply involves replacing existing remote lines with PV-powered systems, while the second opportunity involves offering the PV service to new customer loads that the utility could not serve previously.

Of the utilities with PV services today, virtually all of them consider PV as a new service option for customers who request uneconomical line extensions. In particular, Idaho Power's program has allocated $\$ 5$ million to provide PV-powered systems instead of line extensions. One notable exception, K.C. Electric, has decided that the utility's PV service program will be applied only when existing lines need reconstruction (e.g., storm damage, age, etc.). To this end, K.C. personnel have completed an extensive survey of their system to understand where potential PV service replacements should occur, if the lines need repair.

The second option to consider is which PV equipment to provide with the service. For Northwest Rural, an analogy between traditional line extension service and the PV service was drawn to justify providing only PV power supplies, including any required mounting hardware and controls, to each customer. As with traditional utility services, the customer would assume responsibility for purchasing, operating, and maintaining the "load" (i.e., the pump and motor). In contrast to this approach, a Kansas REC, Norton-Decatur Electric, has provided nearly 30 standardized pumping packages (i.e., PV power supply and pump) to customers. As described previously, Norton-Decatur standardized the pumping system equipment it offered and provided one complete "package" for its customers regardless of their site-specific pumping needs. 
A combination of these two approaches may be beneficial, since pump capability and reliability can vary significantly for PV-powered pumps, yet the utility may only want to (or be able to) offer electric services in a traditional manner. In this case, the utility could finance the PV power supply and any required balance of system equipment, and the customer would be required to purchase any pumping equipment. However, the utility could limit the use of its PV equipment to selected pumps, to ensure that only pumps with a proven reliability record are installed.

Finally, the utility needs to choose which services it will provide to these customers. As shown in the following table, the services provided by 15 utilities in the western U.S. include various combinations of design, installation (combined with fabrication in some cases), and maintenance support.

One trend evident from the table is the fact that 12 of the utilities have decided that one organization (either utility personnel or a local PV vendor) will be responsible for both the design and installation of the PV-powered system. Nine of the utilities have chosen to design and install the systems using utility personnel with PV supplier support, while three utilities have chosen a local PV vendor to design and install the systems. Two of the three utilities that rely on vendors (K.C. Electric and Northwest Rural) have a relatively long history of working with local PV vendors, and each has made a conscious decision to support the local vendor as long as the vendor can provide the required services in a timely manner.

The three exceptions to this trend (San Isabel, Tri-County, and West River) provide an interesting contrast. Each utility has chosen to let a PV vendor design the system, while utility personnel will install it. The primary reason for this variation is the fact that no local PV vendors exist within the utility service territory. As a result, utility personnel will gather site data necessary for system design and send it to a vendor via facsimile machine. The vendor will design the system and specify equipment needs, and utility personnel then will procure the equipment from the vendor and install the system.

Also shown in the previous table is the fact that all 15 utilities have chosen to provide maintenance support to their customers once the system is installed. Eleven of the utilities will maintain the systems with utility personnel, while the other four will use local vendors to provide the maintenance support. Despite the differences, all these utilities want to remain as the primary "energy service" contact for their customers (PV or grid-connected), whether utility personnel provide the maintenance support or not. 


\begin{tabular}{|c|c|c|c|c|c|c|c|}
\hline \multirow[b]{2}{*}{ 4tiluy } & \multirow{2}{*}{$\begin{array}{l}1.081010 \\
1110101\end{array}$} & \multicolumn{2}{|c|}{ systern } & \multicolumn{2}{|c|}{ Systomlinstalled } & \multicolumn{2}{|c|}{ Marntenance } \\
\hline & & onity & vendos & 10143 & nendot & $+1+10$ & Vendod \\
\hline Black Hills Electric & May-92 & & $\bullet$ & & - & $\bullet$ & $\bullet$ \\
\hline Butte Electric & Apr -92 & - & & - & & - & \\
\hline Carbon Power \& Light & Jun-91 & $\bullet$ & & - & & - & \\
\hline Grand Electric & Apr-92 & $\bullet$ & & $\bullet$ & & - & \\
\hline Idaho Power & Apr-92 & $\bullet$ & & - & - & $\bullet$ & \\
\hline K.C. Electric ${ }^{*}$ & May-90 & & - & & - & $\bullet$ & $\bullet$ \\
\hline McKenzie Electric & Apr-91 & - & & - & & $\bullet$ & \\
\hline McLean Electric & Apr-91 & $\bullet$ & & - & & $\bullet$ & \\
\hline Northwest Rural PPD & May-90 & & - & - & - & $\bullet$ & - \\
\hline Norton-Decatur Electric & Nov-90 & $\bullet$ & & - & & - & \\
\hline San Isabel Electric & Nov-91 & & $\bullet$ & $\bullet$ & & - & \\
\hline Slope Electric & Apr-92 & $\bullet$ & . & - & & $\bullet$ & . \\
\hline Tri-County Electric & Mar-92 & & $\bullet$ & - & & - & - \\
\hline Verendrye Electric & Feb-91 & $\bullet$ & & - & & - & \\
\hline West River Electric & Jun-91 & & $\bullet$ & $\bullet$ & & - & \\
\hline
\end{tabular}

*Equipment provided only for reconstruction projects.

${ }^{*}$ Utility always receives service call. If vendor box checked, then local vendor maintains system.

Figure 18. Utility PV Service Options

\section{Procurement Options}

Utilities procuring either equipment or services or both from the PV industry should consider separate and competitive procurements to ensure fair prices.

The objective of this task is to evaluate the cost of equipment and services that will be procured by the utility. The primary tradeoff that exists will occur between obtaining the lowest price 
equipment from the PV industry versus obtaining equipment at a higher price that includes services rendered by a PV industry contractor.

For a utility, such as Idaho Power, that intends to provide services using utility personnel, the added value of higher equipment costs for PV supplier support may be negligible. In this case, equipment will be procured directly from the manufacturer. However, for the utility planning on PV supplier support for program implementation, such as Northwest Rural, the PV equipment will be offered at a higher price to account for PV supplier support services. One way to ensure that both the equipment and the support services are priced fairly is to consider purchasing them separately in separate competitive procurements.

\section{Service Pricing}

Leasing PV equipment to customers will be the most common service pricing method,
since little energy is consumed by most stand-alone applications (compared to the
required equipment costs) and no rate subsidy will occur.

The objective of this task is to establish a service pricing method based on the equipment and services that will be provided. For many utilities, this method will be either an equipment lease or system sales. These options are likely, since billing customers on an energy basis for standalone PV systems is not practical for two reasons. First, little energy is consumed by these loads, so little revenue would be gained. Second, many of the PV service applications will be powered by DC electricity, which is difficult and expensive to meter.

Another reason for developing a leasing method is that only the customer receiving the PV service would pay for the service. Unlike traditional rate-making, this particular service would not be subsidized by any other utility rate-payer, and the service price would equal the utility's costs associated with obtaining, installing, and operating the PV equipment for that particular customer.

For most of the leasing programs implemented to date, the method has included three primary components: (1) a fixed amortization period; (2) the utility's typical rate of return; and (3) dollar for dollar compensation for expenses, such as financing and administrative costs, insurance, taxes, O\&M costs, and depreciation. For utilities presently leasing equipment to livestock water pumping customers, the amortization periods have ranged from three to 20 years. For a pumping system that costs $\$ 2,000$, the monthly payments range from approximately $\$ 15$ to $\$ 60$, and this range is due primarily to the difference in the terms. For the utilities allowed to sell systems to their customers, the sales price has included a nominal mark-up (15 to 30 percent) to account for some of these same expenses.

Despite these relatively simple methods, uncertainty exists about the amount to charge for expenses. For example, maintenance costs for many PV-powered applications will be uncertain until utilities determine these costs by monitoring actual installations. 


\section{Liability Issues}

Liability associated with PV pumping installations can be mitigated with insurance, standardized site security and safety measures, guaranteed site data and water storage capacity, and the realization that, unlike line extensions, PV installations are not fixed.

The objective of this task is to evaluate possible measures to mitigate any liability issues related to the PV service. For livestock water pumping, the liability measures fall into three categories: insurance, design requirements, and installation requirements.

For most of the utilities with PV services in place, the PV system installations are insured for theft, vandalism, and equipment failure due to accidents (e.g., lightning) under existing policies. However, two utilities have required that their customers purchase their own insurance for the PV systems. An additional "insurance" measure used to protect the utility's investment is a customer credit check prior to leasing the PV system.

Obtaining a damage deposit from each customer is another form of insurance. For Northwest Rural, requiring a damage deposit is identical to the utility's present line extension policy, where approximately three months worth of utility bills are collected prior to service hook-up. According to Northwest officials, their PV service customers feel that these service charges are reasonable, despite only seasonal use for many of the livestock water pumping systems.

Guaranteed well data and adequate water storage are two design requirements used to minimize utility liability by reducing the risk of system failure. Guaranteed well data, which can be obtained from a required well test or a signed statement from the customer (Carbon, McLean), can prevent installation problems ranging from dry well failures to insufficient water output. A minimum water storage requirement (i.e., three days) can avoid the issue of insufficient water output due to cloudy weather.

Finally, the installation requirements include site fencing and the implementation of safety procedures. The site fencing protects against damage from livestock, while the safety procedures protect against injury to either utility personnel or their customers. For several of these 15 utilities, the PV system guidelines provided by the National Electric Code (NEC) have become standard practice during installations. Furthermore, these utilities are also required to follow the National Electric Safety Code (NESC) on the utility side of the meter, though there are no PV guidelines in the NESC at this time.

Premature termination of the service is another possible liability issue that is mitigated by the PV system's flexibility. With traditional line extensions, the "fixed" installation does not lend itself to removal should the customer discontinue service prior to the utility recovering 
sufficient revenue to pay for the equipment. With PV power equipment, however, it is a fairly simple task to remove the equipment and install it at another site, thus reducing the loss.

\section{Customer Education}

PV service customers should be educated about the "wise use" of solar electricity, which will mean understanding the constraints imposed by PV system costs and the solar resource regardless of the customer's intended application.

The objective of this task is to develop customer education materials that describe the differences between being grid-connected as with traditional utility service and obtaining services "off the grid" with PV power. Much of this educational focus will be on the "wise use" of electricity for any application, since PV power supplies are costly, regardless of whether they are less expensive than the alternatives, and provide a limited supply of electricity on a daily basis. This education will occur regardless of the customer's application, though the message will be slightly different for each application.

For livestock water pumping customers, the education should emphasize that PV-powered pumping is different than grid-connected pumping in three ways. First, most PV-powered pumps are connected directly to the PV modules and therefore only pump water when the sun is shining (unlike conventional water pumping systems that pump water on demand). This fact requires a water storage tank large enough to provide water through a minimum of three days of cloudy or overcast weather. Second, PV-powered pumping systems have varying seasonal water outputs that may or may not match the customer's needs. Finally, many PV-powered pumps require periodic maintenance unlike the typical AC pump used in grid-connected applications.

For residential systems, the customer should understand that the "wise use" of electricity means powering large electrical loads with other fuels, using only efficient electrical appliances, and implementing conservation measures whenever possible. For example, a 700-W PV system might cost the utility $\$ 15,000$ to install and cost the customer $\$ 100$ per month to lease. However, the customer should understand clearly that this costly system may provide no more than 100 $\mathrm{kWh}$ per month. This fact will require that these customers use electricity only for essential purposes, and other fuel sources, such as propane or solar heat, should be used whenever possible. Specifically, if this customer is a homeowner, home and water heating, cooking, and refrigeration can be accomplished using these other fuels.

When electricity is the only answer for a particular use, such as lighting, PV system users should buy only the most efficient appliances. For example, high-efficiency fluorescent lighting can produce four times more light per watt than normal incandescent bulbs. The most efficient appliances will cost more initially, but they will pay for themselves in the long run by reducing the required size of the PV system and, thus, avoiding the higher PV service charges required for the larger system. 


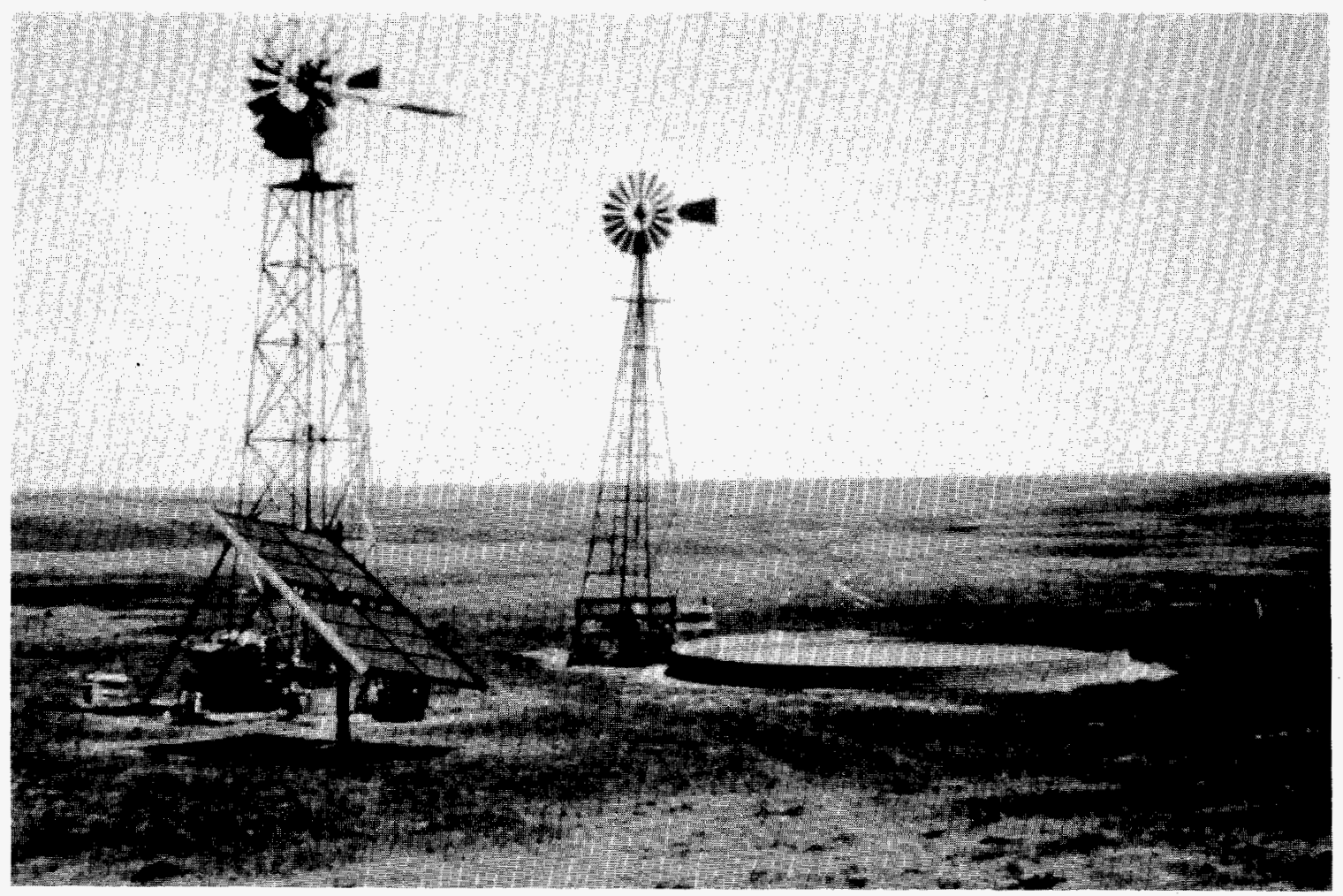

Source: K.C. Electric

Figure 19. PV Pumping System

In addition to switching fuel sources and using efficient appliances, implementing conservation measures should also be suggested as part of the customer education program. In a residence, conservation measures can include simple things like turning lights and appliances off when they are not necessary.

Marketing Plan

The marketing plan can range from an informal effort aimed at avoiding line extensions to an aggressive effort aimed at generating new customers. 
The objective of this task is development of a marketing plan. Presently, most of the RECs with PV service programs do not have any formal marketing program to advertise the PV service option. Instead, the utilities have relied primarily on introducing the PV service to a customer when the customer requests a line extension.

As shown in the following table, however, Idaho Power and San Isabel have developed the most formal marketing campaigns of any of these utilities. The objective of these campaigns has been to actively promote the PV service, as opposed to simply relying on it as a "problem solving" option to line extensions. Idaho Power in particular initiated an aggressive advertising campaign in January 1993 to generate customer interest in their PV service program.

In addition to the "word-of-mouth" method shown in the table, six other marketing methods have been used randomly by most of these utilities. Articles appearing in utility newsletters are the most frequent marketing method used because they are the most readily available. Stories in the local media (i.e., newspaper, TV, radio) and brochures have also assisted utilities in their marketing efforts.

Another marketing method used successfully by several utilities includes public demonstrations at fairs and customer meetings. Though fairs attract a lot of people, PV's effectiveness is limited since it is not demonstrated under real working conditions. Two utilities (McKenzie and San Isabel ) have stressed that meeting at an actual livestock water pumping site produces the most enthusiasm. Thus, customer meetings may be one of the most effective marketing methods available to the utility, since the audience can witness the PV system in operation under actual circumstances.

\section{Implement Full-Scale Program}

At this point in the program implementation effort, all the pieces should be conceived and should now be ready for initiation. Final procurement contracts should be finalized, so the formal marketing program can be initiated. Once initiated, customer requests will occur and utility. PV services will be provided. One of the most important aspects of full-scale implementation will be program monitoring and evaluation, as these activities will provide the information necessary to sustain the program. 


\begin{tabular}{|c|c|c|c|c|c|c|c|}
\hline \multirow[b]{3}{*}{ 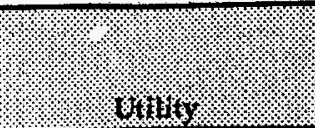 } & \multicolumn{7}{|c|}{ 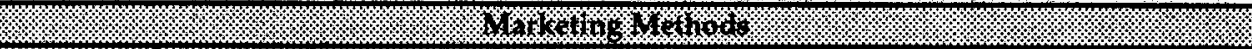 } \\
\hline & \multirow{2}{*}{ } & \multirow[b]{2}{*}{ mown } & \multirow{2}{*}{ Whom } & \multirow{2}{*}{ 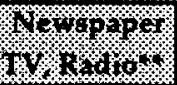 } & \multirow[b]{2}{*}{101010.4 .28} & \multicolumn{2}{|c|}{ 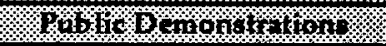 } \\
\hline & & & & & & W11 & 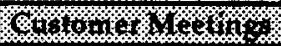 \\
\hline Black Hills Electric & $\bullet$ & & $\bullet$ & & & & \\
\hline Butte Electric & $\bullet$ & & & & & & \\
\hline Carbon Power \& Light & - & & & & & & \\
\hline Grand Electric & - & & - & & & & \\
\hline Idaho Power & $\cdot$ & $\therefore$ & 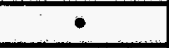 & - & - & & - \\
\hline K.C. Electric & - & $\bullet$ & $\div$ & & & & \\
\hline McKenzie Electric & 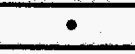 & & $\cdot$ & 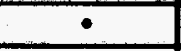 & & 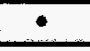 & 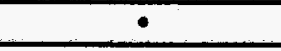 \\
\hline McLean Electric & $\bullet$ & & $\cdot$ & $\div$ & & $\cdot$ & \\
\hline Northwest Rural PPD & - & & $\div$ & & & $\cdot$ & \\
\hline Norton-Decatur Electric & - & & & & & & $\bullet$ \\
\hline San Isabel Electric & $\circ$ & $\div$ & - & $\bullet$ & & $\div$ & - \\
\hline Slope Electric & 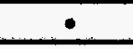 & & $\bullet$ & & & $\cdot$ & \\
\hline Tri-County Electric & $\div$ & & & & & & \\
\hline Verendrye Electric & $\cdot$ & & $\cdot$ & $\bullet$ & & & \\
\hline West River Electric & 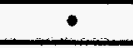 & & $\cdot$ & & & & \\
\hline
\end{tabular}

*Majority of activity due to line extension referral

**Public service announcements, news releases, etc.

Figure 20. Marketing Methods 
Full-Scale Program Design and Implementation

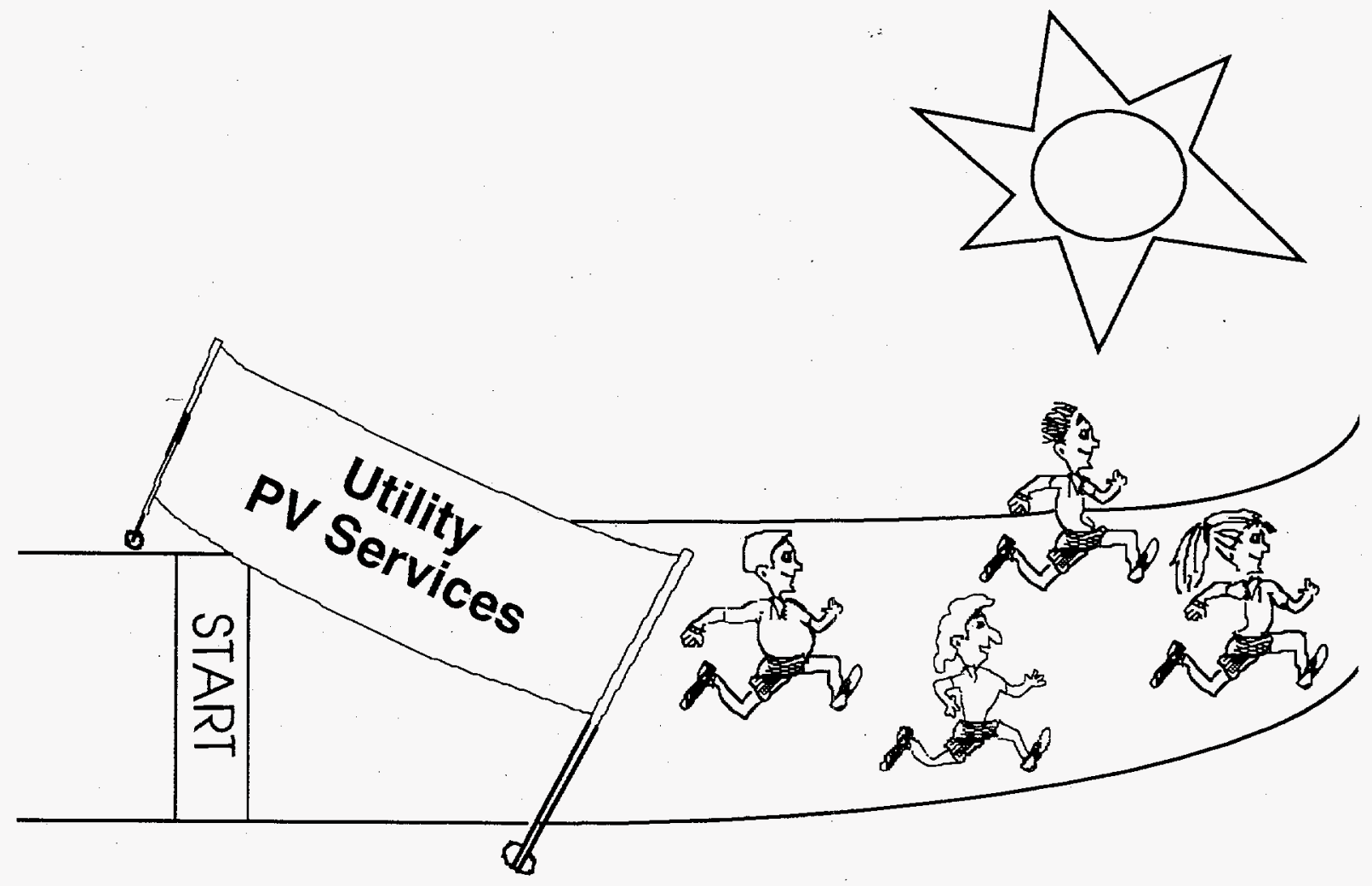

Figure 21. PV Service Implementation 
Full-Scale Program Design and Implementation

PART TWO - PV-POWERED WATER PUMPING GUIDELINES

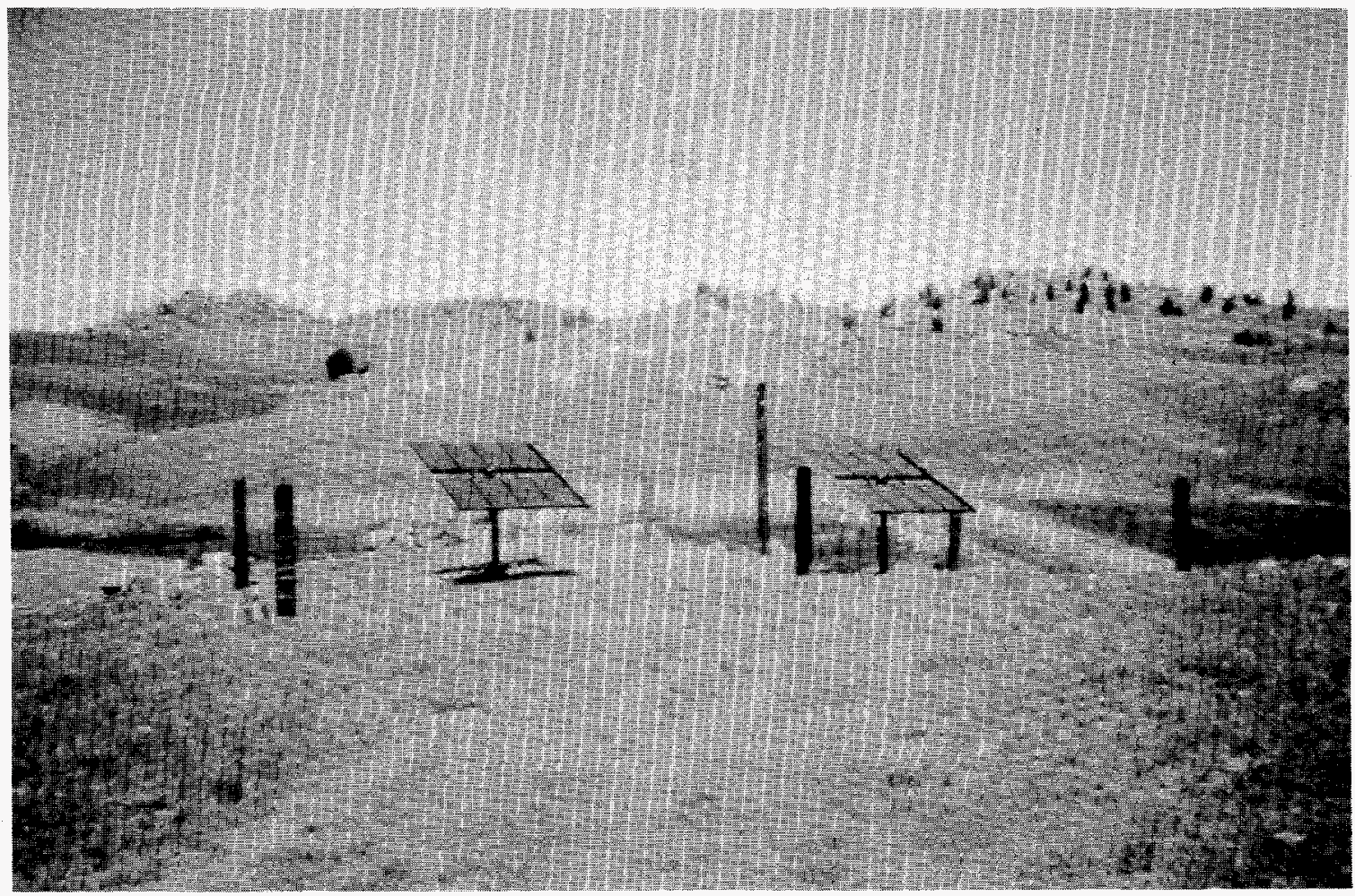

Source: Carbon P\&L, WY

Figure 22. PV Pumping System 
The U.S. cattle industry recorded nearly $\$ 40$ billion in 1990 sales, which accounted for nearly 25 percent of the entire U.S. farm market that year. As shown in the figure below, a significant portion of this influential industry exists in roughly 15 western states, where over 80 percent of all open-pasture livestock grazing occurs. The cattle in these states consume over 75 billion gallons of water per year, and much of this water is pumped with power from electric utilities.

Combine these numbers with the fact that utilities in the region often lose money when providing service to remote livestock wells and the incentives (from the utility's perspective) for utility PV services to these sites become obvious. .However, why would the utility's ranching customer want to use PV-powered pumping systems instead of traditional alternatives like utility power, windmills, or engine generators? The reasons are numerous and include the following:

- utility line extensions are too expensive for customers in most cases;

- ranchers often savor the thought of remaining independent from the grid;

- utility power can be unreliable in remote locations due to the voltage losses associated with long lines; and

- many utility customers prefer to power their systems with PV because it is a renewable energy resource with few environmental impacts.

Furthermore many ranchers today are replacing traditional water pumping methods, such as windmills and engine generators, with PV systems for reasons that include less required maintenance, lower cost, improved mobility, increased system availability over windmills (i.e., in many regions, the sun is a more reliable resource than the wind), and less noise.

For these reasons, the second part of this guidebook details the steps recommended for a utility to implement the installation of a PV pumping system. Figure 25 illustrates the recommended steps in the implementation procedure.

Although the utility may obtain assistance from PV vendors or other outside contractors for implementing these steps, the activities involved in the first three steps, preliminary site screening, site data collection, and data verification, will typically be the responsibility of the utility. Chapter 4, Site Screening, describes the initial customer/site screening procedure for selecting an appropriate PV pumping site. The chapter includes a Cost Estimation Chart that provides a "ball park" figure for pumping system costs, if the daily water requirement and pumping head are known. Chapter 5, Site Data Collection, describes all the detailed site information that must be collected for the proper design of a pumping system and provides a convenient form for recording the data. Chapter 6, Site Data Verification, explains why verification of the collected data is important and describes how to verify it.

Chapter 7, PV Pumping System Components, and Chapter 8, PV-Powered Water Pumps, discuss the components in a PV pumping system and give detailed information on commercially available PV pumps. Chapter 9, System Design and Specification, does not 


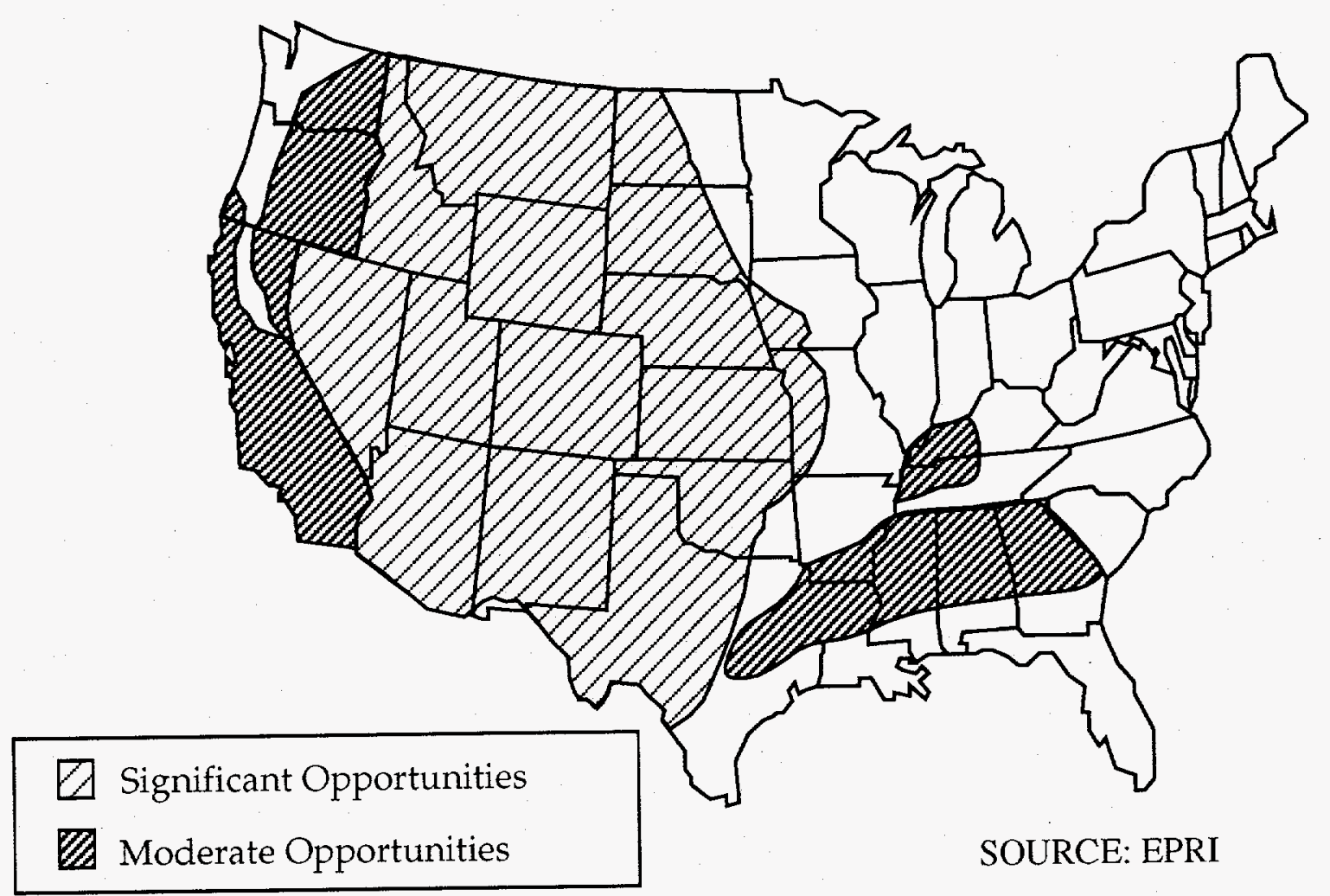

Figure 23. PV Opportunities in the U.S.

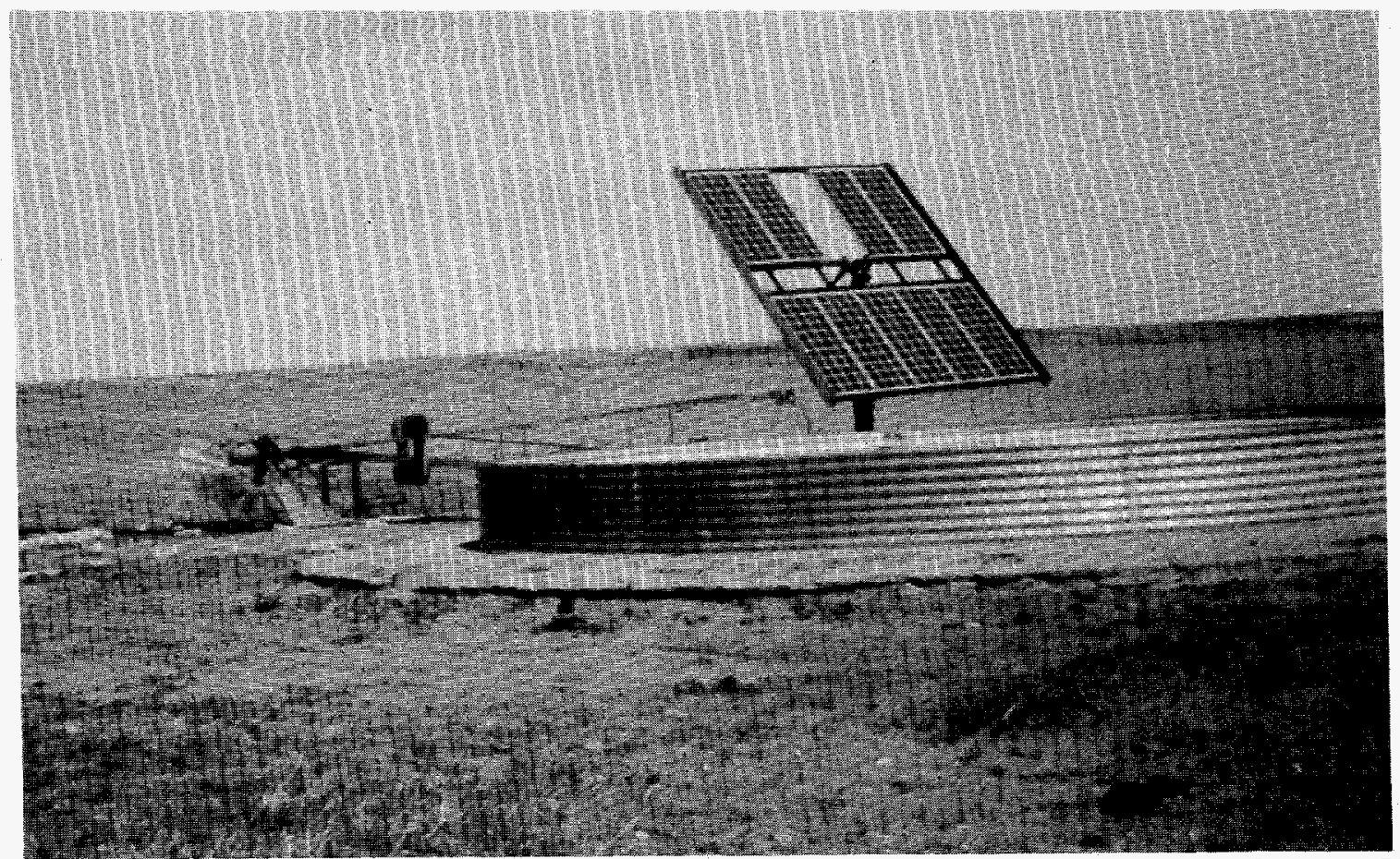

Source: WY

Figure 24. PV Pumping System 
provide complete instructions on how to design a PV-powered pumping system. However, the chapter does describe the process that most PV vendors use to design and specify systems. The information is intended to provide sufficient background on the design process for utility personnel to evaluate the component and pump selections that a vendor may propose to the utility.

Chapter 10 , System Procurement, provides general guidelines for procuring a PV-powered pumping system, while Chapter 11, System Installation, does not include detailed pumping system installation instructions, but provides enough information for a utility to understand the installation procedures. The final chapter, System Maintenance, provides possible preventive maintenance procedures and suggested troubleshooting guidelines. The troubleshooting guidelines describe possible problems encountered with pumping system installations, as well as solutions to the more easily repaired problems.

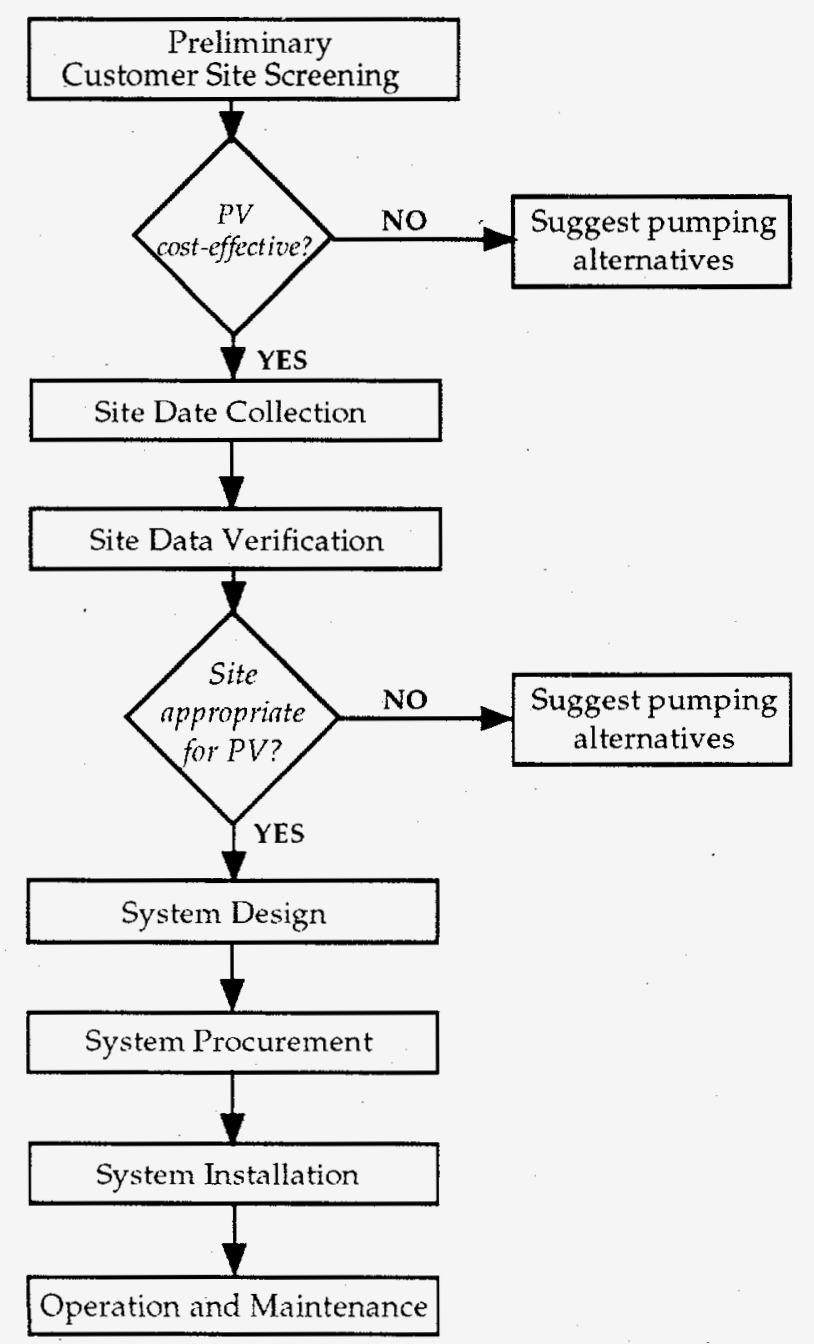

Figure 25. Pumping Implementation Flowchart 


\section{SITE SCREENING}

The utility should initially screen customer sites for customer acceptance of PV-
powered systems and cost-effectiveness.

Not all water sites are appropriate for PV-powered pumping systems. The suitability of a site for PV-powered pumping is determined by many factors such as pumping head, daily water requirement, seasons of use, solar access, water quality, available solar resource for the location, and willingness of the owner to accept a new technology. The selection of a suitable site is one of the most important determinants in the successful operation of a PV-powered pumping system.

One of the first factors to consider when screening a site for PV-powered water pumping is whether the customer is willing to accept a new technology. The customer must be willing to work with a power source that is different from a conventional line extension in many ways. Unlike conventional water pumping systems that pump water on demand, most PV-powered pumps are directly connected to the PV modules and therefore only pump water when the sun is shining. This requires installation of a water storage facility large enough to provide water through a minimum of three days of cloudy or overcast weather. PV-powered pumping systems also have varying seasonal water outputs that may or may not match the customer's needs and many require periodic maintenance.

Another question that must be answered when selecting a suitable site is whether the water requirement can be cost-effectively supplied by PV modules. To obtain a preliminary answer, at least three factors must be known: the pumping head, the water requirement, and the seasons of use. Knowing the pumping head and the water requirement, one can determine the amount of energy required to raise the water and knowing the season of use, one can determine the solar resource available to supply that energy. If the energy requirement is too high or if too little solar resource is available during a season of high use, the cost of the PV modules necessary to provide the energy will become prohibitively expensive, even in comparison to a lengthy line extension. When the cost of a line extension or a PV power supply exceeds certain limits, options such as engine-generator-powered pumps become more attractive alternatives to the customer.

For utilities or their customers unfamiliar with PV-powered water pumping, estimating the cost of a PV-powered pumping system for a particular site can be a difficult task. Although PV vendors can provide these estimates, it is not practical or time-effective to contact a vendor to evaluate each potential water pumping site. Also, pump curves, price sheets and literature from pump manufacturers can be used to estimate the size and cost of a pumping system. However, this assumes that the user has a wide selection of current pump literature and prices and knows how to size a pumping system. Since this is not always the case, a PV Pumping System Cost Estimation Chart is provided in the following pages to help the utility estimate the cost of pumping systems. If the customer's pumping head, and seasonal water requirements 


\section{Site Screening}

are known, this chart can be used to give a rough estimate of the cost of a PV-powered pumping system.

\section{How to Use the Cost Estimation Chart}

The two pages immediately following the Cost Estimation Chart contain insolation maps of the United States. These four monthly maps, which are representative of the four seasons, contain contours that denote the daily amounts of solar insolation received in different regions of the country in $\mathrm{kWh} / \mathrm{m}^{2}$. The daily insolation in $\mathrm{kWh} / \mathrm{m}^{2}$ is also called peak sun hours. The following steps detail how to use the Cost Estimation Chart.

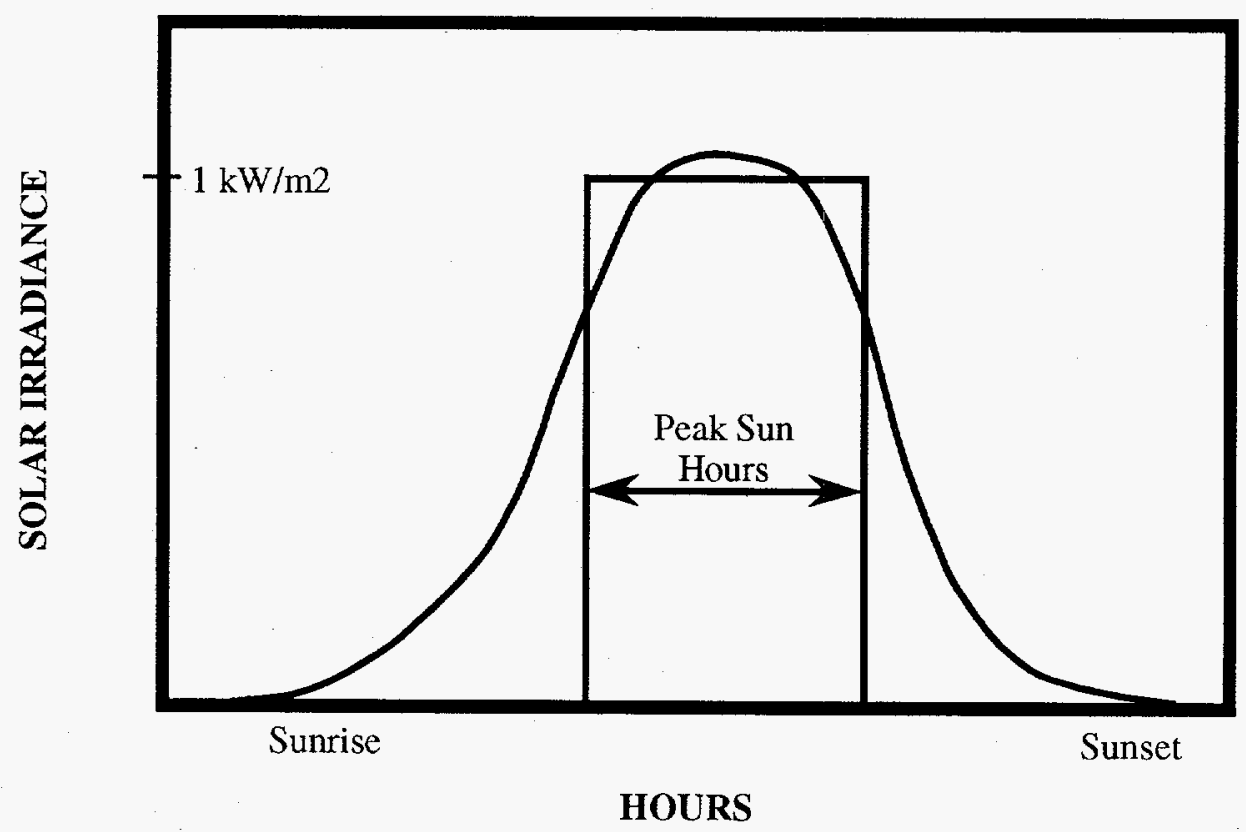

The equivalent number of hours per day when solar irradiance averages $1,000 \mathrm{watts} / \mathrm{m}^{2}$. For example, six peak sun hours means that the energy received during total daylight hours equals the energy that would have been received had the irradiance been 1,000 watts $/ \mathrm{m}^{2}$ for six hours.

Figure 26. Peak Sun Hours 
1. Determine the number of peak sun hours available in your region during the critical season of water use. Use the insolation maps to find the peak sun hours for your location for every season that water is required. Divide each season's water requirement by the number of peak sun hours to get seasonal gallons per sun hour figures. The season with the largest gallons per sun hour is the critical season of use.

2. Locate the peak sun hours associated with the season of critical use on the upper left side of the Cost Estimation Chart. Follow the gallons per day quantities in that column until you find the figure closest to your daily water requirement for the critical season of use.

3. Locate the figure closest to the pumping head for the customer site found along the bottom right side of the Cost Estimation Chart.

4. Finally find the intersection of the water requirement row and the pumping head column. The dollar figure at the intersection is a rough estimate of the cost of a PV-powered pumping system for the customer site.

The estimate is a "ballpark" figure for submersible pumping system equipment with a pump controller and a fixed array. The estimate does not include installation of the system.

At this time, the utility must decide whether the potential cost of the pumping system permits a reasonable monthly customer charge that is acceptable for both the utility and the customer. 


\begin{tabular}{|c|c|c|c|c|c|c|c|c|c|c|c|c|c|c|c|c|}
\hline \multicolumn{7}{|c|}{ Peak Sun Hours } & & & & & & & & & & \\
\hline 2 & 3 & $2=4$ & 5 & . 6. & 7 & 8.8 & \multicolumn{10}{|c|}{ Cost For System (1) } \\
\hline 9,000 & 13,500 & 18,000 & 22,500 & 27,000 & 31.500 & 36,000 & $\$ 10,000$ & $\$ 12,000$ & (2) & (2) & (2) & (2) & (2) & (2) & (2) & (2) \\
\hline 6,000 & 9,000 & 12,000 & 15,000 & 18,000 & 21,000 & 24,000 & $\$ 7,900$ & $\$ 9,300$ & $\$ 13,000$ & $\$ 16,000$ & (2) & (2) & (2) & (2) & (2) & (2) \\
\hline 3,600 & 5,400 & 7,200 & 9,000 & 10,800 & 12,600 & 14,400 & $\$ 7,000$ & $\$ 8,000$ & $\$ 9,700$ & $\$ 13,000$ & $\$ 14,000$ & $\$ 16,000$ & (2) & (2) & (2) & (2) \\
\hline 2,400 & 3,600 & 4,800 & 6,000 & 7,200 & 8,400 & 9,600 & $\$ 7,000$ & $\$ 6,900$ & $\$ 7,800$ & $\$ 9,100$ & $\$ 10,000$ & $\$ 12,000$ & $\$ 14,000$ & (2) & (2) & (2) \\
\hline 1,800 & 2,700 & 3,600 & 4,500 & 5,400 & 6,300 & 7.200 & $\$ 6,000$ & $\$ 7,000$ & $\$ 7,000$ & $\$ 8,500$ & $\$ 8,900$ & $\$ 10,000$ & $\$ 11,000$ & $\$ 14,000$ & (2) & (2) \\
\hline 1,200 & 1,800 & 2,400 & 3,000 & 3,600 & 4,200 & 4,800 & $\$ 5,700$ & $\$ 5,800$ & $\$ 7,000$ & $\$ 7,300$ & $\$ 8,200$ & $\$ 9,100$ & $\$ 9,100$ & $\$ 12,000$ & $\$ 13,000$ & (2) \\
\hline 960 & 1,440 & 1,920 & 2,400 & 2,880 & 3,360 & 3,840 & $\$ 5,600$ & $\$ 5,700$ & $\$ 6,100$ & $\$ 6,900$ & $\$ 7,400$ & $\$ 8,500$ & $\$ 8,900$ & $\$ 11,000$ & $\$ 13,000$ & $\$ 16,000$ \\
\hline 720 & 1,080 & 1,440 & 1,800 & 2,160 & 2,520 & 2,880 & $\$ 5,300$ & $\$ 5,400$ & $\$ 5,700$ & $\$ 6,800$ & $\$ 6,800$ & $\$ 7,300$ & $\$ 7,800$ & $\$ 9,000$ & $\$ 11,000$ & $\$ 14,000$ \\
\hline 480 & 720 & 960 & 1,200 & 1,440 & 1,680 & 1,920 & $\$ 3,200$ & $\$ 3,200$ & $\$ 3,300$ & $\$ 6,000$ & $\$ 6,400$ & $\$ 6,800$ & $\$ 7,100$ & $\$ 8,300$ & $\$ 9,200$ & $\$ 11,000$ \\
\hline 360 & 540 & 720 & 900 & 1,080 & 1260 & 1,440 & $\$ 2,300$ & $\$ 2,400$ & $\$ 2,500$ & $\$ 3,000$ & $\$ 3,500$ & $\$ 6,700$ & $\$ 6,900$ & $\$ 7,800$ & $\$ 8,900$ & $\$ 9,500$ \\
\hline 240 & 360 & 480 & 600 & 720 & 840 & 960 & $\$ 2,100$ & $\$ 2,100$ & $\$ 2,100$ & $\$ 2,200$ & $\$ 2,600$ & $\$ 2,600$ & $\$ 2,800$ & $\$ 6,900$ & $\$ 8,100$ & $\$ 9,000$ \\
\hline 120 & 180 & 240 & 300 & 360 & 420 & 480 & $\$ 1,500$ & $\$ 1,600$ & $\$ 1,600$ & $\$ 1,700$ & $\$ 1,800$ & $\$ 2,100$ & $\$ 2,200$ & $\$ 2,600$ & $\$ 6,900$ & $\$ 7,100$ \\
\hline 60 & 90 & 120 & 150 & 180 & 210 & 240 & $\$ 1,200$ & $\$ 1,200$ & $\$ 1,200$ & $\$ 1,300$ & $\$ 1,400$ & $\$ 1,500$ & $\$ 1,500$ & $\$ 1,900$ & (2) & (2) \\
\hline \multirow{2}{*}{\multicolumn{7}{|c|}{$\begin{array}{l}\text { Water Output } \\
\text { (Gallons Per Day) }\end{array}$}} & 20 & 30 & 50 & 75 & 100 & 125 & 150 & 200 & 250 & 300 \\
\hline & & & & & & & \multicolumn{10}{|c|}{ Pumping Head (Feet) } \\
\hline
\end{tabular}

Note: This chart gives a rough first estimate of the cost of PV pumping systems excluding installation. These estimates are based on a sampling of available and PV system components. For a more refined estimate, contact a PV professional.

(1) The costs and water output (GPD) are based on a direct-coupled system (no batteries) that includes a pump controller and a fixed array set for latitude tilt (2) No pumps identified for this size application.

Figure 27. Cost-Estimation Chart 


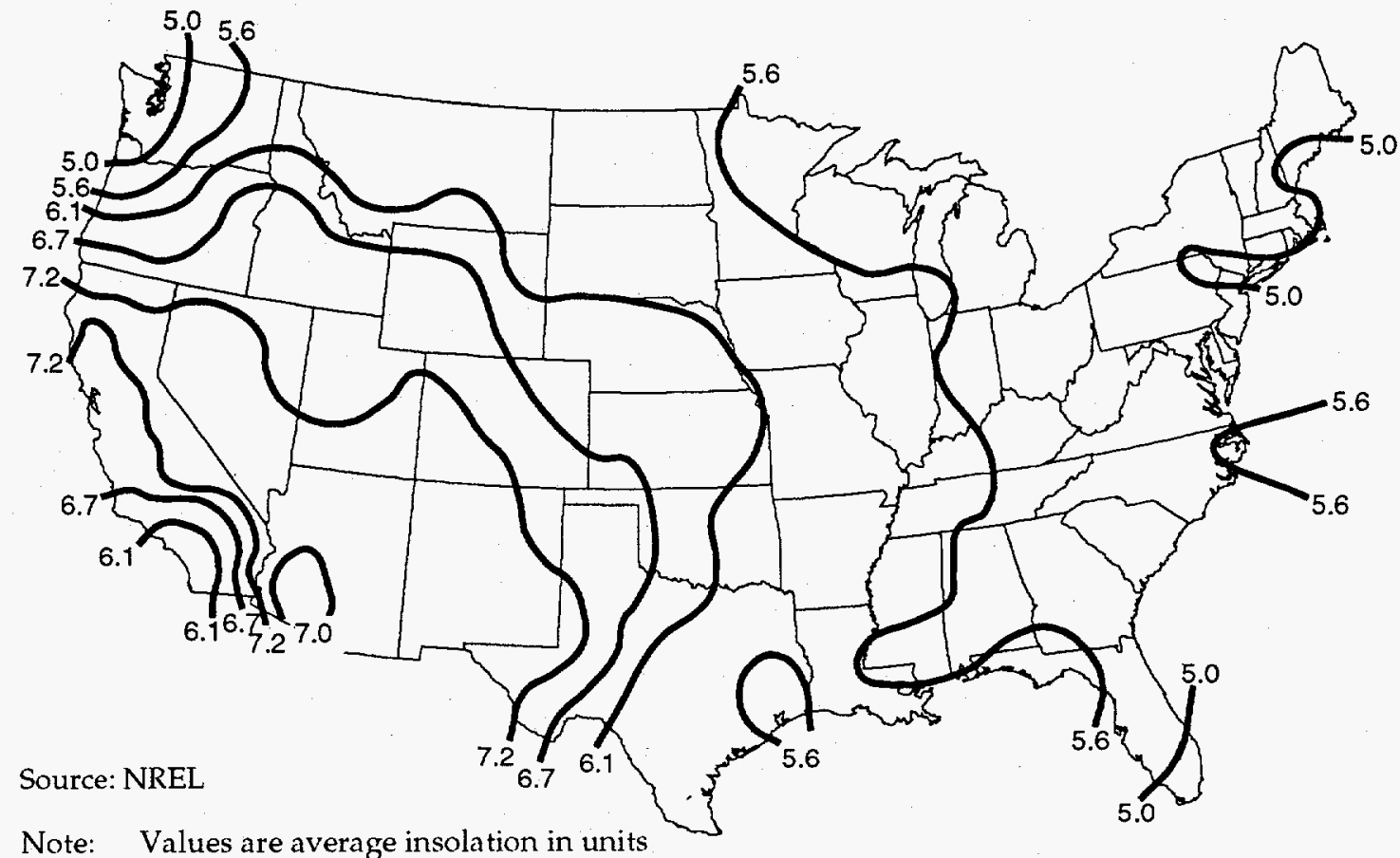
of $\mathrm{kWh} / \mathrm{m}^{2}$ for a surface at latitude tilt.

Figure 28. Average Daily Solar Insolation - June

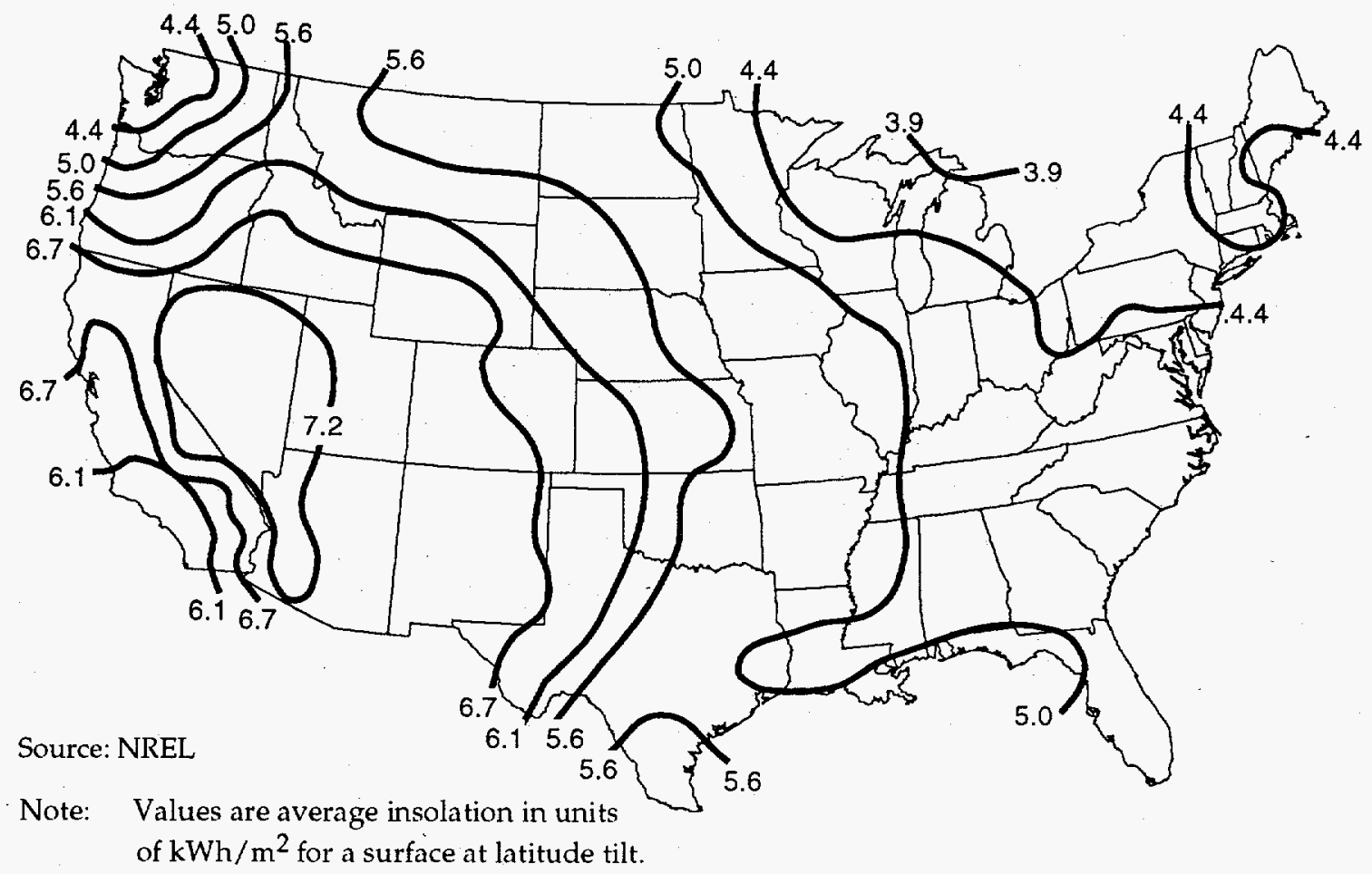

Figure 29. Average Daily Solar Insolation - September 
Site Screening

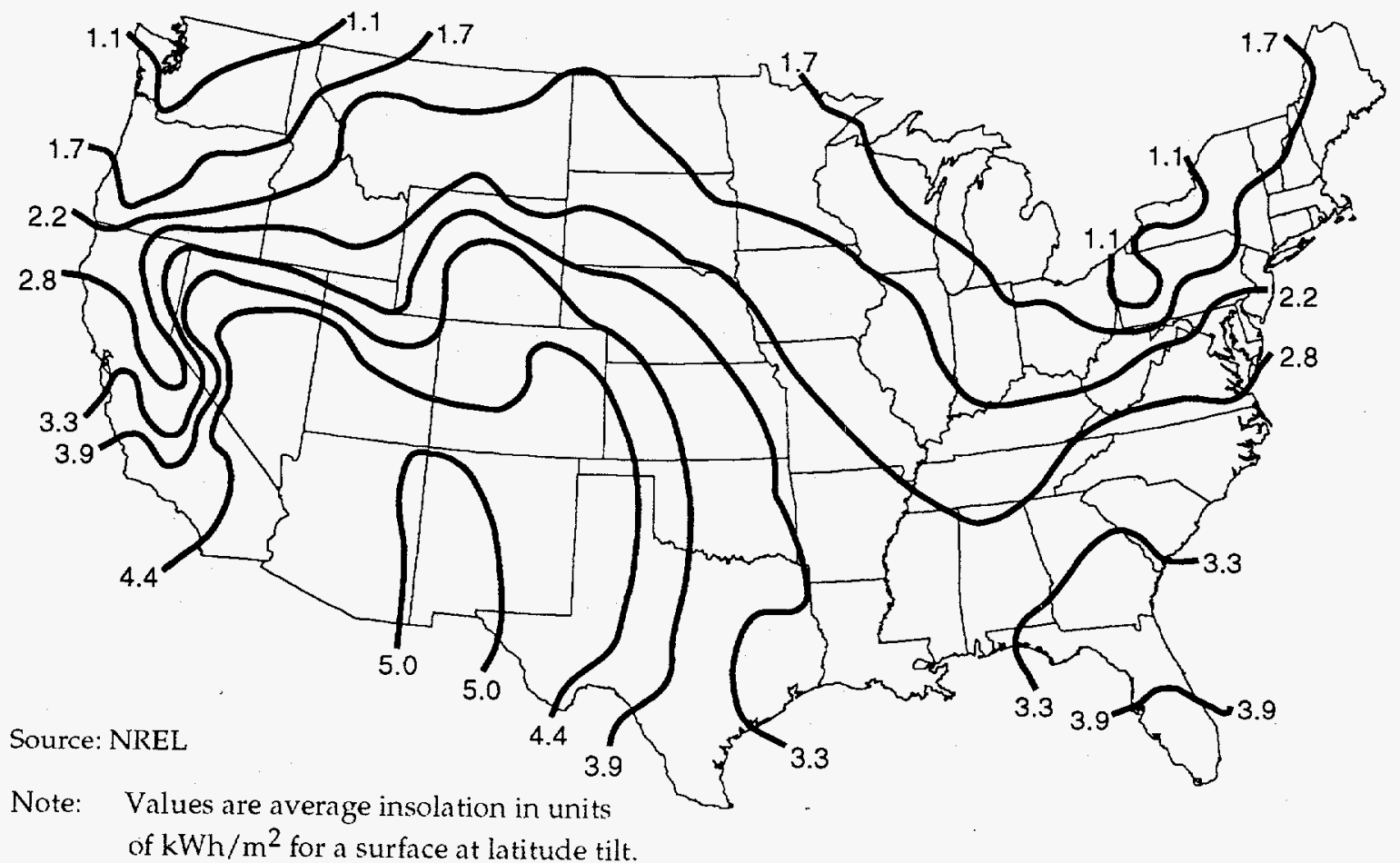

Figure 30. Average Daily Solar Insolation - December

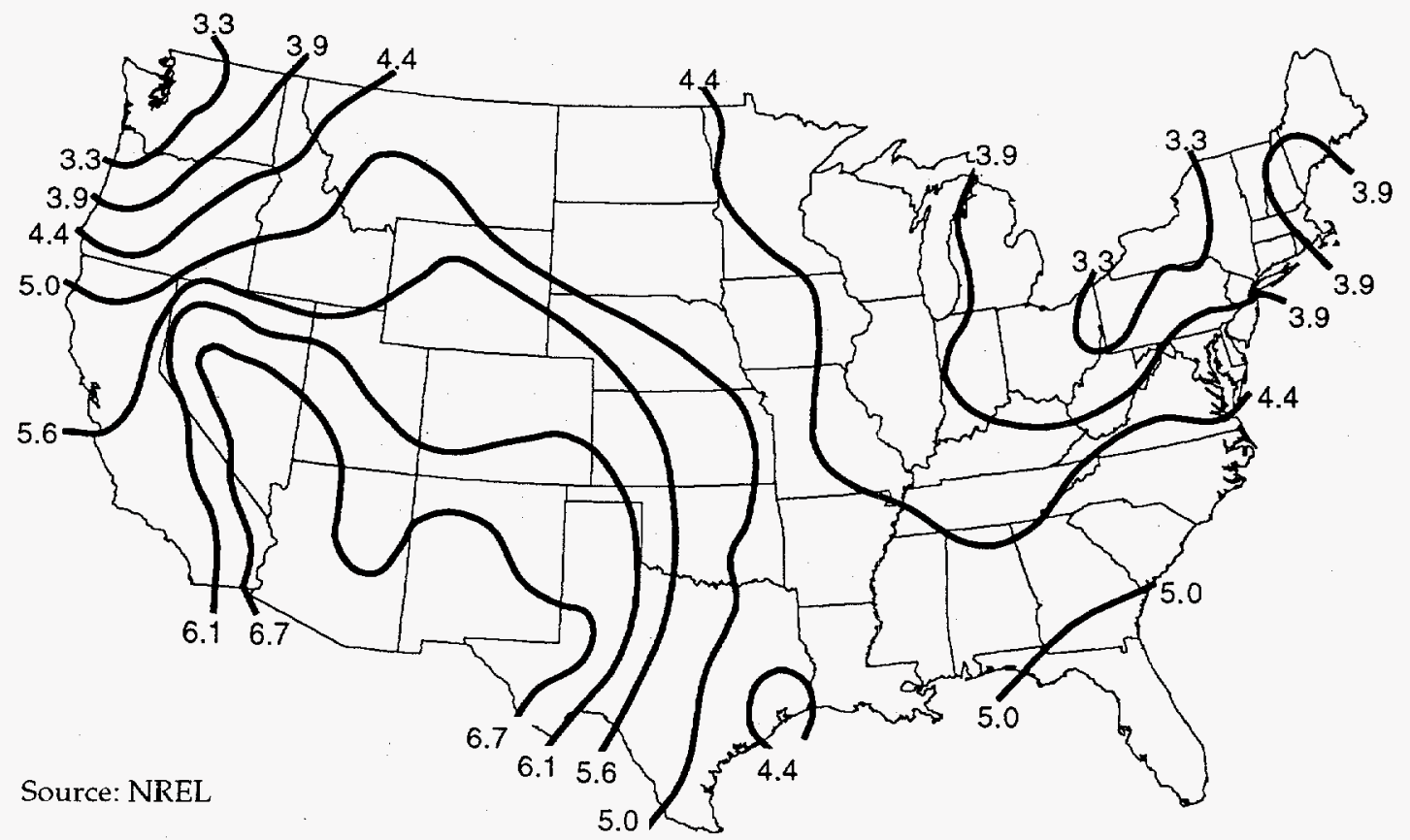

Note: Values are average insolation in units of $\mathrm{kWh} / \mathrm{m}^{2}$ for a surface at latitude tilt.

Figure 31. Average Daily Solar Insolation - March 


\section{SITE DATA COLLECTION}

Once a prospective site is selected, detailed information must be collected on the customer's water use and the water source.

After a pumping site is initially determined to be cost effective for PV-powered water pumping, additional information needs to be collected on the prospective site. This additional information is used to help verify the water requirements and the pumping head and to further determine the suitability of the site for PV-powered water pumping. The information is also the essential foundation upon which proper system design is based whether the system is to be designed and specified by the utility or by a PV vendor. To facilitate the collection of the information, a site data form was developed for recording the data (see Figure 33). The form is divided into three main categories: Customer Information, Water Use Information, and Water Source Information. The information requirements for each section are discussed in the following pages.

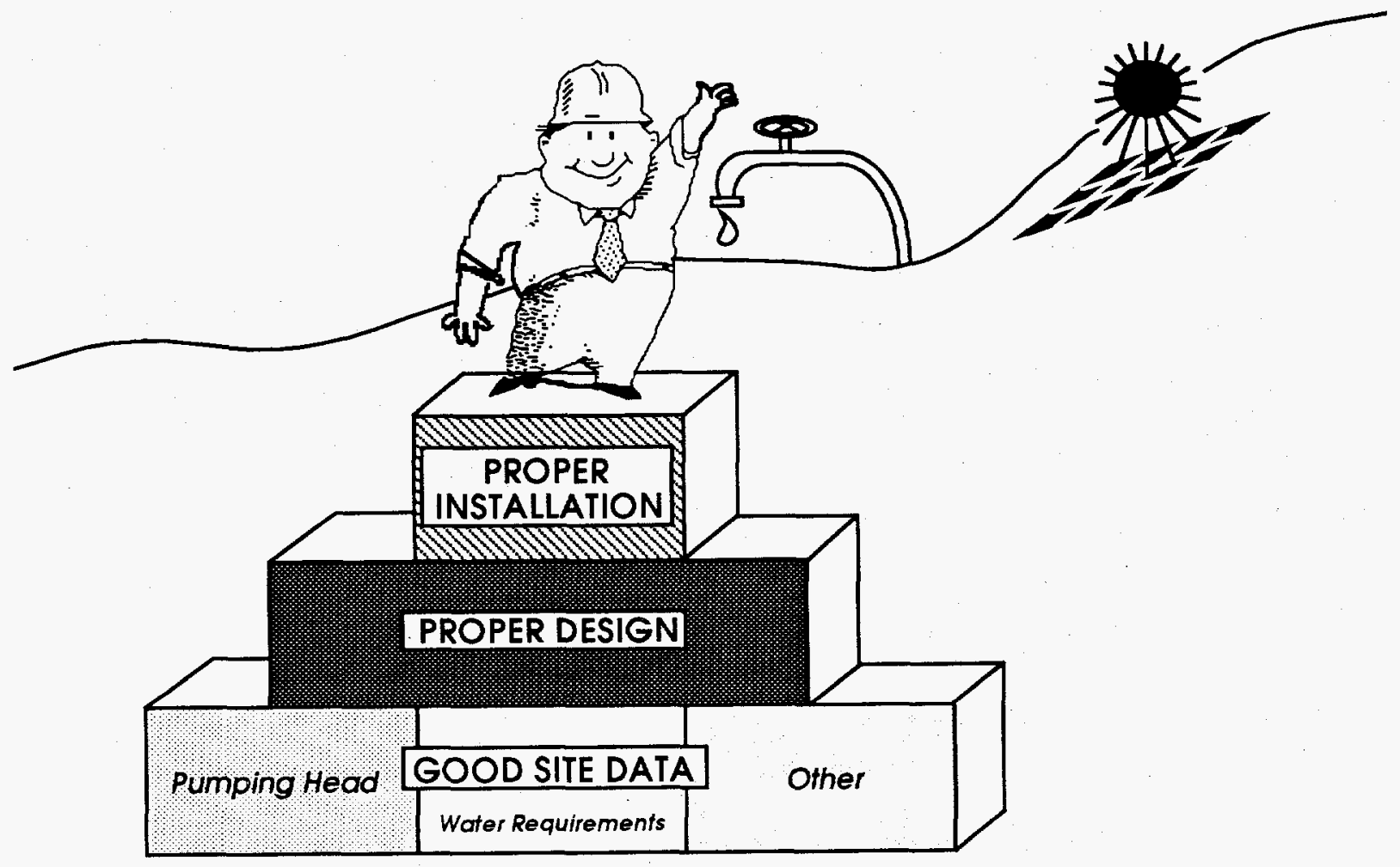

Figure 32. Installation Building Blocks 


\begin{tabular}{|c|c|}
\hline \multirow{2}{*}{\multicolumn{2}{|c|}{ 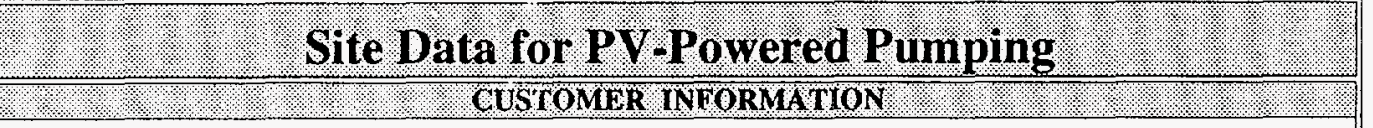 }} \\
\hline & \\
\hline \multicolumn{2}{|l|}{ Customer Name } \\
\hline \multicolumn{2}{|l|}{ Address } \\
\hline \multicolumn{2}{|l|}{ State \& Zip Code } \\
\hline \multicolumn{2}{|c|}{ Telephone Number } \\
\hline \multicolumn{2}{|c|}{ WAIER USE INFORMATION } \\
\hline Water End Use: (Please circle one) & $\begin{array}{l}\text { 1. Livestock watering - Number of head } \\
\text { Type of livestock: } \\
\text { 2. Domestic household use - Number of people } \\
\text { 3. Other - Please specify: }\end{array}$ \\
\hline Average Daily Water Requirement: & $\begin{array}{l}\text { Summer: } \quad \text { Gallons/Day } \\
\text { Fall: } \\
\text { Winter: } \\
\text { Spring: }\end{array}$ \\
\hline Water Storage: (Please circle one) & $\begin{array}{l}\text { 1. Above ground tank - Size: } \_ \text {Pressure: } \\
\text { 2. Pressure tank - Size: } \_ \text {Gallons } \\
\text { 3. Other }\end{array}$ \\
\hline \multicolumn{2}{|c|}{ WATER SOURCF INFORMATION } \\
\hline \multicolumn{2}{|c|}{ 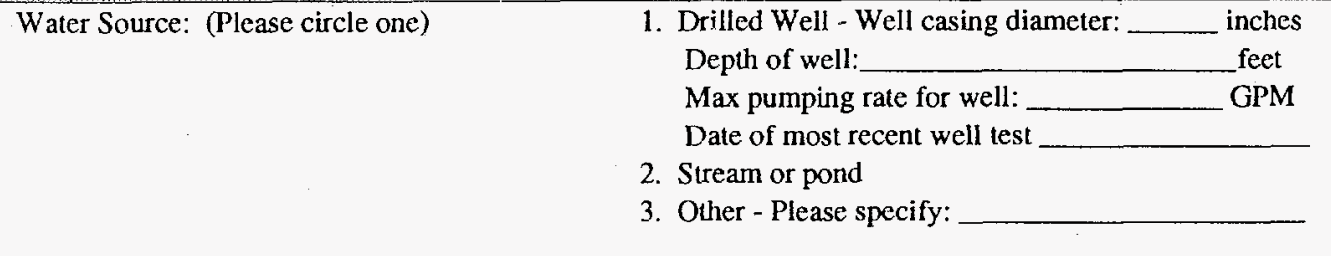 } \\
\hline Is this water source presently being used? & $\begin{array}{l}\text { YES } \\
\text { If yes, how is it being pumped? }\end{array}$ \\
\hline $\begin{array}{l}\text { Static Water Level: (Distance from ground } \\
\text { surface to water when not pumping) }\end{array}$ & F Feet \\
\hline $\begin{array}{l}\text { Drawdown Level: (Distance water level drops } \\
\text { when pumping at normal rates) }\end{array}$ & Feet. While pumping at __ GPM \\
\hline $\begin{array}{l}\text { Discharge Head: (Vertical distance water } \\
\text { is pumped uphill to tank or distribution) }\end{array}$ & Feet \\
\hline Pressure head: (Tank pressure in psi $\times 2.31$ ) & Feet \\
\hline Friction head: (see description in guide book) & Feet \\
\hline \multicolumn{2}{|l|}{ Total Pumping Head: (sum above distances) } \\
\hline $\begin{array}{l}\text { Water Quality: } \\
\text { Water Contains: }\end{array}$ & $\begin{array}{l}\text { Very Good __ Good _ Fair __ Poor _ _ Very Poor __ } \\
\text { Silt___ Sand __ Rust___ }\end{array}$ \\
\hline Does the site have unrestricted solar access? & YES _ NO N \\
\hline
\end{tabular}

Figure 33. Site Data Form 


\section{Customer Information}

This first section of the site data form provides spaces for the customer's name, address, and phone number to identify the information on the form.

\section{Water Use Information}

Water End Use - This information can be used to help verify the customer's water requirements. Circle the customer's end use for the water. If the pump will be used for livestock watering, also record the number of head of livestock that will be watered and the type of livestock (dairy cows, cow/calf pairs, yearling cattle, sheep, etc.) If the pump will be used for domestic household use, also record the number of people in the household that will be using the water. If the end use is something other than stock watering or domestic households, circle "Other" and record the end use.

Average Daily Water Requirement - Determine as accurately as possible the customer's average daily water requirements for this water site in each season of use and record the quantities here.

Water Storage - Because most PV-powered pumping systems provide water only when the sun is shining, customer satisfaction with a PV-powered system relies heavily on sufficient water storage. At a minimum, the water storage should be sufficiently large to supply three day's water requirements. For critical applications and cloudy climates the storage facility should be larger. Circle the type of water storage that the customer will be using and record the storage capacity in gallons. If the existing storage facility at the site is not sufficient and the customer is willing to replace or increase the storage facility, circle and record the information for the improved storage facility.

\section{Water Source Information}

Water Source - The pumps that can be used at a pumping site are in large part determined by the type of water source at the site. Circle the type of water source to be used at the site. If the source is a well, also record the inside diameter of the well casing, the depth of the well, and enter the date of the most recent well test. The diameter of the casing determines the types and sizes of pumps that can be installed in the well. The depth of the well indicates how far below the static water level a pump can be submersed. Knowledge of whether a recent well test had been performed will indicate the accuracy of the well data. If the water source is other than a drilled well, stream or pond, circle "Other" and record the type of water source.

Is this water source presently being used? - The answer to this question gives the pumping system installer an indication of whether additional work may have to be done at the site before a PVpowered system is installed. For example, if the water is being pumped by a windmill and a submersible solar pump best suits the application, all of the windmill's down hole equipment must be removed prior to installation of the new pump. This question also alerts the installer to 
possible problems with water quality. A well that has not been pumped for a lengthy amount of time may initially contain some quantities of silt and sand or rust if the casing is made of cast iron. Check "YES" or "NO". If the water source is being used, record the method used to pump the water (windmill, gas generator, grid connection, etc.)

Static Water Level - This is the distance from the ground surface to the water level in the well, stream, or pond when the water source is not being pumped (see the following diagram). This water level may change seasonally or from year to year especially if the source is a stream subject to fluctuations. Record the lowest known static level.

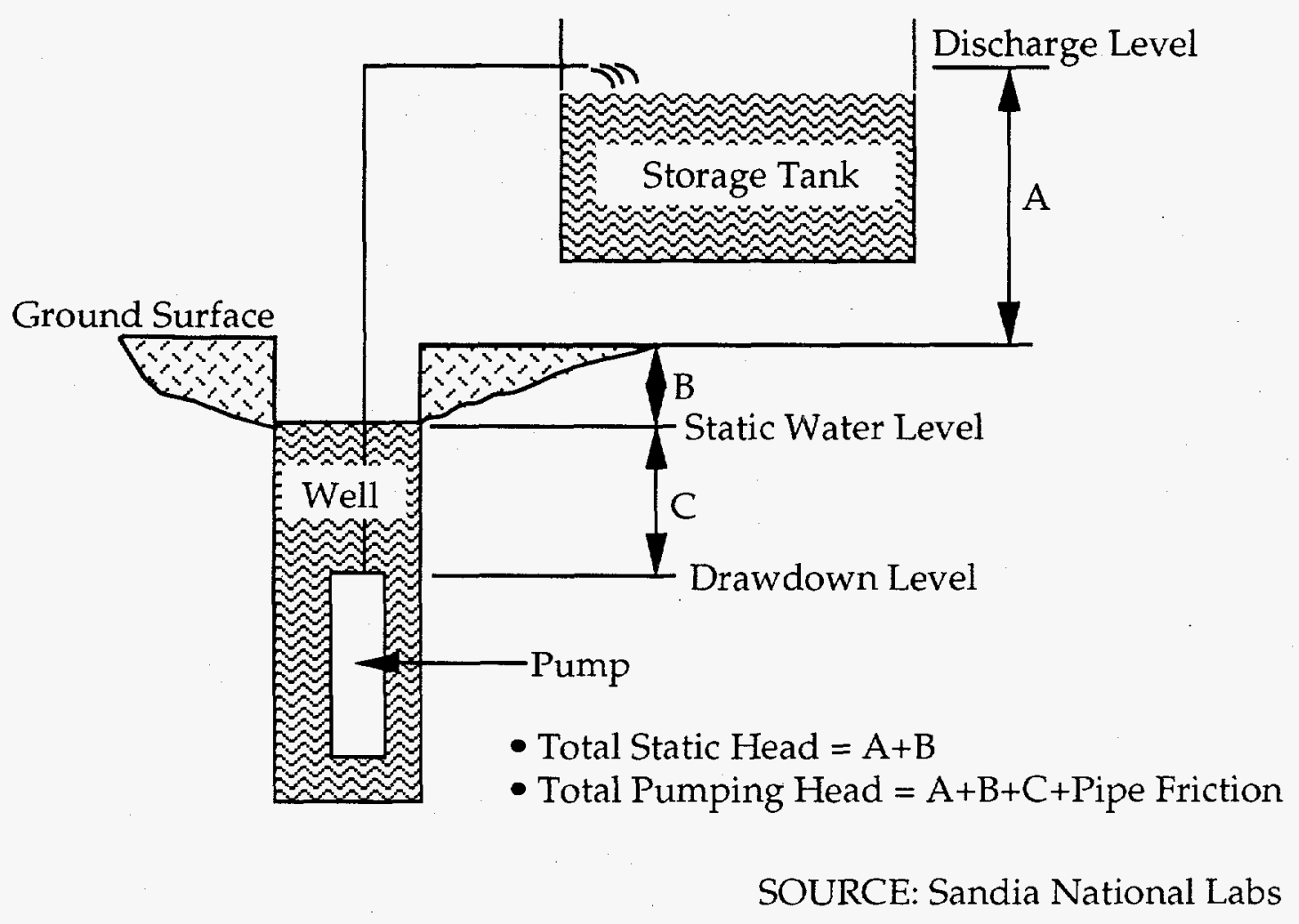

Figure 34. Well Schematic 
Drawdown Level - As well as being an important component of the total dynamic head, the drawdown level indicates to the pump installer how deep the pump or water intake must be installed to remain submerged while the source is being pumped. The drawdown level is the distance the water level drops when the water source is being pumped (see the following diagram). In water sources such as streams and ponds, the water level will most likely not change. However, in wells, the distance that the water level drops may change seasonally and from year to year. Record the largest known drawdown level while the source is being pumped at a rate large enough to supply the daily water requirements within five or six hours. Also record the pumping rate. For example, if the customer needs 3000 gallons of water per day, divide 3000 by five hours to get 600 gallons per hour. Divide 600 by 60 minutes to get 10 gallons per minute ( $\mathrm{gal} / \mathrm{min}$ ). For the example, the drawdown level is the distance that the water level drops while the source is being pumped at $10 \mathrm{gal} / \mathrm{min}$.

Discharge Head - This is the vertical distance that the water must be pumped uphill from the ground level to a storage tank or a distribution point (see diagram). In most cases, the water will be used or stored in the area immediately adjacent to the water source and the discharge head will be very small ( 2 to 10 feet). However, water is sometimes pumped uphill to tanks or distribution points in other pastures and the vertical rise in the pipeline can add significantly to the total pumping head. Record the vertical distance to the highest storage tank or distribution point.

Pressure Head - If a pressure tank is used to store the water (usually in domestic water systems) and if the same pump used to move the water must also pressurize the tank, the pressure in the tank must be translated to an equivalent head of water. To do this, multiply the mean tank pressure (value between pump turn on and turn off settings) in pounds per square inch (psi) by 2.31 to get the equivalent head in feet. Record this number. If a pressure tank is not used, record zero.

Friction Head - The friction head is the pressure loss due to friction of the moving fluid in the piping. It is a function of the length of the pipe run, the diameter of the pipe, the smoothness of the pipe, and the velocity of the fluid. In most cases, when the water is used in the vicinity of the water source, the friction head is insignificant and can be ignored. However, if the water is pumped for any distance away from the source (over $300 \mathrm{ft}$.) the friction head may need to be included in the total pumping head. The friction head can be estimated by consulting engineering handbooks or by calling the local soil conservation service office. Record the friction head if significant, otherwise record zero.

Total Pumping Head - The total dynamic pumping head is the sum of the above five distances. This is the number that is used when sizing pumping systems. Total the five distances and record here.

Water Quality - For water that contains small amounts of sand, silt, or rust, pumps may need additional screens or filters for proper operation. If the water contains too many abrasive 
particles, the water source may not be appropriate for PV-powered or any other type of pumping. Check the quality of the water contained in the water source.

- $\quad$ Check VERY GOOD it the water contains no abrasive particles.

- Check GOOD if the water contains minimum amounts of silt.

- $\quad$ Check FAIR if the water contains small amounts of silt, sand, or rust.

- $\quad$ Check POOR if the water contains moderate amounts of silt, sand, or rust on a non-regular basis.

- $\quad$ Check VERY POOR if the water contains moderate amounts of silt, sand, or rust on a regular basis.

Does the site have unrestricted solar access? - Does the area surrounding the site contain any trees, hills, or buildings that may block the sunlight reaching the water site at any time of the day during any season? If so, the PV array may have to be located some distance away from the pump. A cable run to a distant array can add expense to a pumping system for the heavy gauge outdoor rated wire that must be used. In addition, the wire must be either buried or strung overhead to prevent damage to it from livestock or traffic. Cable runs for smaller, low voltage systems should be kept to a minimum to avoid voltage drops. If the water site for a small pumping system is surrounded by tall trees, PV may not be the best option for powering the pump. 


\section{SITE DATA VERIFICATION}

Because good site data is essential for proper system design, the utility must attempt to verify the accuracy of the previously collected data.

As stated previously, good site data is the essential foundation upon which proper system design is based. Care must be taken to collect accurate information and to verify that information whenever possible. Too often, the design of PV pumping systems has been based on incomplete or inaccurate site data producing disastrous results.

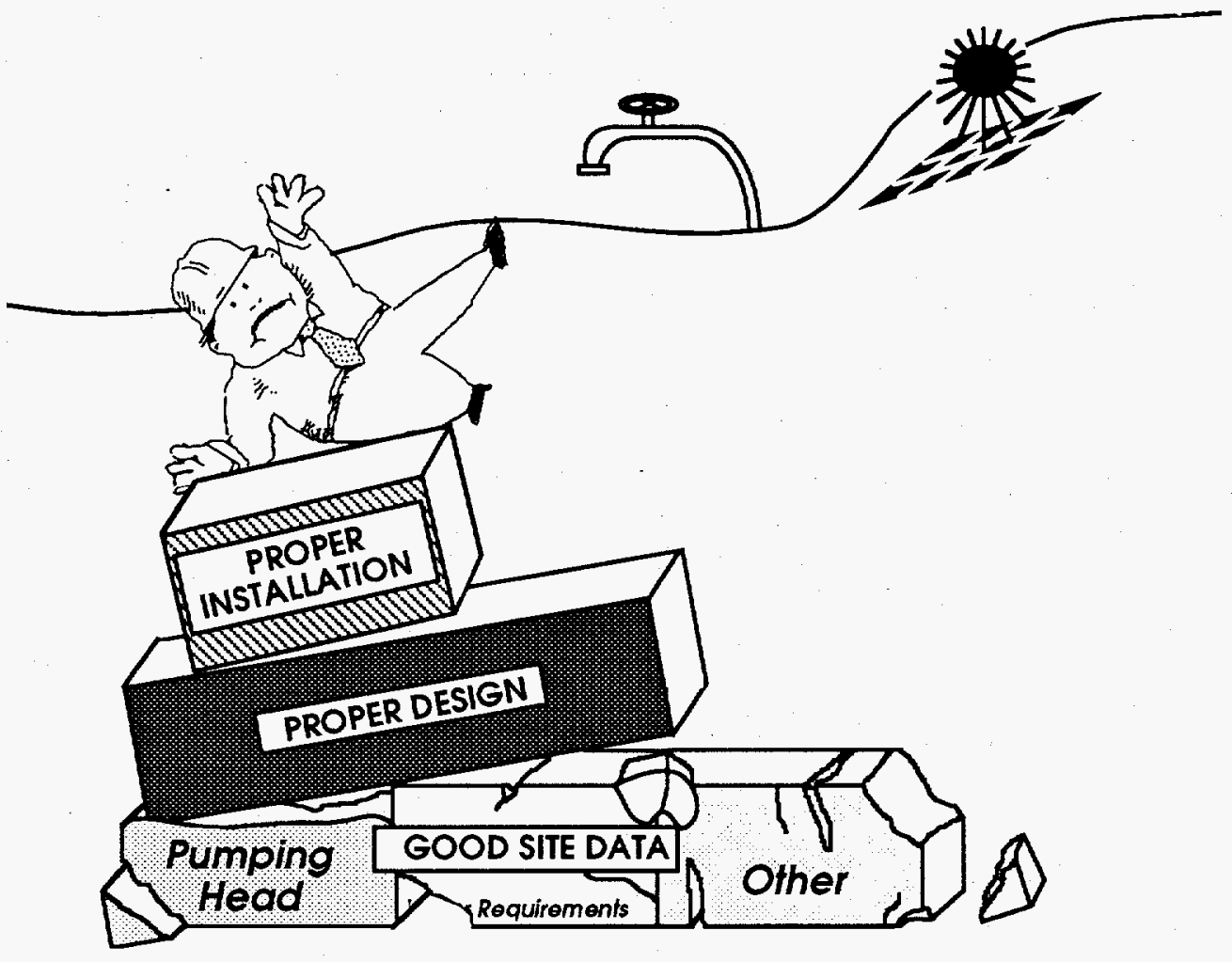

Figure 35. Crumbling Installation Building Blocks

\section{Water Use Information}

One item of site data that needs to be carefully examined is the customer's water requirement. It must be determined if the customer's stated requirement is a realistic evaluation of actual need. Quite often, ranchers will overstate their water requirements for three primary reasons: their uncertainty about their livestock's actual needs, their uncertainty about a PV system's ability to deliver the needed water, or their desire to ensure plentiful water for future expansions. Taking the time to fully understand a customer's water needs is important because under-sizing a PV pumping system can lead to customer dissatisfaction and over-sizing can be expensive for both the utility and the customer. 
The water end use information in the Site Data form is used to verify the customer's water requirements. The table shown below provides estimates of the daily water requirements for domestic household use and for different stock animals. To verify the customer's stated water requirements, multiply the number of people in the household or the number of livestock with the estimates for daily use from the table. However, the water requirements for livestock may vary greatly in different regions of the country. The daily volume of water required by each stock animal is a function of air temperature, humidity, amount of moisture in the feed, and size and breed of the animal. For more accurate regional estimates of livestock water requirements, contact your local state or county agricultural extension unit.

Another important figure to verify is the site's water storage capacity, since customer satisfaction with a PV-powered pumping system relies heavily on adequate storage. To verify storage capacity for conventional cylindrical storage tanks, simply measure the height $(\mathrm{H})$ and diameter (D) of the tank in feet and calculate the volume in gallons, using the formula below. (The conversion factor to convert cubic feet to gallons is 7.48.)

$$
\text { Volume (gallons) }=3.14 \times(\mathrm{D} / 2)^{2} \times \mathrm{H} \times 7.48
$$

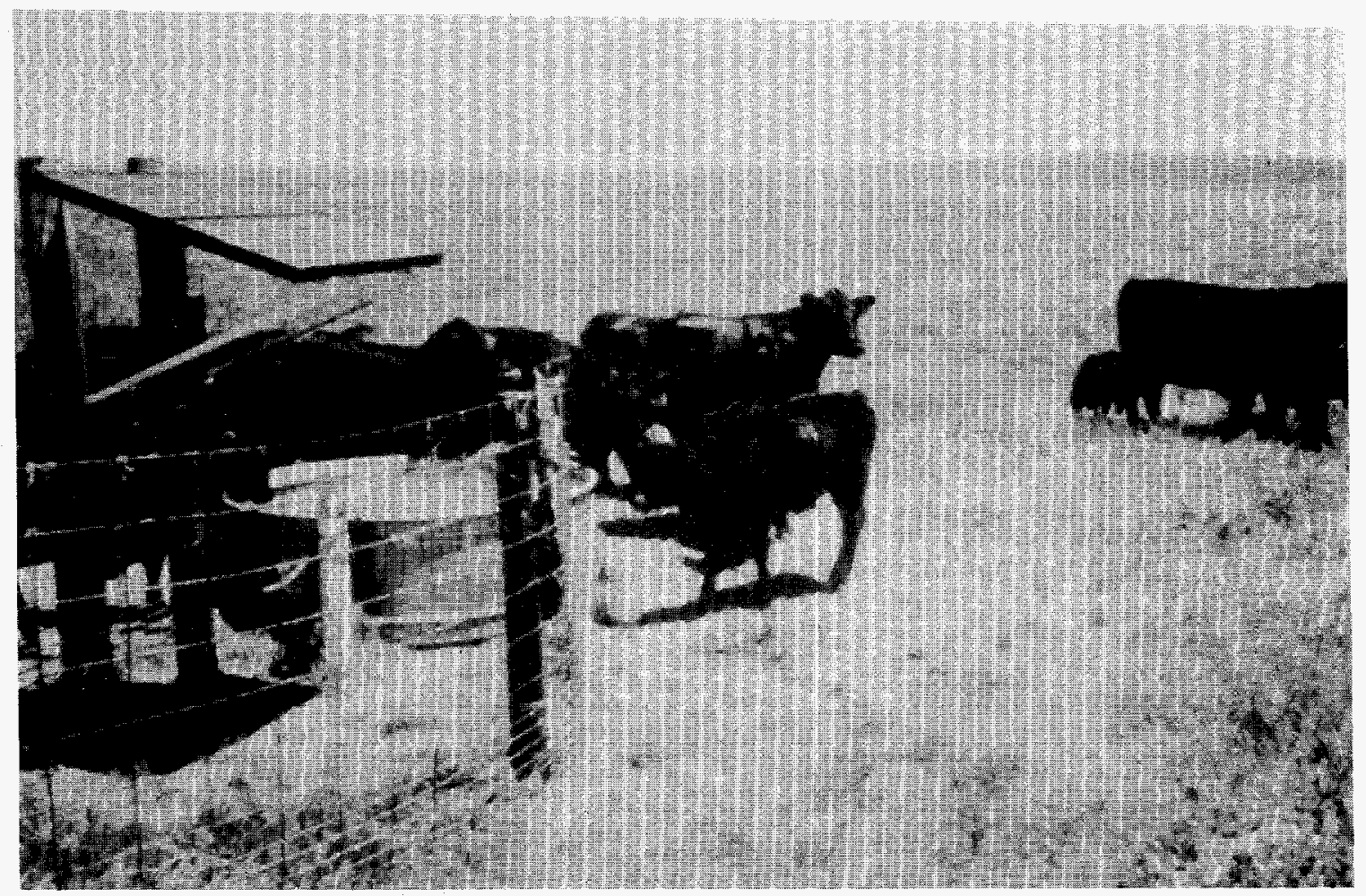

Source: Northwest Rural

Figure 36. PV Pumping System 


\begin{tabular}{|c|c|}
\hline Endros & 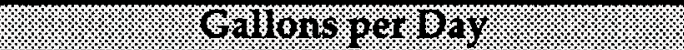 \\
\hline People & $40-100$ \\
\hline & Depending on "Conservation Practices" \\
\hline Dairy Cows & 35 \\
\hline Dry Cows & 15 \\
\hline Cow/Calf pairs & 20 \\
\hline Beef Cattle $-400 \mathrm{lb}$. & 10 \\
\hline Beef Cattle - $800 \mathrm{lb}$. & 15 \\
\hline Bulls & 19 \\
\hline Horses & 12 \\
\hline Sheep & 2 \\
\hline
\end{tabular}

Figure 37. Water Requirements for Livestock

\section{Water Source Information}

If the customer's water source is a stream, pond, or other open source, verifying water source information is a fairly straightforward matter. The static water level is easily seen and measured and in most cases there is no drawdown.

However, if the water source is a well, information on its characteristics is more difficult to verify. When a well is drilled, important well characteristics such as the well depth, static water level, drawdown levels (at different pumping rates), maximum pumping rates, size and depth of the casing, and water quality are usually recorded. However for an old well, the records may no longer exist, or the data may no longer be accurate since the characteristics of a well can change over time.

If the customer does not have recent well data, a well test must be conducted to obtain the accurate information that is necessary for a properly designed and sized pumping system. Although a well test is an added expense, it can prevent the expenditure of unnecessary funds later for an oversized PV system or for the correction of an undersized or improperly designed system.

Well tests are performed by most well and pump service companies. Those companies that are local to a region will be familiar with the aquifer and will know the general characteristics of regional wells. If the region has a fairly stable and uniform aquifer, a well or pump service person may be able to give enough general information about the wells in one area for a utility to get a sense of whether the area is suitable for PV-powered pumping.

A well test does not need to be elaborate or expensive but should give the following minimum information: (1) the well depth, (2) the static water level, (3) the water quality and (4) the water 
drawdown level. The drawdown level should be determined for the pumping rate that can provide the customer's daily water requirement within the peak sun hours available for the critical season of use. For instance, if the customer needs 3000 gallons per day in the spring and the location receives five peak sun hours, the drawdown for the pumping rate of 10 ( $\mathrm{gal} / \mathrm{min}$ ) or 600 gallons per hour must be determined.

There are several different methods of testing the drawdown but one of the most common involves the use of a generator-powered submersible pump. A pump capable of moving water at a rate greater than the customer needs is placed below the static water level. The well is pumped and the drawdown is measured when the water level stabilizes. For instance, if the customer needs to know the drawdown at $10 \mathrm{gal} / \mathrm{min}$, a $20 \mathrm{gal} / \mathrm{min}$ pump is placed in the well and the drawdown for the $20 \mathrm{gal} / \mathrm{min}$ pumping rate is measured. The well is assumed to have a linear recharge rate so that the drawdown level for $10 \mathrm{gal} / \mathrm{min}$ would be half that for 20 $\mathrm{gal} / \mathrm{min}$.

The cost of a well test can vary greatly depending on variables such as the distance the service person must travel to the well site, whether any down-hole equipment must be removed, and the method used for testing. However, for most sites, a suitable well test can be obtained for approximately $\$ 200$.

Other water source information to verify include the discharge head, the pressure head, the friction head, the water quality, and the solar access. The discharge head is easily measured if the point of discharge is close to the water source. However, if the water is pumped far away from the site, the discharge head may not be as easily determined. In such cases, accurate measurements may require a surveyor, but the discharge head can be estimated using a topographic map.

The pressure head can be verified by multiplying the gage pressure (in feet) on the water tank by 2.31. To verify the friction head the length and size of the discharge pipe must be known in addition to the pumping rate. If the pipe run is longer than 300 feet, the friction head should be estimated using the table in Appendix A. The water quality for a well is easily verified by pumping a quantity of water into a white bucket and examining the bottom for sand or silt.

Finally, to verify the solar access of the site, the site should be visited and inspected for trees, hills, or buildings that might block sunlight from reaching the PV modules. If there is any doubt about whether the site is shaded during any of the months of water use, commercially available sun tracing devices can be used to determine the sun's path and locations of shadows for different times of the year. 


\section{Seasonal Sun Trajectories at $40^{\circ} \mathrm{N}$ Latitude}

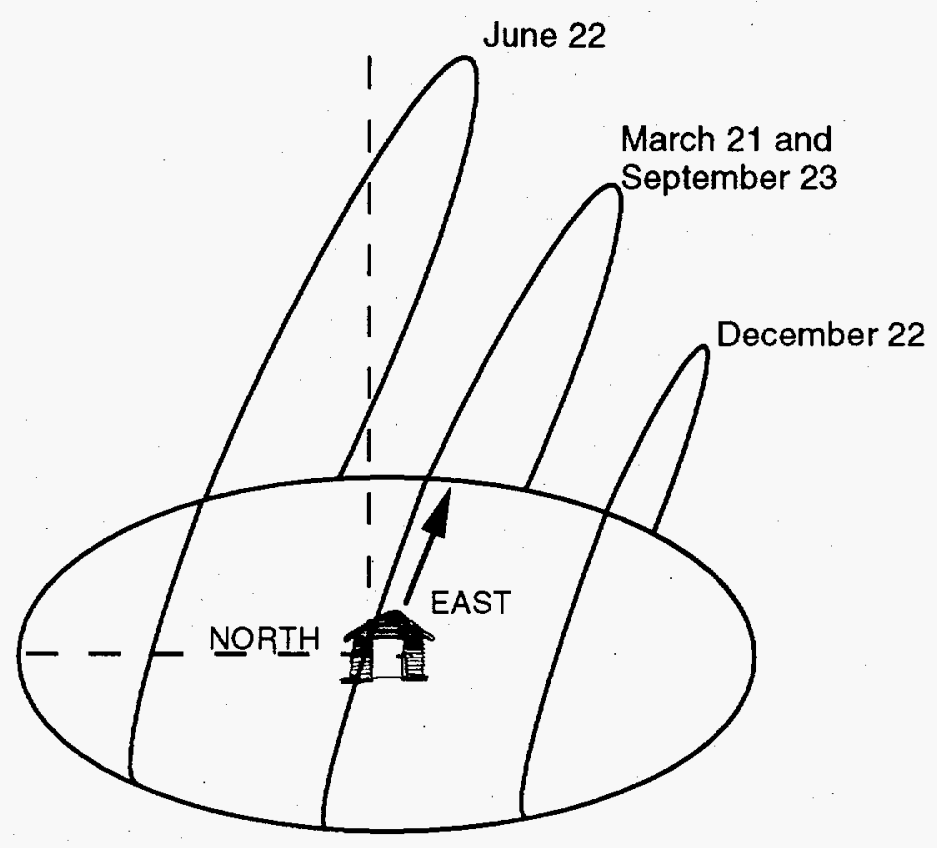

The number of peak sun hours (or incident solar energy) varies throughout the year according to the relative positions of the sun and earth. In the summer, the sun's trajectory provides long days and greater peak sun hours, allowing greater daily electricity production by the PV array. In the winter, the sun's shallow trajectory provides far fewer peak sun hours, thus less electrical energy is produced by the same PV array.

Figure 38. Solar Resource Basics 


\section{PV PUMPING SYSTEM COMPONENTS}

Before initiating the design and specification process for a PV-powered pumping system, the purpose and function of the components must be known.

PV-powered pumping systems consist of at least a PV array, a water pump, and a storage tank. Other components may include batteries and charge controller, a solar tracker, a pump controller, and water level sensors or float switches. Knowledge of the purpose, function, and operation of each component is important to be certain that the pumping system has the correct design and specifications. Each pumping system component (except for the actual pump, which will be described in the following chapter) is described in the following pages.

\section{PV Modules}

PV modules are the power source for a PV-powered pumping system. The modules typically used for water pumping comprise single or poly-crystalline PV cells laminated between a glass front and plastic backing and surrounded by an aluminum frame. Most have a nominal voltage of 12 volts. A single module can power a small 12-volt pump. Also, several modules can be connected in series and parallel combinations to supply the voltages and currents required by larger pumps. Two or more PV modules connected together in this way are called a PV array. The modules, typically used in pumping systems, range in size from 50 to 64 peak watts and cost from $\$ 350$ to $\$ 450$ apiece.

PV modules have been found to be the most reliable component of PV pumping systems. The types of modules used for pumping have been engineered to withstand extreme temperatures, severe winds, and impacts from hail. These modules have an expected life expectancy of 20 to 30 years and the manufacturers warranty them against power degradation for 10 to 12 years.

PV modules also require no regular care or cleaning. Rain or snowfall is usually sufficient to keep the surfaces clean. However, in the rare instances when the surface requires cleaning, care should be taken not to scratch the anti-reflective coating on the module surface. The safest way to clean PV modules is to simply rinse the surface with water.

\section{Solar Trackers}

Solar trackers increase the energy production of PV modules by keeping them faced toward the sun as it travels across the sky. This function increases the effective length of the pumping day and decreases the number of modules necessary to pump a given amount of water. However, trackers add to the complexity of a pumping system with their moving parts and do not gain significant energy during winter months, especially in northern climates. Also, some have been found to perform poorly in locations with consistent winds of $25 \mathrm{mph}$ or more. Some tracker manufacturers make special trackers for operation in high wind areas. Your local PV system vendor should be consulted. 
When selecting components for a PV pumping system, the advantage of gaining energy with a solar tracker must be carefully weighed against the cost and added complexity of the tracker. For small systems ( $\mathrm{six}$ or fewer modules), the cost of a tracker can exceed the cost of additional modules that gain as much energy as a tracker in the summer and more in winter.

\section{Pump Controllers}

At a given temperature and solar irradiance, a PV array's power output depends on the load resistance. For every array there is a load resistance level that optimizes the power output of the array. Unfortunately, the load resistance of most pumps do not match that optimal resistance for the array. Pump controllers, electronically adjust the load resistance so that the array will operate closer to its optimal power output with a less than optimum load. There are three types of pump controllers commonly used: maximum power point trackers (MPPT) adjust the pump speed (load power) to precisely match the maximum power point of the array, constant voltage trackers hold the array at a constant voltage regardless of pump speed, and Linear Current Boosters (LCB) increase the current output of the array to provide higher torque for motor starting. Some controllers combine all three.

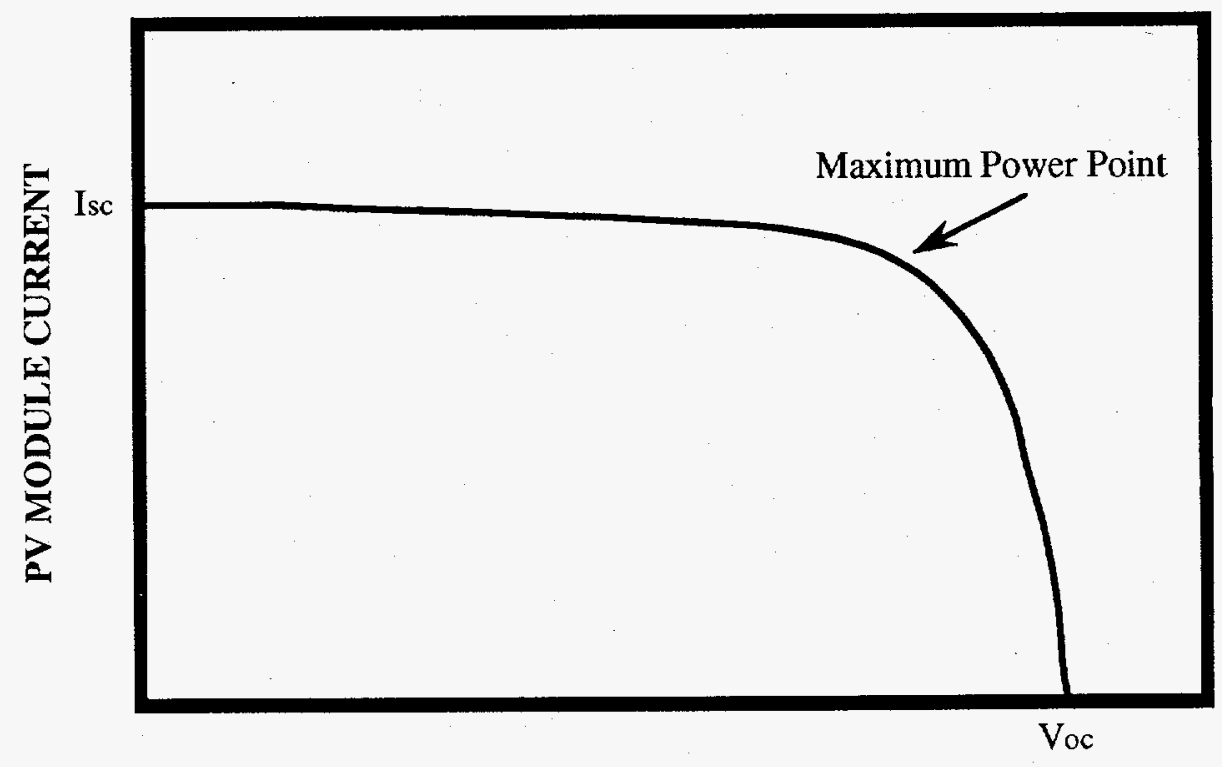

PV MODULE VOLTAGE

The plot of the current versus voltage characteristics of a photovoltaic cell, module, or array is called an I-V curve. Three important points on the I-V curve are the open-circuit voltage, shortcircuit current, and peak power operating point.

Figure 39. I-V Curve Basics 
The operating characteristics of centrifugal pumps (voltage, current, and resistance) generally match the output of PV arrays better than those of volumetric pumps whose power requirements vary during their operational cycles. If matched carefully with the PV array, most centrifugal pumps will operate well without a power controller. However, volumetric pumps, such as jack and piston pumps, require a pump controller to efficiently utilize the PV power source, especially at start-up when they have high current requirements.

Another advantage of using power controllers is the convenient connections that many provide for both water level sensors and float switches. Unfortunately, one disadvantage of using a power controller is their uneven track record. Many of these controllers are relatively new to the market, and some of the early models have been less than reliable especially those used to provide high starting currents for larger positive displacement pumps. The manufacturers of these controllers have been working to increase the durability of the electronics in the controllers, but the fact remains that they can be one of the least tested components of a pumping system. ${ }^{13}$

\section{Batteries and Charge Controllers}

Batteries are not used in most water pumping applications because water storage is generally more cost effective than the storage of electricity in the batteries. Also, batteries add to the complexity of a pumping system, must be protected from freezing conditions, require regular maintenance, and have a limited life. However, batteries are necessary for some applications. These include wells with a slow recharge rate that must be pumped over a period of time greater than normal sunlight hours. Other applications dependent on batteries are those that have limited water storage due to water quality concerns. Finally, some manufacturers of PVpowered pumping systems include batteries in their systems because the DC motors used in their pumps are adversely affected by the variable voltages and currents provided by a direct connected PV array.

Whatever the reason for including batteries with a PV-powered system, care must be taken to assure that they are protected from freezing temperatures. A discharged lead acid battery will freeze at approximately the same temperature as water. Once frozen, a battery will need to be replaced due to damage sustained by the casing or internal connections.

An important factor in the reliability and life of a battery is its charge controller. The controller has two separate functions: to prevent overcharging of the battery and to keep the battery from being too deeply discharged. Battery life can be severely shortened by either of these conditions. Not all battery chargers perform these functions equally well and a small difference in charger quality can lead to a significant difference in battery life.

${ }^{13}$ Contact Sandia's Design Assistance Center for more information. 


\section{Water Level Sensors and Float Switches}

Some pumps are equipped with controllers that can electronically sense when the pump runs dry and will automatically shut off the power to the pump. However, for pumps without that type of controller, external water level sensors can be installed. These sensors are connected to a controller that shuts off power to the pump when the water drops below the level of one sensor and turns it on again once the water rises back up to the level of a second sensor. Water level sensors or float switches can also be installed in water storage tanks to stop the flow of water once the tanks are full.

\section{Storage Tanks}

For PV pumping systems without batteries, the water storage tank should be large enough to fulfill a customer's water requirements through a minimum of three days of cloudy or overcast weather. In areas of frequent overcast conditions or for critical applications the storage capacity should be greater. For stock watering applications, the tanks are usually open cylindrical tanks of galvanized steel with diameters that range from eight to twenty feet and heights of two to three feet. 


\section{PV-POWERED WATER PUMPS}

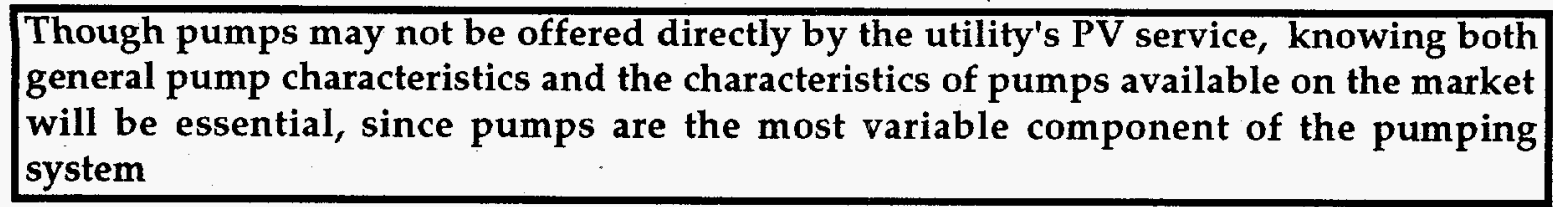

The pump descriptions in this chapter are divided into two sections, "General Pump Characteristics" and "Commercially Available PV Pumps". In "General Pump Characteristics" the operation and attributes of the two general classifications of pumps are discussed. In "Commercially Available PV Pumps" the characteristics and availability of the different types of commercially available PV-powered pumps are discussed.

\section{General Pump Characteristics}

There are two basic classifications of pumps, centrifugal and volumetric (also known as positive displacement). The two classifications are based upon the mechanisms by which the pumps move water. Each type has its own inherent advantages and disadvantages, and knowledge of the basic characteristics of each type can be instrumental in choosing the correct pump for an application.

Centrifugal pumps move water by means of blades or impellers that rotate at high speeds. The centrifugal force imparted to the water in the casing by the motion of the impellers forces the water to flow from an inlet at the center of the casing to an outlet at the perimeter. Because the movement of the water depends on the force created by the impeller, the water flow rate is directly proportional to the speed of the impeller, which in turn depends on the power supply to the motor. The pump's vertical lift capability is also a function of impeller speed and power input. Because of this connection between the vertical lift capability and power input, a centrifugal pump may fail to deliver any water if there is a significant decrease in the pump's power supply (i.e., a decrease in solar insolation).

A centrifugal pump with a single impeller can only lift water through fairly low heads, but if several impellers are stacked in a pump, enough pressure can be created to lift water to higher heads (up to 450 feet in some cases). In general, centrifugal pumps are good for pumping large volumes of water at low to medium heads.

Because centrifugal pumps have no seals or mating surfaces to wear out, they require relatively low maintenance and are fairly tolerant of dirty water. However, if the water contains excessive sand or grit, the impellers can eventually clog and erode.

Volumetric pumps move water by mechanically advancing a sealed quantity of water. There are many different mechanisms for achieving this end. Some of the more common mechanisms used for solar powered pumps include pistons, cylinders, and elastic diaphragms. 
A volumetric pump's flow rate or the speed at which a sealed quantity of water advances, is directly related to the motor speed and power input. But in contrast to centrifugal pumps, its vertical lift capacity is relatively unaffected by the motor speed or power input. With low power input a volumetric pump will move a quantity of water to the same vertical lift as with high power input except at a slower rate. Therefore, volumetric pumps have high starting torques as they must always work against the full system pressure even at low speeds and typically require a current booster controller when used with a PV power source. In general, volumetric pumps are good for pumping small to moderate amounts of water to medium and high heads.

Since all volumetric pumps have seals or mating surfaces that can wear, most require regular maintenance to replace or repair worn parts. These pumps also tend to be less tolerant of dirty water that can accelerate the erosion of seals. Even though pre-pump filters can be used with some of these pumps, frequent replacement of the filters may make the use of these pumps impractical with water of poor quality.

\section{Commercially Available PV Pumps}

There are many different types of commercially available PV-powered pumps with very diverse operating characteristics. These pumps can be divided into the two main pump classifications, centrifugal and volumetric, and also into two different applications types, submersible and nonsubmersible. The table shown below gives an overview of the types of pumps for each classification. The pumps listed as submersible have a pump and motor enclosed in one casing that operate together under water.

\begin{tabular}{|c||c||c|}
\hline \multicolumn{1}{c||}{} & SUBMERSIBLE (1) & NON-SUBMERSIBLE \\
\hline \hline \multirow{4}{*}{ CENTRIFUGAL } & Stacked Impeller & \\
\cline { 2 - 3 } & & Vertical Turbine \\
\cline { 2 - 3 } & & Floating Centrifugal \\
\hline \hline \multirow{3}{*}{ VOLUMETRIC } & Diaphragm & Surface Centifugal \\
\cline { 2 - 3 } & & Jack \\
\cline { 2 - 3 } & & Piston \\
\cline { 2 - 3 } & & Rotary Vane \\
\hline
\end{tabular}

(1) Pumps listed as submersible have an encased pump and motor unit that operate together under the water surface.

Figure 40. Commercially Available PV Pump Types 
The following pages contain descriptions of the various types of commercially available PVpowered pumps.

\section{Centrifugal: Stacked Impeller}

The stacked impeller submersible centrifugal pumps contain a series of impellers that can create a large pressure differential. The number of impellers employed in a particular pump ranges from 1 to over 20 for heads from 5 to 400 feet. These pumps are available with either AC or DC brushless motors and are therefore maintenance free. Brushless DC motors are typically sealed in an oil-filled housing along with the power electronics required for the brushless motor. AC motors typically are wet rotor design and do not need to be sealed as water is used to cool and lubricate the motor. Pumps with AC motors are provided with a special surface-mounted pump controller/inverter unit, which is often mounted beneath the array.

These submersible pumps are used to move moderate to large volumes of water from shallow to moderately deep wells and reservoirs. Although these pumps are longer and heavier than the micro-submersibles, they are still narrow enough to be submerged in wells with casings as small as four inches in diameter. While they are typically used in boreholes, they can also be laid on their side and used to pump from streams, springs, or other surface water sources when the total lift and volume toe pumped is appropriate. According to manufacturer's data these pumps are designed to pump water up to 400 feet of vertical lift and have flow rates of 200 to 40,000 gallons of water per day.

Of all the solar pumps available, the submersible centrifugals have the least maintenance requirements. In fact, no regular maintenance is recommended by the manufacturers since the impellers have no seals or sliding parts and the sealed, brushless motors are maintenance free. These pumps are also tolerant of silt, sand, and particles in the water as long as enough power is provided to the motor to keep the impellers clear of sediment accumulation.

\section{Centrifugal: Vertical Turbine}

Vertical turbine pumps consist of a set of submerged stacked impellers powered by a long drive shaft from a surface mounted motor. This type of pump is not suitable for use with surface water sources and is best used in shallow to moderate depth wells. An advantage of this type of pump is that the surface mounted motor is easily accessed for repair or maintenance operations and there is no power lost in a cable run down the well. However, pump efficiency is reduced by twisting, vibration, and friction in the drive shaft and the installation of these pumps is more difficult and time consuming than submersible pumps.

As far as can be determined, all the solar vertical turbine pumps available in the U.S. are sold as part of systems that include batteries and are not warranted if used without them. These PV pumping systems including batteries range in price from $\$ 3000$ to $\$ 8000$. 


\section{Centrifugal: Floating Centrifugal}

Floating centrifugal pumps have a single impeller and motor unit that is suspended just beneath the surface of the water by a float. Because the single impeller can only develop a modest pressure differential, the lift capacity of these pumps is limited to approximately 20 feet. This type of pump is used to transfer water from surface sources such as ponds, streams, and cisterns. Because these pumps are typically used at the surface of open water sources, they are not suitable for use in freezing temperatures.

\section{Centrifugal: Surface Centrifugal}

Surface centrifugals have a pump and motor unit mounted above the water source with an intake suction pipe in the water. The suction head of a simple surface centrifugal pump is limited to 20 feet at sea level (minus one foot for every 1000 feet of elevation). However, several models of these pumps can be fitted with jet adapters that will increase the suction and total pumping heads but decrease the pump efficiency. These pumps also are not very suitable for use in freezing conditions unless care is taken to house the pump in a heated or well insulated enclosure. However, a significant advantage of these pumps is their prices which start at $\$ 600$.

\section{Volumetric: Diaphragm}

The submersible diaphragm pumps are also called micro-submersibles. All of these pumps employ cams and elastic diaphragms to move water and are all powered by brushed DC motors.

These submersible pumps can be used to move small quantities of water from deeper wells or reservoirs where surface pumps would be limited by their suction head. These pumps can also be used to pressurize storage tanks and lift water to a discharge head above ground surface. Because of the small size of these pumps, they can be submerged in wells with casings as small as four inches in diameter.

According to manufacturers' data, these pumps are designed to pump water up to 225 feet of vertical lift at flow rates of 200 to 1400 gallons per day. A typical example of output from a field tested pump is 300 gallons of water per day at 200 feet of head. The same pump moved to a different location produced 800 gallons per day at 50 feet of head.

Some of the micro-submersible pumps on the market can be submerged up to 100 feet depending on the manufacturer. However, each manufacturer warrants its pumps to a maximum depth that should not be exceeded, since one of the most common causes of pump failure is water leakage into the motor housing. Because of this limitation, some microsubmersible pumps with lower submersion limits may not be suitable for a well with a large drawdown level. 
These volumetric pumps require a fair amount of periodic maintenance. Depending on the hours of use and depth of head pumped, the elastic diaphragms may need replacement every 12 to 24 months. The brushes in the DC motor also wear with use so the motor also needs periodic rebuilding or replacement. According to manufacturers, replacement diaphragms cost approximately $\$ 8-\$ 10$ and replacement motors cost $\$ 200-\$ 250$. However, not all makes of these pumps are field serviceable. Several are manufactured with factory sealed casings and must be returned to the manufacturer for service. If this type of pump is to be used for a critical application, a second pump may be kept on hand as a back-up in case of diaphragm failure.

The solar micro-submersibles were recently developed to fill a need for a small, low volume, inexpensive, submersible pump with low power requirements. Because the micro-submersibles are the newest class of pumps in the solar market, they are the least proven technology. Efforts are currently being made by manufacturers to expand their range of applications and to improve their reliability. These pumps typically cost from $\$ 500$ to $\$ 1100$ and carry a one year warranty.

\section{Volumetric: Jack}

The solar jack pump classification includes pumps with a surface reciprocating jack mechanism powered by a DC motor. The reciprocating jack is connected by a long sucker rod to a cylinder in the well. The down hole equipment is no different from that of a conventional jack pump; in fact existing down hole equipment can often be used when converting from a windmill to a solar powered jack pump.

In solar applications, jack pumps are used to pump moderate amounts of water from medium to deep wells. In many wells with narrow casings (less than four inches in diameter) jack pumps with narrow down hole cylinders are the only pumping option. According to manufacturers' data, solar jack pumps can pump up to 1200 feet of vertical lift and have flow rates of 400 to 5400 gallons per day.

Jack pumps are a typical example of volumetric pumps which require regular maintenance. Leathers on a plunger at the end of the long sucker rod create a seal against the cylinder walls. This seal is essential to the pump's ability to raise water. In order to change worn leathers, at a minimum the entire sucker rod and plunger assembly must be pulled from the well. Depending on the quality and quantity of the water pumped, the leathers must be changed every 6 to 24 months. In addition, the jack mechanism must be oiled, the gearbox oil must be changed approximately once a year, and the drive belts need periodic replacement.

As with all above-ground pumping equipment, jack pumps must be protected from freezing if operated in the winter. However, this protection may be difficult to accomplish, especially if a metal sucker rod is used. In one installation, the water in the down well cylinder froze despite the owners attempts to insulate the top of the well. It is believed that the metal sucker rod conducted enough heat out of the well to freeze the water discharge pipe. 
Solar jack pumps come in a wide range of sizes, therefore the prices also range widely. Jack pumps with motors and down hole equipment can range in cost from $\$ 3000$ to over $\$ 10,000$.

\section{Volumetric: Piston}

Piston pumps have a surface mounted motor connected to one or more reciprocating pistons which draw water through a suction supply pipe. These pumps are used to draw water from shallow or surface sources, to pressurize storage tanks, or to move water through long or tall pipe runs. When these pumps are used to lift water out of shallow wells or reservoirs, the suction head is limited to approximately 20 feet, however, they are capable of pushing the water to much higher heads. According to manufacturers' data this type of pump can push water up 1600 feet of vertical lift and can pump up to 3000 gallons per day at low heads.

Piston seals, crucial to the proper operation of these pumps, are fairly intolerant of silt, sand, or abrasive particles in the water. Although filters can be used to remove particles, the filters have to be changed frequently when used in dirty water. As with all surface mounted pumps, care must be taken to protect piston pumps from freezing conditions.

\section{Volumetric: Rotary Vane}

Rotary vane pumps contain spinning rotors with vanes that seal against the casing walls. The sealed cavities of water between the vanes are advanced and forced out of the pump outlet when the wall of the casing draws closer to the vanes and pressurizes the water. Although the majority of these pumps are surface mounted, a few models are designed to be hung inside a well just above the water level. However, because the suction head is limited to twenty feet, this type of installation requires a well with a very stable water level and a small water drawdown. These types of pumps are also very intolerant of silt, sand, and abrasive particles that can rapidly accelerate the wear on the vanes and wall of the casing. As with piston pumps, filters may be used to remove the dirt but customers may find frequent changing of the filters inconvenient. 


\section{SYSTEM DESIGN AND SPECIFICATION}

The utility may not need to know the details of PV pumping system design, but the process should be understood to assure that the resulting system is appropriate for the customer and the application.

Once all of the necessary site data are collected and verified and the site is determined to be appropriate for a PV-powered pumping system, a good foundation exists upon which to base a suitable pumping system design. At this point, the utility may choose to either hand over the entire design task to a PV vendor or participate in the design and specification of the pumping system. In either case, some knowledge of the design process is important to assure that the final system design and specifications are appropriate for the site and compatible with the customer's expectations.

This chapter does not provide complete instructions on how to design a PV-powered pumping system. Detailed instruction in the proper design of a pumping system is beyond the scope of this guidebook. However, this chapter does describe the process that PV vendors use to design and specify systems, since most utilities will work with a PV vendor on this step. ${ }^{14}$ This chapter gives enough information on the design process for the utility to understand and assess the component and pump selections that a vendor may propose. Since one of the most critical components for a properly designed pumping system is the pump itself, the majority of the chapter focuses on providing the utility with a method to correctly specify a type of pump for an application. The chapter also discusses PV array sizing, balance of the system (BOS) specification, and safety and code considerations.

For all but the most simple (and smallest) systems the complete design of the pumping system will not be possible using the information provided in this chapter without assistance from a PV vendor. This assistance is necessary for several reasons: 1) In most cases the utility will not have ready access to accurate solar insolation data for their region; 2) The pump manufacturers generally do not give enough information in their pump literature to correctly select a pump for an application, size the array, or specify the BOS; and 3) PV vendors typically have or have access to computer sizing tools for many pump models.

\section{Pump Selection}

Selecting the proper pump for the application is an essential first step and the following pump selection procedure provides utility personnel with greater assurance that the resulting system is appropriate for the customer and the application.

In PV-powered water pumping, as with any water pumping, there are a wide variety of pump applications and water site specifications. Different types of pumps have very specific capabilities and work best under certain operating conditions. Therefore, the first task in

${ }^{14}$ For an alternative pumping system design approach, see Sandia National Labs' Stand Alone Photovoltaic Systems Handbook. 
proper pumping system design is to match the correct pump to the application and site conditions. This matching normally requires comprehensive knowledge of the commercially available PV-powered pumps and their capabilities. However, the following procedure simplifies the selection process by providing the characteristics of different commercially available pump types in one chart and two graphs (see the following Pump Selection Chart and Pump Curves \#1 and \#2 graphs).

The pump types previously described in Chapter 8 are listed along the top of the Pump Selection Chart and pump characteristics are listed in the leftmost column of the chart. The characteristics for a particular pump type are in the same column as the pump type. Please note that the capabilities and requirements listed in the chart are the maximum or optimal ones for each pump type. There is at least one actual pump of each type that has one or more optimal characteristics, but there are no actual pumps that have all the optimal characteristics. This chart can be used to gain an overall view of the pump characteristics for each type of pump or it can be used to select a pump for a specific application.

The following instructions detail how to use the chart to select a pump suitable for a specific set of site data.

1. Make photocopies of the Pump Selection Chart and Pump Curves \#1 and Pump Curves \#2 graphs and place them in front of you. You will be writing directly on the Pump Selection Chart.

2. Place a completed Site Data Form in front of you.

3. On the Site Data Form, locate the Total Pumping Head. On the Pump Selection Chart locate the row labeled Maximum Total Head. Compare the Total Pumping Head with the numbers in the Maximum Total Head row and circle any numbers in the row that are larger than the Total Pumping Head.

4. On the Site Data Form, locate the largest Average Daily Water Requirement. On the Pump Selection Chart locate the row labeled Max. Daily Water Output. Compare the largest Average Daily Water Requirement with the numbers in the Max. Daily Water Output row and circle any numbers in the row that are larger than the largest Average Daily Water Requirement.

5. Look at the Pump Curves \#1 graph. Each curve on this graph gives the maximum water output at any head capable by a pump type. Pump Curves \#2 gives the same information as Pump Curves \#1 but it shows more detail in the area of lower heads and outputs. Select the graph that best shows your Maximum Total Head and largest Average Daily Water Requirement and find the intersection of these two numbers on it. Place a small $x$ on the graph at the point of intersection. Now look at all the curves that appear above the $x$ and note the pump types associated with the curves. These are the pump types that are 


\begin{tabular}{|c|c|c|c|c|c|c|c|c|c|}
\hline \multirow{2}{*}{$\begin{array}{l}\text { Pump } \\
\text { Characteristics }\end{array}$} & \multicolumn{9}{|c|}{ Pump Type } \\
\hline & $\begin{array}{l}\text { Submers. } \\
\text { Diaphragm }\end{array}$ & $\begin{array}{l}\text { Submers. } \\
\text { Centrifugal }\end{array}$ & $\begin{array}{l}\text { Vertical } \\
\text { Turbine }\end{array}$ & $\begin{array}{l}\text { Jack } \\
\text { Pump }\end{array}$ & $\begin{array}{c}\text { Floating } \\
\text { Centrifugal }\end{array}$ & $\begin{array}{l}\text { Rotary } \\
\text { Vane }\end{array}$ & Piston & $\begin{array}{c}\text { Surface } \\
\text { Centrifugal }\end{array}$ & $\begin{array}{l}\text { Surf. Cent. } \\
\text { w/Jet in well }\end{array}$ \\
\hline $\begin{array}{l}\text { 1. Maximum } \\
\text { Total Head }\end{array}$ & $230 \mathrm{ft}$. & $400 \mathrm{ft}$. & $230 \mathrm{ft}$. & $1200 \mathrm{ft}$. & $20 \mathrm{ft}$. & $440 \mathrm{ft}$. & $2700 \mathrm{ft}$. & $400 \mathrm{ft}$. & $100 \mathrm{ft}$. \\
\hline $\begin{array}{l}\text { 2. Max. Daily* } \\
\text { Water Output }\end{array}$ & 1980 GPD & 50000 GPD & 9775 GPD & 5400 GPD & 6500 GPD & 1550 GPD & 9000 GPD & $150,000 \mathrm{GPD}$ & 5880 GPD \\
\hline $\begin{array}{l}\text { 3. Output at } \\
\text { Head }\end{array}$ & $\begin{array}{c}\text { See } \\
\text { Graphs }\end{array}$ & $\begin{array}{c}\text { See } \\
\text { Graphs }\end{array}$ & $\begin{array}{c}\text { See } \\
\text { Graphs }\end{array}$ & $\begin{array}{c}\text { See } \\
\text { Graphs }\end{array}$ & $\begin{array}{c}\text { See } \\
\text { Graphs }\end{array}$ & $\begin{array}{c}\text { See } \\
\text { Graphs }\end{array}$ & $\begin{array}{l}\text { See } \\
\text { Graphs }\end{array}$ & $\begin{array}{c}\text { See } \\
\text { Graphs }\end{array}$ & $\begin{array}{c}\text { See } \\
\text { Graphs }\end{array}$ \\
\hline $\begin{array}{l}\text { 4. Maximum }{ }^{\star \star} \\
\text { Suction Head }\end{array}$ & NA & NA & NA & NA & NA & $21 \mathrm{ft}$. & $21 \mathrm{ft}$. & $21 \mathrm{ft}$. & $\begin{array}{c}100 \mathrm{ft} . \\
\text { (jet assisted) }\end{array}$ \\
\hline $\begin{array}{l}\text { 5. Minimum } \\
\text { Well Diameter }\end{array}$ & 4 inch & 4 inch & 4 inch & 3 inch & 0 inch & 6 inch & $2 \mathrm{in.}$ & $2 \mathrm{in.}$ & $2 \mathrm{in.}$ \\
\hline $\begin{array}{l}\text { 6. Water } \\
\text { Quality }\end{array}$ & $\begin{array}{l}\text { Fair or } \\
\text { Better }\end{array}$ & $\begin{array}{l}\text { Fair or } \\
\text { Better }\end{array}$ & $\begin{array}{l}\text { Fair or } \\
\text { Better }\end{array}$ & $\begin{array}{l}\text { Good or } \\
\text { Better }\end{array}$ & $\begin{array}{l}\text { Poor or } \\
\text { Better }\end{array}$ & $\begin{array}{l}\text { Good or } \\
\text { Better }\end{array}$ & $\begin{array}{l}\text { Good or } \\
\text { Better }\end{array}$ & $\begin{array}{l}\text { Poor or } \\
\text { Better }\end{array}$ & $\begin{array}{l}\text { Fair or } \\
\text { Better }\end{array}$ \\
\hline $\begin{array}{l}\text { 7. Freeze } \\
\text { Protection }\end{array}$ & Easy & Easy & Moderate & Moderate & $\begin{array}{c}\text { Not } \\
\text { Possible }\end{array}$ & Difficult & Difficult & Difficult & Difficult \\
\hline $\begin{array}{l}\text { 8. Maintenace } \\
\text { Requirement }\end{array}$ & $\begin{array}{c}\text { Diaphragms } \\
\text { need } \\
\text { replacement } \\
\text { Motor brushes } \\
\text { may need } \\
\text { replacement } \\
\end{array}$ & $\begin{array}{l}\text { No regular } \\
\text { maintenance } \\
\text { required }\end{array}$ & $\begin{array}{c}\text { Motor brushes } \\
\text { may need } \\
\text { replacement }\end{array}$ & \begin{tabular}{|c|} 
Gearbox oil \& \\
leathers need \\
replacement, \\
jack needs oil, \\
motor brushes \\
may need rplmt
\end{tabular} & $\begin{array}{c}\text { Motor brushes } \\
\text { may need } \\
\text { replacement }\end{array}$ & $\begin{array}{c}\text { Motor } \\
\text { brushes \& } \\
\text { \& filters } \\
\text { may need } \\
\text { replacement }\end{array}$ & $\begin{array}{c}\text { Motor } \\
\text { brushes, } \\
\text { seals, \& } \\
\text { fitters } \\
\text { may need } \\
\text { replacement }\end{array}$ & $\begin{array}{c}\text { Motor brushes } \\
\text { may need } \\
\text { replacement }\end{array}$ & $\begin{array}{l}\text { Motor brushes } \\
\text { may need } \\
\text { replacement }\end{array}$ \\
\hline 9. Pump Cost & $\$ 550-1000$ & $\$ 2250-3990$ & $\$ 2550-2650$ & \begin{tabular}{|r|}
$\begin{array}{c}\$ 3250-6000 \\
\text { no down hole } \\
\text { equip. included }\end{array}$ \\
\end{tabular} & $\$ 325-530$ & $\$ 510-650$ & $\$ 1450-5200$ & $\$ 635-2750$ & $\$ 1050-2070$ \\
\hline
\end{tabular}

- Maximum daily water output from manufacturer literature is based on fixed arrays receiving $6 \mathrm{kWh} / \mathrm{m} 2$. Quantities may be greater if trackers are used.

** Subtract one foot from the numbers in the suction head row for every $1000 \mathrm{ft}$ above sea level. 
System Design and Specification

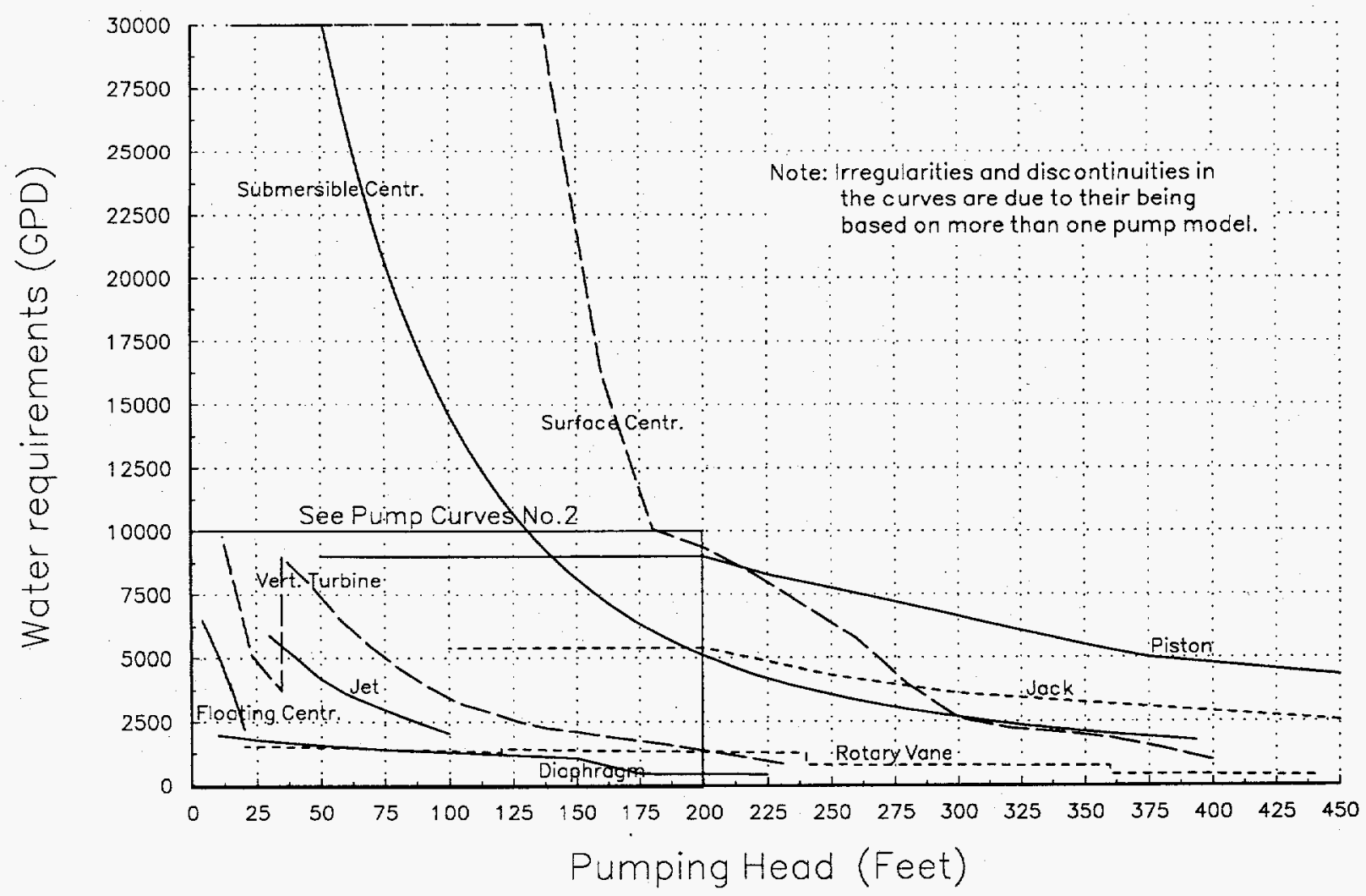

Figure 42. Pump Curves \#1

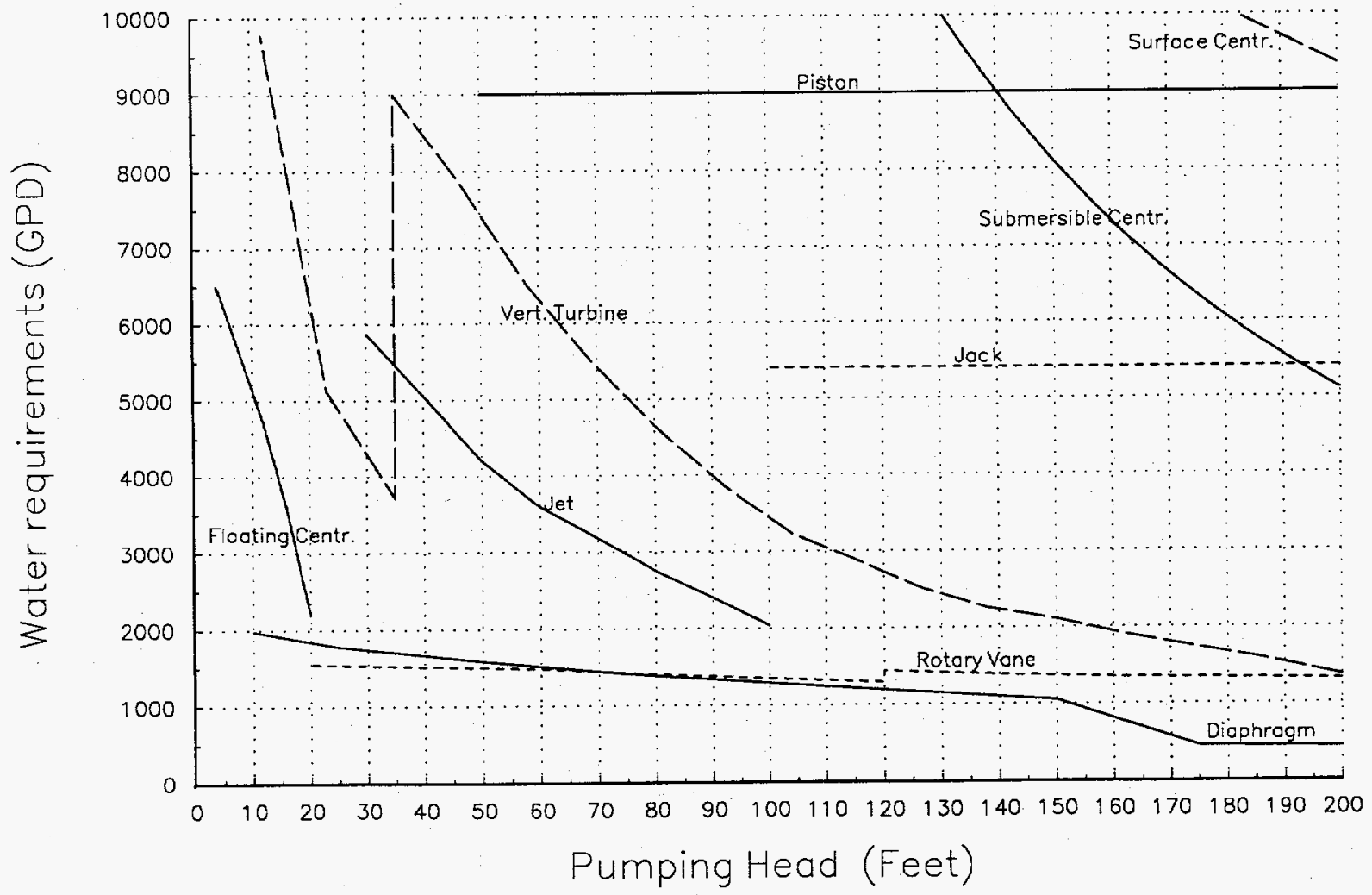

Figure 43. Pump Curves \#2 
large enough to handle your customer's daily water requirements. However, keep in mind that these curves are obtained from manufacturer literature and are based on a set level of solar insolation, which sometimes may be optimistically high. Go back to the Pump Selection Chart and place a circle in the Qutput at Head row for every pump type with a curve above the $x$. (If you are using Pump Curves \#2, don't forget to include any curves above the same point in Pump Curves \#1 that don't appear on Pump Curves \#2).

6. On the Site Data Form locate the Static Water Level and the Drawdown Level and add the two together. Compare the result to the numbers in the Pump Selection Chart row labeled Maximum Suction Head. Circle any numbers in this row that are larger than the two added numbers. Pumps with submersed pumping mechanisms do not have a suction head, therefore "NA" (Not Applicable) appears in the column for these pumps.

7. If the water source is a well, on the Site Data Form, locate the Well Casing Diameter. On the Pump Selection Chart locate the row labeled Minimum Well Diameter. Compare the Well Casing Diameter with the numbers in the Minimum Well Diameter row and circle any numbers in the row that are larger than or equal to the Well Casing Diameter. If the water source is not a well, circle all the numbers in the Minimum Well Diameter row.

8. On the Site Data Form locate the Water Quality and compare it to the requirements in the Pump Selection Chart row labeled Water Quality. Circle any quality in this row that is equal to or worse than that on the Site Data Form.

At this time take a look at the first six rows of the chart. Are there any columns that contain either circles or "NA" in every row through Water Quality? If so, these pump types can be used for your site. If a column does not contain circles or "NA" in every row through Water Quality, there are no models of that pump type currently available that can handle the specific requirements of your site. If there are not any columns that contain circles or "NA" in every row through Water Quality, the site is not appropriate for PV-powered water pumping. If more than one column contains circles or NA, you have a choice of pump types and the selection may be narrowed by considering the last three rows of the chart. Continue with steps nine through eleven to further narrow the choice of pumps.

9. On the Pump Selection Chart, locate the row labeled Freeze Protection. In this row each pump type is rated for the amount of effort required to protect it from freezing. An "Easy" rating is given to submersibles because only the discharge pipe needs protection above the frost line. This is often easily accomplished by drilling a weep hole in the discharge pipe so the water drains from the pipe when the pump is not running. A "Moderate" rating means that more extensive measures must be taken to protect the pump because the pump has a submerged pumping mechanism but also has a motor and possibly other parts at the ground surface. A "Difficult" rating requires an insulated and or heated enclosure for the pump or an enclosure buried below the frost line. On the Site Data Form, locate the Average Daily Water Requirement. Is any water required at the site during winter, spring, 
or fall and is there any danger of freezing weather during those seasons? If so, circle any ratings in the Freeze Protection row that the utility or customer is willing to accept. If no water is required during freezing weather, circle all the ratings in this row.

10. On the Pump Selection Chart, locate the row labeled Maintenance Requirement. In this row, the typical maintenance operations for each pump type are listed. Circle any maintenance operations that the utility or customer is willing to accept.

11. On the Pump Selection Chart locate the row labeled Pump Cost. This row contains the range in costs for each pump type. (The range is for manufacturer list prices for the pumps only.) Circle all the cost ranges that are acceptable. Keep in mind that the pump cost is only a part of the entire system cost.

Now look at the entire chart. Are there any columns that contain either circles or "NA" in every row through Pump Costs? If so, these pump types will be the best choices for your site. If not, you may have to reconsider what freeze protection, maintenance requirements, or pump costs are acceptable.

Once a pump type is selected, the next step in the pumping system design process is to select a specific model pump that best fits the site's specifications. In order to continue, you must have access to pump manufacturer literature for information on specific models of the selected pump type. The PV-Powered Water Pumps chart shown below lists manufacturers of each pump type. These manufacturers can be contacted for literature that describes the characteristics of their pumps or the literature can be obtained from PV vendors. The addresses and telephone numbers for these manufacturers or their distributors as well as PV equipment vendors are listed in Appendix B.

The manufacturer's literature provides information about the characteristics of their pumps and can be used to further narrow the pump selection. The information provided in the literature varies for each manufacturer and pump but it will likely include the pump's maximum pumping head, maximum water output, outside diameter (for submersible pumps), construction materials, a photograph or drawing of the pump, and a pump curve or chart.

The pump curve or chart gives a pump's daily water output in gallons per day (gal/day) or its instantaneous output in gallons per minute ( $\mathrm{gal} / \mathrm{min}$ ) or gallons per hour (gal/hr) for different pumping heads. (Some give the metric equivalents of cubic meters per day or cubic meters per hour.) The curves and charts also provide the numbers and wattages of PV modules necessary to obtain these outputs. The instantaneous output is based on the assumption that the PV modules receive solar irradiation levels of $1000 \mathrm{~W} / \mathrm{m}^{2}$. This solar irradiance is near the maximum power that can be expected on a bright sunny day. The daily output is usually based on the assumption that the modules receive $6 \mathrm{kWh} / \mathrm{m}^{2}$ of insolation per day, which is a good average for summertime in the mid-U.S. However, some manufacturers base their curves on a higher value for solar insolation as this yields better pumping outputs, so be sure to clarify that 


\begin{tabular}{|c|c|c|}
\hline & SUBMERSIBLE (1) & NON-SUBMERSIBLE \\
\hline \multirow{4}{*}{$\begin{array}{c}\mathbf{C} \\
\mathbf{E} \\
\mathbf{N} \\
\mathbf{T} \\
\mathbf{R} \\
\mathbf{I} \\
\mathbf{F} \\
\mathbf{U} \\
\mathbf{G} \\
\mathbf{A} \\
\mathbf{L}\end{array}$} & $\begin{array}{l}\quad \text { Stacked Impeller } \\
\text { A.Y. McDonald - Solar Subs } \\
\text { CAP - HS, PS } \\
\text { Grundfos - Solartronics series }\end{array}$ & \\
\hline & & Apollo Vertical Turbine \\
\hline & & CAP - $\begin{array}{l}\text { Floating Centrifugal } \\
\text { RU }\end{array}$ \\
\hline & & $\begin{array}{l}\quad \text { Surface Centrifugal } \\
\text { A.Y. McDonald - Surface } \\
\text { Flowlight - Solar Centrifugal } \\
\text { Solarjack - SC series } \\
\text { Apollo - } 773\end{array}$ \\
\hline \multirow{4}{*}{$\begin{array}{l}V \\
O \\
L \\
U \\
M \\
E \\
T \\
R \\
I \\
C\end{array}$} & $\begin{array}{l}\text { Diaphragm } \\
\text { CAP - F3, F5 } \\
\text { Cimarron - SolarSubs } \\
\text { Flowlight - Quad } 5000 \\
\text { Photocomm - Model } 250 \\
\text { Robison - RanchPump } \\
\text { Shurflo } \\
\text { Solarjack - SDS series }\end{array}$ & \\
\hline & & $\begin{array}{l}\text { Flowlight - Solar Pump Jacks } \\
\text { Photocomm }\end{array}$ \\
\hline & & $\begin{array}{l}\text { Siston } \\
\text { Solarjack - SPB series } \\
\text { Flowlight - Solar Force }\end{array}$ \\
\hline & & $\begin{array}{l}\quad \text { Rotary Vane } \\
\text { Flowlight - Solar Slow Pumps } \\
\text { Flowlight - Booster Pumps }\end{array}$ \\
\hline
\end{tabular}

(1) Pumps listed as submersible have an encased pump and motor unit that operate under the water surface.

Note: This chart is a general overview of available solar powered pumps and is not intended to be a comprehensive survey.

Figure 44. Commercial PV Pump Types with Manufacturers 
the value being used is similar to the insolation you expect for your specific location. PV system suppliers often have computer simulation programs that can be used to estimate hourly instantaneous and average daily outputs for solar pumps based on your site specific input parameters.

If the pump curve or chart only gives the pump's instantaneous output (gal $/ \mathrm{min}$ ), the daily output can be estimated by multiplying it by 60 and the number of sun hours the location receives. However, this estimation will not be very accurate for centrifugal pumps. Volumetric pumps have fairly linear relationships of instantaneous to daily output but this is not the case for centrifugal pumps whose efficiencies vary with the different solar irradiation levels received during the day.

Often the daily water outputs in these pump curves and charts are based on the use of a pump controller to maximize the output. Although many manufacturers recommend the use of a pump controller with their pumps, this information is not always included in the literature even though their pump curves may be based on controller use.

Other information often not included in the pump literature is a pump's maintenance requirements and tolerance for dirty water. In order to obtain enough information about a specific pump to select it for a pumping site, the manufacturer or PV vendor familiar with the pump may have to be contacted.

\section{PV Array Sizing}

Once a specific make and model of pump is selected for the pumping system, the PV array must be sized properly so that the pump delivers the necessary amount of water. In order to size the array for a specific location, the daily solar insolation received by the location must be known. To be most useful, the units for the insolation data should be in $\mathrm{kWh} / \mathrm{m}^{2}$ per day and the data should be obtained for plane of array tilt angles of latitude, latitude $+15^{\circ}$, and latitude $-15^{\circ}$ for at least the four seasons. One source of such data is the Stand-Alone Photovoltaic Systems Handbook available from Sandia. The insolation data for 38 U.S. cities and world insolation maps are included in the handbook. A good source for local data is a local PV vendor.

The manufacturer pump charts list the number and wattages of PV modules required to deliver a daily volume of water at the specific insolation level of $6 \mathrm{kWh} / \mathrm{m}^{2}$ per day. These PV module recommendations are based on the energy necessary to lift the water through the total pumping head and the pump's efficiency. However, the literature does not provide information on how to size the PV array for different solar insolation levels.

To work around this limitation, the water output per sun hour is often assumed to be constant in order to extrapolate the output for greater or fewer sun hours. However, this method only gives an approximation. Although volumetric pumps have a relatively constant output per peak sun hour, this is not the case for centrifugal pumps whose efficiencies can vary with 
different power levels. To be certain that the array is correctly sized for an application, contact a distributor or dealer of the selected pump for assistance in sizing.

\section{Balance of the System Specification}

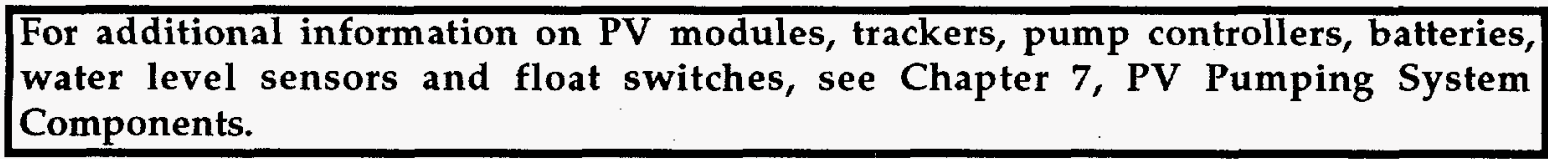

\section{Array Mounts}

An important consideration when specifying the mounting arrangement for the array is whether the pumping system is to be a permanent or portable system. By nature, most PVpowered pumping systems lend themselves to portability because of their modularity and compact size. If a customer has several pumping sites with similar site specifications and different seasons of use, one pumping system can be rotated among the sites as the need arises. This is often the case with ranching customers who rotate livestock through seasonal pastures. Although any pump (even jack pumps) can be made portable with special mounting equipment such as trailers and skids, submersible pumps are the most portable because they are extremely compact and require no special equipment for portability. These pumps are simply pulled from one water source and lowered into another.

If an array is to be designed for portability, the single pole mounting method should be considered. This method involves mounting the PV array on a single pole anchored in the ground by a concrete footing. An inexpensive pole mount must be installed at each pumping location so that the array can be lifted from one pole and installed on the next. If the array is limited to four or fewer modules, it will weigh approximately 100 pounds or less and can be moved fairly easily by two people. However, if a portable pumping system requires more than four modules, they can be either pole mounted in sets of four, or utility equipment can be used to lift and transport a larger array.

Another common method of mounting arrays is the A-frame mount. This mount involves fastening the modules to an A-frame rack secured to a foundation of concrete or heavy lumber. One of three types of foundations can be used: a concrete slab on grade, individual wood or concrete footings for the four corners of the array, or grade beams (parallel beams of concrete or heavy lumber that support the north and south ends of the A-frame). If portability of the system is desired, the A-frame can be attached to a trailer or skid but care must be taken to secure the array against wind. This can be achieved by using guy wires or earth anchors.

For both the single pole and A-frame mount, the specifications of the foundation such as the depth of the footings, size of the pole or size of the concrete slab are determined by the size of the array, the type of soil at the location, expected wind loading on the array, and also by the frost line. The manufacturers of module mounting racks give general recommendations for 
these variables, but the responsibility for correctly sizing the foundation lies with the system designer.

When a PV-powered pumping system is used to replace a windmill, the array can be mounted on the existing windmill tower. Although this is a fairly convenient and inexpensive method for mounting the array, the windmill head should be removed to prevent birds from soiling the array's surface.

Another important consideration in selecting the array mount is the accessibility of the pumping site. If the site is in a remote location and concrete must be mixed by hand, any concrete specified in the design should be minimized.

\section{Solar Trackers}

Trackers can increase the energy gained by a PV array by as much as 30 or 40 percent, thus allowing fewer PV modules to be used in the array. However, the amount of energy gained depends on the time of year and the latitude of the application. To determine the difference in energy gained by tracking and non-tracking arrays at your location, PV simulation programs such as a PVFORM (may be obtained by request from Sandia) can be used or insolation tables such as in Sandia National Labs Stand-Alone Design Manual can be consulted. A local PV vendor should be consulted for detailed local information. If solar trackers are to be included as part of the pumping system, a single pole mount must be specified as the array mount.

\section{Pump Controllers}

Many pump manufacturers recommend the use of pump controllers to maximize the output of their pump. These manufacturers will often offer a pump controller that is matched to their pump or they will recommend a particular make and model that is most compatible with it. Also, some will not warrant their pumps unless a particular controller is used. Check with the pump manufacturer or dealer to determine whether a certain controller is recommended for your selected pump, and whether it is necessary for your application. If the pump is of a type that can operate well enough without one, the pumping system will be simpler with fewer electronic parts that can fail if a controller is not used.

\section{Batteries}

As described previously, batteries are not typically included in PV-powered systems. However, if batteries are to be included in the system, the customer and the utility must first decide on the days of system autonomy. That is, the number of days that the system can pump water using only batteries. The amount of energy necessary for pumping each day's requirement (in watt hours) is next calculated and multiplied by the days of autonomy. The resulting figure is the necessary battery storage capacity. However the capacity figure must be increased to reflect the depth of discharge and temperature de-rate characteristics of the battery selected for the system. 
(See Sandia's Stand-Alone Photovoltaic Systems Handbook for a detailed description of batteries and a procedure for sizing them.)

\section{Water Level Sensors and Float Switches}

External water level sensors are used in wells with uncertain or marginal capacities when the pump/controller does not provide dry running protection. If the output capacity of the well is close to the maximum pumping capacity of the selected pump, sensors should be installed in the well to prevent damage to the pump from running dry. However, some pump manufacturers claim that their pumps are not damaged by running dry. Consult pump literature or manufacturer to determine if sensors are necessary.

Float switches are used to keep water storage tanks from overflowing. In almost all applications float switches should be installed to prevent wasting water.

\section{Wiring}

The wire used to connect the pump to the array must be sized properly to minimize line losses. This is especially important for low voltage systems ( 12 and 24 volts) where a voltage drop of a few volts can be a significant percent of the total. Also, because most PV-powered, DC pumps operate at lower voltages than traditional $A C$ pumps, the wiring for these pumps must be significantly heavier. The tables in Appendix $C$ give the maximum lengths for wire runs of various size wires. The tables are for $12,24,48$, and 120 volt $D C$ systems. If your selected pump runs on a different voltage, consult a PV vendor for the correct size wiring.

\section{Bypass Diodes}

Bypass diodes are used in strings of PV modules to prevent the shading of one module in the string from affecting the output of the entire string. The different manufacturers of PV modules make recommendations as to when to use bypass diodes with their modules. However, they are seldom used in systems of four or fewer modules (two strings of two modules).

\section{Safety and Code Considerations}

The pumping system must be designed with safety in mind. This is not an option for the designer but a requirement by law. In most jurisdictions the National Electric Code (NEC) is used as the local electrical code and PV systems are required to meet the code. The NEC contains an article (Article 690) that specifically addresses safety standards for PV systems; however, all the other NEC articles apply to PV systems as well. The NEC is not a design tool for PV systems, but it does dictate that the design contain specific safety features. The following are some of the requirements for PV systems listed in the NEC:

- Proper grounding of conductors and equipment. 
- Disconnects on the array and all equipment.

- Strain relief on module connecting wires.

- Fuses or circuit breakers on every ungrounded conductor.

- Properly sized and insulated wiring.

- Short circuit current protection on battery systems.

- The use of DC rated fuses and switches.

The NEC is available from better book stores and electrical supply houses and everyone designing and installing PV systems should become familiar with its contents. However, one drawback of the NEC is that some portions of it are worded ambiguously and it is subject to interpretation. A useful booklet, titled "Photovoltaic Power Systems and the National Electric Code" by John Wiles with the Southwest Technology Development Institute, attempts to clarify some of the requirements of the NEC with regard to PV systems and was developed specifically to help PV designers and installers become familiar with the code.

Once a utility is ready to seriously consider the design of a PV pumping system, the upcoming installation should be discussed with the local electrical inspector. This way the utility can work with the inspector to be certain that the system will meet all local electrical codes. 


\section{SYSTEM PROCUREMENT}

Whether the utility decides to procure PV equipment or service support or both, a competitive procurement process can be beneficial for initial purchases.

As mentioned in Part 1, the primary tradeoff that will exist for utilities procuring PV pumping system equipment will occur between obtaining the lowest price equipment from the PV industry versus obtaining equipment at higher costs that include services rendered by a PV industry contractor.

For utilities that use utility personnel instead of PV suppliers to provide the PV services, the procurements will typically occur to reduce hardware costs to the lowest possible level. However, for utilities planning on PV supplier support for program implementation, the equipment may be procured with service support included, though separate procurements for equipment and services may be desirable.

For utilities interested in PV supplier support, a competitive procurement process can be useful for obtaining necessary system design and installation services and equipment from the PV industry. For these utilities, the procurement process can have three primary goals:

(1) Procure a well-designed PV pumping system package appropriate for a range of applications;

(2) Procure quality system equipment at a reasonable price; and

(3) Establish a trade ally relationship between the utility and a selected PV industry contractor.

A procurement "tool" often used to obtain the necessary design and installation services and equipment is a request for proposal, since prospective PV suppliers should be evaluated initially for available equipment, design competence, PV experience, and costs. When either a reliable PV supplier relationship is established or the pumping systems become standardized, a formal procurement process may not be necessary for further pumping system purchases.

To ensure that the proposal evaluation process is fair and thorough, the evaluation criteria shown in the following table can be used by utilities to evaluate PV vendor proposals.

Bidder capability and experience. PV-powered water pumping is a specific PV application that requires direct experience with wells and pumps. General PV experience is no substitute for experience in pumping. Customer references can be valuable in determining a vendor's knowledge and experience with PV-powered pumping.

A consideration to keep in mind when selecting a PV system installer is the fact that several states have licensing requirements for pump installers. Certain states such as Colorado and Wisconsin require licensing of any individual that does any work in a well. Other states such as Arizona require licensed individuals to drill or make changes to wells but not to install pumps. 
Yet other states such as Wyoming and Nevada have no licensing requirements at all. If you are unsure about the licensing requirements in your state, contact your state agency that regulates water quality.

Proposal Quality and Technical Content. Proposal quality and technical content are evaluated primarily on the suggested system design. However, a thorough proposal should contain more than just the resulting system design. It should also contain system component descriptions, reasons for component selections, and explanations of how these components fulfill the design criteria (pumping head, water requirements, etc.).

Proposal Adequacy and Completeness. When a pumping system is thoroughly documented in the proposal, each criterion is more easily evaluated. Furthermore, an incomplete proposal may be an indication of the vendor's lack of interest or responsiveness.

System Reliability. The length of the warranties offered by the manufacturers and vendors is an indication of the reliability of a pumping system and its components. However, the system's reliability can also be affected by improper system design and whether the components receive regular required maintenance.

System Availability. This design parameter refers to whether the estimated seasonal water output meets the need. At a minimum, this information should be stated clearly in the proposal and should be considered first when deciding whether the system is appropriate for the application. Preferably, the design insolation for the average day in the season of use will also be described.

Maintenance Support. If a vendor's ability to provide maintenance support is important to a utility, then the proposal should state both the time required to respond to a service call and the vendor's infrastructure for providing that service.

System Cost. Although the pumping system cost is a primary consideration for most utilities and their customers, it should not be the only consideration. Two factors for evaluating cost are whether the initial equipment cost is reasonable (i.e., competitive) and whether the cost included for maintenance support is valued fairly. Additionally, an estimate of the system's life cycle cost is valuable. The lowest initial system cost will not always result in the lowest life cycle cost, especially if there is a significant difference in maintenance or reliability of the pumping systems being considered. 
System Installation

\section{SYSTEM INSTALLATION}

The utility must know at least enough about the installation procedures, sequences and options to monitor the installation for possible complications and safe practices.

There are many degrees of involvement possible for utility personnel during the installation of a PV-powered pumping system. The involvement may range from monitoring the installation to assisting the installer with utility heavy equipment to completing the entire installation. The purpose of this chapter is not to give detailed instructions on how to install PV pumping systems. There are many reasons why professionals should be involved in the installation process, such as the need for specialized installation equipment and knowledge of unique safety concerns. Also, many states require that all work in wells be performed by licensed well service professionals.

The purpose of this chapter is to provide general information on installation procedures, sequences, and options so that a utility can decide how involved they care to be with installations. Also, knowledge of the installation process can alert a utility to potential problems with an installation and enable them to ask informed questions of the installer.

The installation of PV-powered pumping systems can be divided into three main operations, installation of the PV array, installation of the pump, and installation of the balance of the system (BOS), which can include controllers, switches, and batteries. Although installation procedures for pumps vary greatly from pump to pump, the procedures for installing arrays and BOS are relatively similar for all systems. Therefore, installation procedures for arrays and BOS will be discussed independent of the type of pump installed. Then, the general installation procedures for three different types of pumps (submersible, surface, and jack pumps) will be discussed. The installation steps are given in a certain sequence that is typical for pumping system installation, but the steps may or may not be followed by all installers.

\section{PV Array}

Important considerations in the installation of the PV array are its proper placement to receive maximum sunlight, its orientation toward true south, and setting the correct tilt angle for the application. The understanding and proper implementation of these concepts is essential to optimize the function of the array.

There are many different arrangements used to mount PV modules. However, two are used more commonly than others: the single pole mount and the A-frame rack on a concrete foundation. 


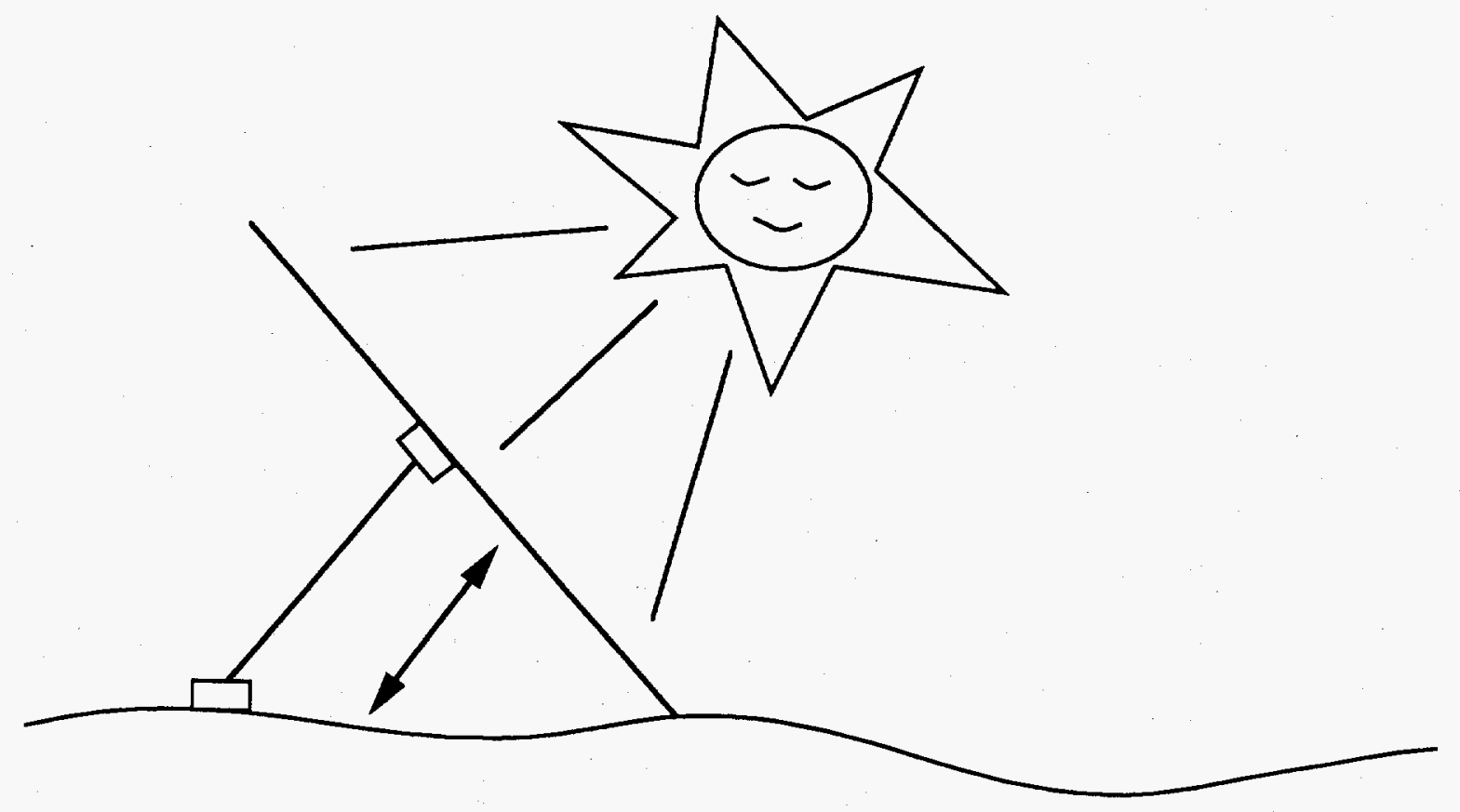

The array tilt angle refers to the angle that the array is tilted up from the horizontal. To optimize the array for use in the spring and fall, the array should be tilted up from horizontal to the same angle as the latitude of the pumping site. To optimize the array for summer use, the array should be tilted to latitude minus 15 degrees, and for winter use, the angle should be latitude plus 15 degrees. Array orientation refers to the compass direction which the array faces. In most cases the orientation should be toward true south. To locate true south, find magnetic south on a compass and add or subtract the magnetic declination. The declination is the number of degrees that magnetic north differs from true north.

Figure 45. PV Array Tilt Angle and Orientation

\section{Single Pole Mount}

The single pole mount involves setting a pole in a concrete footing and fastening the PV modules to a rack attached to the pole. This mount must be used for an array with a solar tracker, but a fixed array can be pole-mounted as well. The following steps are involved in the installation. 
- A hole is dug in the ground where the array is to be installed, a pole is set upright in the hole and concrete is poured into the hole around the pole to support and anchor it. The depth and width of the hole, the size and material of the pole, and the quantity of concrete to be used can all vary according to the number of PV modules to be supported, the type of soil at the location, and the expected wind loading. The manufacturers of module mounting racks give general recommendations for the above variables but the responsibility for correctly sizing the pole and foundation lies with the system designer. This step is completed at least a day before the actual installation of the equipment to give the concrete time to set and cure.

- A fixed or tracking rack, which holds the modules, is next fastened to the pole. This usually involves slipping a sleeve attached to the center of the rack over the end of the pole and tightening the sleeve with screws.

- Once the rack is on the pole, the individual PV modules are attached to the rack. For smaller systems (four modules or less) the modules can be pre-mounted and wired on the rack and the whole assembly fitted to the pole.

- After all the modules are attached to the rack they need to be wired together in series and parallel combinations to give the voltage and current required by the pump. If bypass diodes are required for the system, they should be installed at this time.

\section{A-frame Mount}

The A-frame mount involves fastening the modules to an A-frame rack secured to a foundation of concrete or heavy lumber. The following are steps involved in the installation.

- The ground is prepared for one of three types of foundations: a concrete slab on grade, individual footings for the four corners of the array, or grade beams. As with the single pole mount, the specifications of the foundation are determined by the size of the array, the type of soil at the location, expected wind loading on the array, and also by the frost line. If concrete is necessary for the foundation, this step is completed at least a day before the actual installation of the equipment to give the concrete time to set. Also for concrete foundations, the bolts to secure the rack to the foundation may be either set into the concrete while it's wet or holes for expansion bolts may be drilled after the concrete has set.

- The fixed rack which holds the modules is next set onto the foundation and fastened to it. The rack may be set directly on the foundation or set on carrier beams attached to the foundation. 
- Once the rack is on the foundation, the individual PV modules are installed on the rack. For smaller systems (four modules or less) the modules can be pre-mounted and wired on the rack and the whole assembly fitted to the foundation.

- After all the modules are attached to the rack they need to be wired together in series and parallel combinations to give the voltage and current required by the pump. If bypass diodes are required for the system they should be installed at this time.

\section{Balance of System}

\section{Pump Controllers}

The pump controller is in most cases simply attached to the array mounting pole or A-frame under the array to help protect it from overheating. Controllers not contained in weatherproof boxes must be mounted inside weatherproof enclosures.

\section{Batteries}

If batteries are included in a pumping system, they must be installed in a weatherproof enclosure that is vented to permit hydrogen gases to escape. The enclosure must also be insulated to prevent the batteries from freezing in cold weather or overheating in hot weather. Protection from extreme temperatures is sometimes achieved by burying the batteries in a ground vault. However, they must be accessible for periodic maintenance.

\section{Pumps}

The general installation procedures for three general categories of pumps (submersible, surface, and jack) will next be discussed. The majority of the pump types fit into one of these three categories and the procedures cover the vast majority of pumps that are actually installed. Many of the steps are similar for all three categories. Where the procedures differ is mainly in the placement of the pumps.

\section{Submersible Pumps}

These pumps include both the submersible diaphragm and submersible centrifugal pumps. The main differences in the installation procedures for these two pump types have to do with their handling requirements due to their size and weight differences. The following steps pertain to each of the two pump types unless otherwise noted.

- The array is mounted, wired, and connected to the pump controller if one is included in the system. 
- The well is uncapped and the static water level is checked.

- The pump cable is spliced to the electrical lead from the pump.

- The other end of the cable is briefly connected to the controller or array to test the pump for operation.

- A section of discharge pipe, typically 20-foot-long PVC pipe or galvanized steel pipe, is attached to the pump. If the pump is to be moved periodically from location to location, a flexible hose is often used instead of rigid pipe.

- A safety rope is also connected to the pump with the other end attached to the top of the casing or the well cap. The rope will prevent the pump from becoming lost in the well if the discharge pipe and cable should come loose.

- If water level sensors are used, at this time the sensors and their wiring would be attached to the pipe and cable at the appropriate distances above the pump.

- The pump with attached cable, discharge pipe, and safety rope are then lowered into the well. Sections of pipe are added as the pump is lowered. This procedure usually requires a tripod, a well service truck with a boom, or an existing windmill tower to support the overhead sections of pipe as they are lowered. Because the pump, cable, and pipe can become heavy for deep wells as sections of pipe are added, a winch may also be required to lower the assembly. Most submersible diaphragm pumps using a flexible hose for discharge can be lowered into the well by hand.

- The well cap is replaced and sealed and the water discharge is routed to the storage tank or distribution point.

- The pump cable is reconnected to the array or controller and the pumping system is thoroughly tested for proper operation.

Note: In new wells or if sediment has been stirred during installation, the pump should be started at mid-day and allowed to operate for a number of hours to clear the well sediment that could clog the pump.

\section{Surface Pumps}

Surface pumps include surface centrifugal, piston, and rotary vane pumps. Although the pumping mechanisms may be centrifugal or volumetric, the following installation procedures are essentially the same for each pump type. 
- The array is mounted, wired, and connected to the pump controller if one is included in the system.

- The pump is mounted on a foundation of either concrete or pressure treated wood and housed in a weatherproof enclosure.

- One end of the pump wiring is connected to the pump and the other end is briefly connected to the controller or array to test the pump for operation.

- One end of the suction intake pipe is connected to the pump and the other end is fixed in the water source. For centrifugal pumps, the end in the water must have a screen to keep out large debris and a foot valve to retain the water once the pump stops operating. Volumetric pumps also require a screen at the water intake and a silt and sand filter placed anywhere in the intake line. Depending on the material and location of the piping, the water intake pipe may need to be buried to prevent damage from sunlight or traffic.

- The water discharge is routed to the storage tank or distribution point.

- The pump wiring is reconnected to the array or controller and the pumping system is thoroughly tested for proper operation.

\section{Jack Pumps}

Jack pumps are in a way a combination of submersible and surface pumps, since they have a submerged cylinder and plunger assembly for moving water and a surface motor and jack mechanism. These pumps are the most difficult of the three categories to install and installation in most cases requires a professional pump service person with a well service or work over truck.

- A secure foundation of concrete, pressure-treated wood, or railroad ties is set in place around the well casing. If concrete is used, this step is completed at least a day before the actual installation of the equipment to give the concrete time to set.

- The array is mounted, wired, and connected to the pump controller.

- The well is uncapped and the static water level is checked.

- The cylinder plunger, attached to a length of sucker rod, is placed in the cylinder and a length of steel discharge pipe is connected to the top of the cylinder. The whole assembly is then lowered into the well until only a foot or so remains clamped above the casing. The next length of sucker rod and discharge pipe are then connected and lowered into the well. This process is repeated until the cylinder is at the required depth in the well. The lengths 
of sucker rod and discharge pipe are both 21 feet long and the installation requires a well service truck or a work over truck. These trucks have booms or towers with a winch and cable that lift the next section of pipe and sucker rod in place to attach to the previous sections and lower the assembly into the well. Care must be taken to securely clamp each section of pipe to the well head before the next section is added, else the entire assembly could be lost in the well.

- When the last section of pipe and sucker rod are lowered into the well, the pipe is secured to the top of the well casing with a well seal and a packing gland is installed around the suction rod.

- The jack mechanism and motor are mounted on the foundation, taking care to line up the working head over the center of the casing. For concrete foundations, the bolts to secure the base to the foundation may be either set into the concrete while it's wet or holes for expansion bolts may be drilled after the concrete has set.

- One end of the pump wiring is connected to the motor and the other end is briefly connected to the controller to test the motor and jack mechanism for operation.

- The working head is then connected to the end of the suction rod and the water discharge is routed to the storage tank or distribution point.

- The pump cable is reconnected to the controller and the pumping system is thoroughly tested for proper operation.

\section{Other Considerations}

\section{System Testing}

Once a PV pumping system is installed, it must be thoroughly tested for proper operation and the test results need to be recorded and filed. The testing not only ensures that the system is installed properly, but the recorded results are a reference point for proper system operation in the event of later system malfunction. Important elements to record at the time of the test are ambient conditions such as the air temperature, wind speed and direction, irradiance levels, and the static water level before testing. The testing should be conducted during optimal conditions of bright sunshine with irradiance levels above 800 watts per square meter. This test condition ensures that the tests reflect the true capabilities of the pumping system.

The system should be tested for array open circuit voltage, array short-circuit current, voltage to load, current to load, and instantaneous water output in gallons per minute. In addition, cumulative water output should be measured for a one-hour period. By comparing the test results to manufacturer literature and vendor proposal estimates of water output, it can be 
System Installation

determined whether the system is operating properly and at its full capacity. To facilitate the recording of test data, a test data form shown below can be used. 


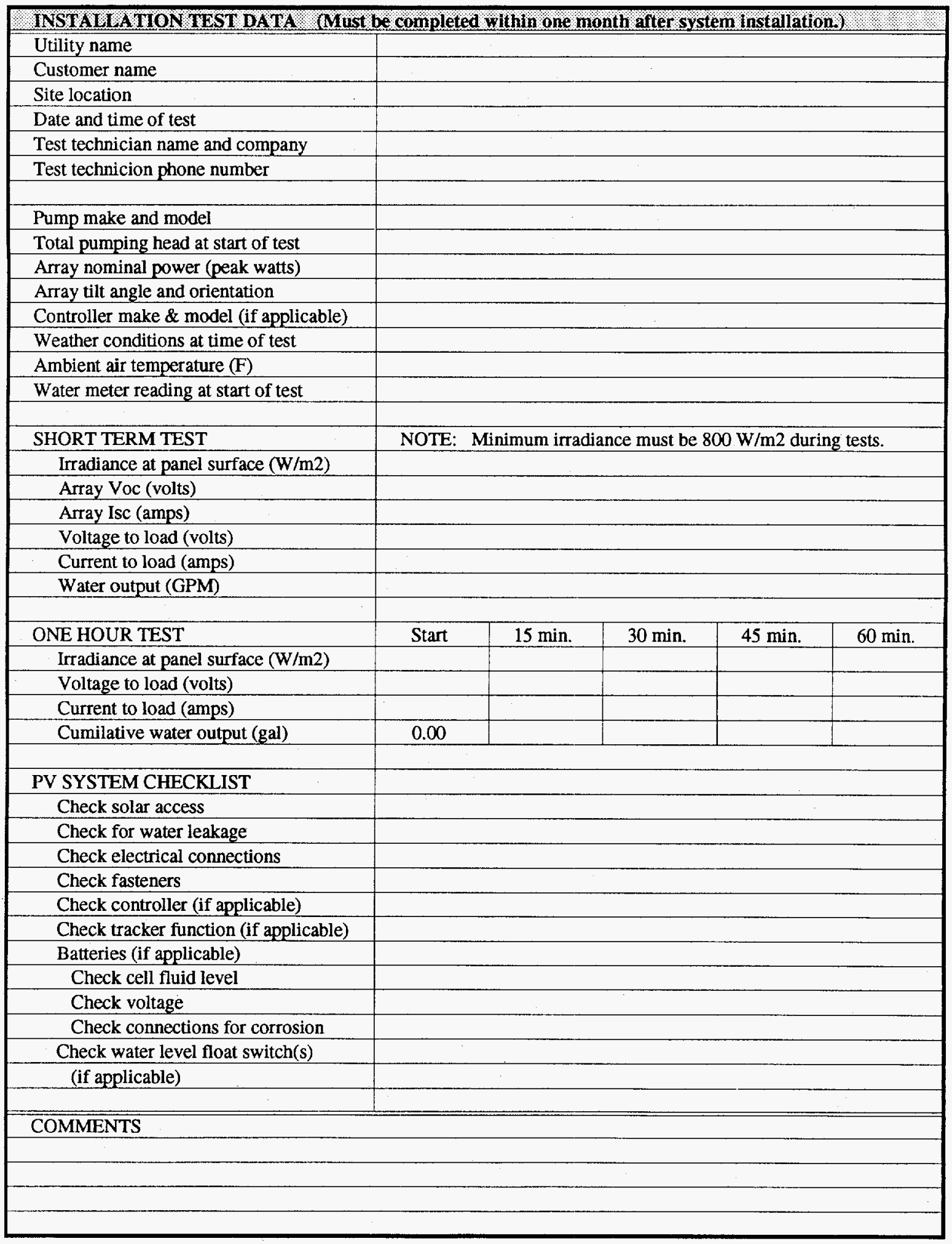

Figure 46. Test Data Form 


\section{Site Fencing}

A consideration for PV pumping systems used by ranchers is protection of the equipment from livestock. Livestock, cattle in particular, are fond of leaning on and scratching against any object raised above the ground such as fences, trees, pumps, and PV arrays. In such applications, fencing of the array and pump or well cap is essential for reliable operation of the system. Also, some above ground pumps, such as jack pumps, have moving parts that can be dangerous to people as well as livestock. These pumps should always be fenced whether or not the site is used for livestock watering.

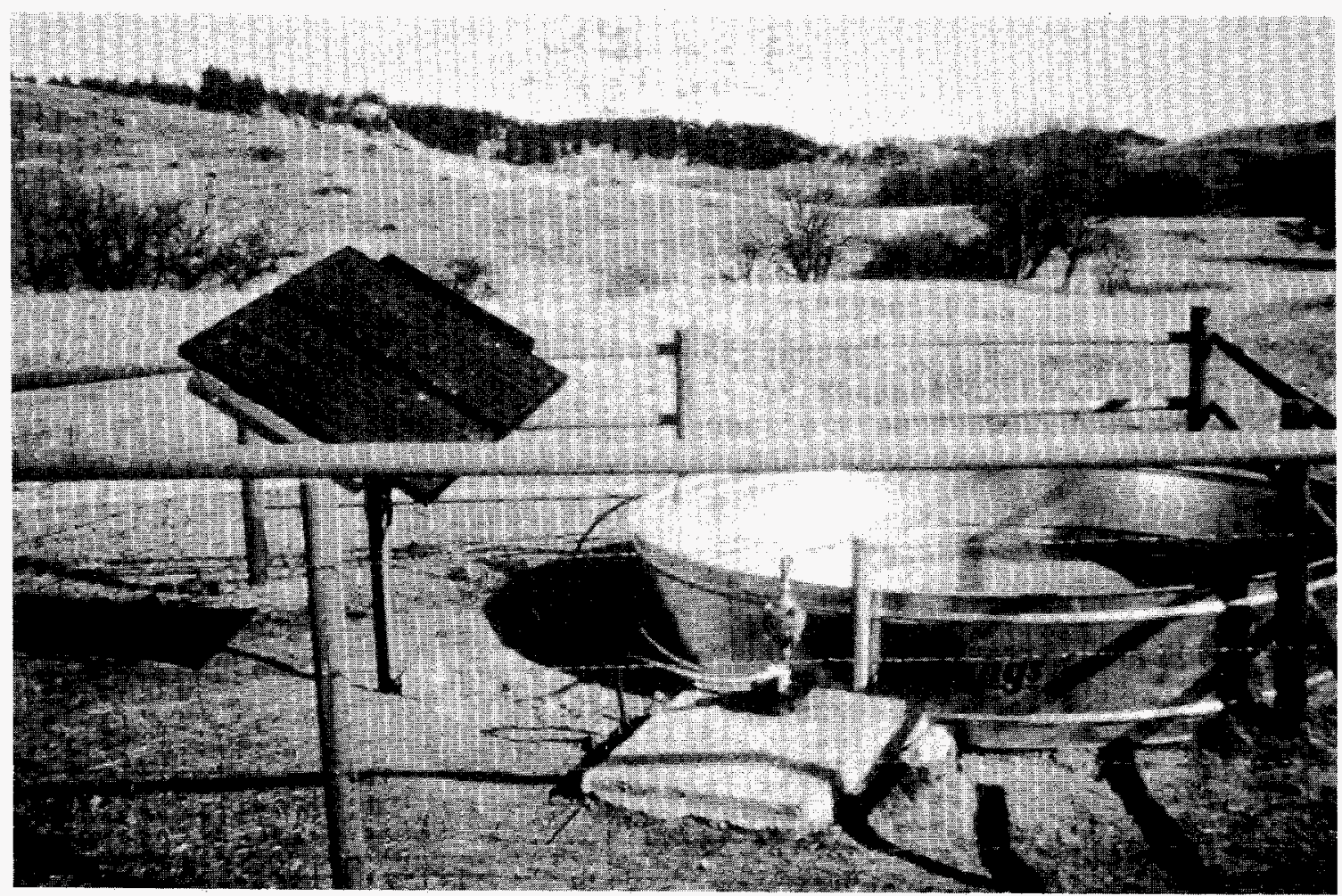

Source: Tri-County Electric

Figure 47. PV Pumping System 
System Installation

\section{Safety}

Safe procedures should be followed for every system installation and maintenance operation whether the work is being performed by the PV vendor or utility personnel. Although PV power systems are often viewed as benign sources of energy, a shock hazard exists whenever the array contains more than two PV modules. Common safety. procedures include never working alone on a PV system, wearing dry leather gloves to reduce risk of electrical shock, always measuring for conductivity from metal frames to ground and voltage to ground, and wearing rubber gloves, apron, and safety goggles when handling batteries. For an in-depth examination of safe PV procedures, consult the booklet, Working Safely with Photovoltaic Systems, by Daystar, Inc. 


\section{SYSTEM MAINTENANCE}

Most PV pumping systems do not require much preventive or corrective maintenance,
but the utility should be aware of common problems and basic troubleshooting
procedures.

Both preventive maintenance and troubleshooting procedures for PV-powered pumping systems are discussed in this chapter. The preventive maintenance discussion lists some of the periodic procedures that a system may require. The troubleshooting section provides guidelines for locating and correcting minor problems in a pumping system.

\section{Preventive Maintenance}

PV-powered pumping systems require relatively little maintenance compared to windmills and engine generators; however, they do require some care. The following is a list of possible preventive maintenance procedures for PV pumping systems.

- The pump may require periodic replacement of filters, diaphragms, piston seals, cylinder leathers, or DC motor brushes depending on the type of pump. (See the PV-powered pumps chapter for the needs of the different pump types.)

- If a tracker is included in the system, the pivots should be lubricated once a year. The pivot points and tracking mechanism should also be inspected for rust and painted as required.

- If wet cell batteries are included in the system, the electrolyte level must be checked periodically and distilled water should be added if the level is low. Also, the terminals must be checked for corrosion and cleaned if necessary.

- Trees, shrubs, grasses, and other vegetation may have to be trimmed to keep the PV array clear of shading.

- If the system is not operated in the winter, surface pumps, intake pipes, and discharge pipes should be drained to prevent freeze damage.

\section{Troubleshooting}

The intent of this guide is to fulfill two functions. The primary function is to inform the reader of some common problems encountered in photovoltaic pumping systems. The second function is to offer a step by step procedure that can be used to identify and correct common system malfunctions. It is assumed that the system being tested was operating properly after the system was installed. Furthermore, this guide is not intended to be an extensive diagnostic tool. The broad range of pumping applications and products would require a series of specific diagnostic guides that are beyond the scope of this document. 
This guide recommends the use of professional services whenever the diagnostic procedures require advanced skills or equipment. In no case should anyone perform any of the tests suggested in this guide if they do not have the knowledge or equipment to perform these diagnostic steps. The voltages and moving mechanical parts encountered in many photovoltaic pumping systems can be harmful to inexperienced personnel.

\section{How to Use the Tubleshooting Guide}

This guide is divided into three main problem areas based on the most obvious malfunctions encountered in solar pumping systems. They are as follows:

\section{Pump Not Operating}

No physical operation of the water pump can be detected and no water is being delivered.

\section{Pump Operating/No Water Output}

The pump is operating, but no water is delivered.

\section{Pump Operating/Reduced Water Output}

The pump is operating, but delivers less water than previously observed. The pump may also be delivering less water than stated in its performance specification.

To use the guide, the first step is to identify which one of these main symptoms applies to a malfunctioning pumping system. (The problems are listed in the left-hand column of the chart.)

In all cases, knowledge of whether the pump is operating is an important part of assessing assumptions. Determining pump operation is simple in surface pump applications because its behavior can usually be observed directly. However, the operation of submerged pumps and pumping mechanisms can be difficult to detect. In some submerged installations, sound or vibration can be detected, which indicates that the pump is probably operating. If a user cannot detect operation in a submerged pump, the guide can still be used to eliminate other system components as the cause for a system failure.

Knowledge of pumping system output is also important for assessing symptoms. To determine if a pump is operating at a reduced output, its production must be measured. When testing pump performance, a method of measuring the production (such as a water meter or container of known volume) should be employed along with a clock or a wristwatch. These measuring tools will determine production over a specific time period (i.e., gallons per minute).

Once the general symptoms have been assessed, the second step is to perform a series of simple diagnostic procedures outlined in the troubleshooting table. The person performing the tests must have the skills needed to use an electrical multimeter on systems containing live electrical conductors and moving mechanical parts. 
As shown, the chart identifies possible causes for a malfunction. The causes are listed in sequence from the simplest to the most complex. This sequence enables the user to logically eliminate possible problems while working through the table. If the problem is not resolved by the suggested action, the user should proceed on to the next possible cause. Solutions are suggested for the simpler problems, while technical assistance should be sought for the more complex ones. If enacting any solution is beyond the capability of the user, professional assistance should be obtained.

\section{System Testing Guidelines}

Whether or not systems contain batteries, they should only be tested during periods of full sunlight. For optimum results, the tests should be performed around noon on a cloudless day. To perform the tests recommended in the troubleshooting guide, the following tools are recommended.

- Digital Multimeter (To measure voltage and circuit continuity)

- $5 / 16^{\prime \prime}$ straight blade screwdriver

- $1 / 8^{\prime \prime}$ straight blade screwdriver

- No. 2 Phillips screwdriver (Used for removing access covers and terminal screws)

- Water meter or measurement container (To measure water volume being pumped)

- Timepiece (To measure volume of water delivered over time)

To make most minor repairs on PV pumping systems, the following tools are recommended.

- Combination wrench set (1/4" through $\left.7 / 8^{\prime \prime}\right)$

- $3 / 8^{\prime \prime}$ drive socket set $\left(1 / 4^{\prime \prime}\right.$ through $\left.7 / 8^{\prime \prime}\right)$

- $18^{\prime \prime}$ pipe wrench

- 12 " slip joint pliers

- 10" adjustable wrench

- Wire stripper 


\section{TROUBLESHOOTING GUIDE for PV-Powered Water Pumping Systems}

\begin{tabular}{|c|c|c|c|}
\hline 30161010 & 100551610 \%av1se. & How 10 Ghel. & Comective lactions? \\
\hline \multirow[t]{2}{*}{$\begin{array}{l}\text { Pump Not } \\
\text { Operating }\end{array}$} & Switches off & $\begin{array}{l}\text { Check position of all system } \\
\text { switches. }\end{array}$ & $\begin{array}{l}\text { - Turn on array and control } \\
\text { switches; } \\
\text { - Verify that float or pressure } \\
\text { switches are operating } \\
\text { correctly. }\end{array}$ \\
\hline & $\begin{array}{l}\text { Water discharge } \\
\text { valve closed }\end{array}$ & Check valve position. & Open valve. \\
\hline & Fuses blown & Check continuity of fuses. & $\begin{array}{l}\text { Replace open fuses after } \\
\text { correcting source of overload. }\end{array}$ \\
\hline & $\begin{array}{l}\text { No power from } \\
\text { batteries due to } \\
\text { low state of } \\
\text { charge }\end{array}$ & $\begin{array}{l}\text { Check controls for a low } \\
\text { voltage disconnect } \\
\text { condition. }\end{array}$ & $\begin{array}{l}\text { If controls have disconnected } \\
\text { the pump from the batteries, } \\
\text { allow the array to recharge } \\
\text { the batteries. }\end{array}$ \\
\hline & $\begin{array}{l}\text { No power at } \\
\text { controller }\end{array}$ & $\begin{array}{l}\text { - Check continuity of wiring } \\
\text { between array and } \\
\text { controller; } \\
\text { - Check continuity of wiring } \\
\text { between batteries and } \\
\text { controller. }\end{array}$ & Repair open circuit. \\
\hline & $\begin{array}{l}\text { No power from } \\
\text { array due to } \\
\text { open circuit }\end{array}$ & $\begin{array}{l}\text { Check voltage at the array } \\
\text { terminals. }\end{array}$ & $\begin{array}{l}\text { Close open circuit in the } \\
\text { array. }\end{array}$ \\
\hline & $\begin{array}{l}\text { No power from } \\
\text { batteries due to } \\
\text { open circuit }\end{array}$ & $\begin{array}{l}\text { Check voltage at battery } \\
\text { terminals. }\end{array}$ & $\begin{array}{l}\text { Close open circuit in the } \\
\text { battery bank. }\end{array}$ \\
\hline & $\begin{array}{l}\text { Controller } \\
\text { malfunction }\end{array}$ & $\begin{array}{l}\text { Check indicator lights if } \\
\text { present. }\end{array}$ & Correct fault indicated. \\
\hline & $\begin{array}{l}\text { No output from } \\
\text { controller }\end{array}$ & $\begin{array}{l}\text { Check for voltage at } \\
\text { controller output terminals. }\end{array}$ & $\begin{array}{l}\text { If no voltage is found, seek } \\
\text { assistance from supplier. }\end{array}$ \\
\hline & $\begin{array}{l}\text { No voltage to } \\
\text { pump }\end{array}$ & $\begin{array}{l}\text { Check continuity of wiring } \\
\text { between pump and } \\
\text { controller. }\end{array}$ & Repair open circuit condition. \\
\hline & Defect in pump & $\begin{array}{l}\text { Check for voltage at pump } \\
\text { terminals. }\end{array}$ & $\begin{array}{l}\text { If voltage is present at pump } \\
\text { but no operation is observed, } \\
\text { contact supplier for } \\
\text { assistance. }\end{array}$ \\
\hline
\end{tabular}




\begin{tabular}{|c|c|c|c|}
\hline Problen: & Possible Vause & 17,1 How to Check $/ 1 / 17 \%$ & 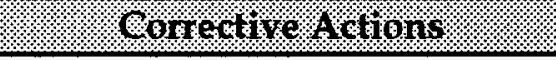 \\
\hline \multirow{7}{*}{$\begin{array}{l}\text { Pump } \\
\text { Operating/ } \\
\text { No Water } \\
\text { Output }\end{array}$} & $\begin{array}{l}\text { No water at } \\
\text { pump }\end{array}$ & $\begin{array}{l}\text { Check source draw down } \\
\text { and yield. }\end{array}$ & $\begin{array}{l}\text { Lower pump intake or reduce } \\
\text { pumping rate. }\end{array}$ \\
\hline & intake & & \\
\hline & $\begin{array}{l}\text { Water discharge } \\
\text { valve closed }\end{array}$ & Check valve position. & Open valve. \\
\hline & $\begin{array}{l}\text { Pump intake } \\
\text { obstructed }\end{array}$ & Inspect pump intake. & Remove obstruction. \\
\hline & $\begin{array}{l}\text { Discharge pipe } \\
\text { obstructed }\end{array}$ & Look for obstructions. & Remove obstruction. \\
\hline & $\begin{array}{l}\text { Broken } \\
\text { discharge pipe }\end{array}$ & Check discharge pipe. & Repair breaks in pipe. \\
\hline & Defect in pump & None & $\begin{array}{l}\text { If the pump runs but still does } \\
\text { not deliver water, seek } \\
\text { assistance from the supplier. }\end{array}$ \\
\hline
\end{tabular}




\begin{tabular}{|c|c|c|c|}
\hline Froblens & Possiblevause & How to Check. & Corrective trtions \\
\hline \multirow[t]{11}{*}{$\begin{array}{l}\text { Pump } \\
\text { Operating/ } \\
\text { Reduced } \\
\text { Water } \\
\text { Output } \\
\end{array}$} & $\begin{array}{l}\text { Inadequate } \\
\text { water source }\end{array}$ & Check yield of source. & $\begin{array}{l}\text { If pump rate exceeds that of } \\
\text { source, seek qualified } \\
\text { assistance. }\end{array}$ \\
\hline & $\begin{array}{l}\text { Partially closed } \\
\text { discharge valve }\end{array}$ & Check valve position. & Open valve fully. \\
\hline & $\begin{array}{l}\text { Pump intake } \\
\text { restricted }\end{array}$ & Inspect pump intake. & Remove restriction. \\
\hline & $\begin{array}{l}\text { Le a k in } \\
\text { discharge pipe }\end{array}$ & Inspect discharge pipe. & Repair leak(s). \\
\hline & $\begin{array}{l}\text { Reduced power } \\
\text { from batteries } \\
\text { due to low state } \\
\text { of charge }\end{array}$ & Check battery voltage. & $\begin{array}{l}\text { If battery voltage is below } \\
\text { nominal system voltage (i.e., } \\
12,24 \text {, etc.), recharge batteries. }\end{array}$ \\
\hline & $\begin{array}{l}\text { Reduced power } \\
\text { from array due } \\
\text { to shading or } \\
\text { broken modules }\end{array}$ & $\begin{array}{l}\text { Check for shading or broken } \\
\text { modules. }\end{array}$ & $\begin{array}{l}\text { Remove cause of shading or } \\
\text { replace broken modules. }\end{array}$ \\
\hline & $\begin{array}{l}\text { Reduced power } \\
\text { from array due } \\
\text { to open circuits }\end{array}$ & $\begin{array}{l}\text { Inspect array wiring } \\
\text { connections using system } \\
\text { schematic. }\end{array}$ & Close open circuits. \\
\hline & $\begin{array}{l}\text { Reduced power } \\
\text { from array due } \\
\text { to misaligned } \\
\text { tracker }\end{array}$ & $\begin{array}{l}\text { Make sure that the tracker is } \\
\text { facing the sun. }\end{array}$ & $\begin{array}{l}\text { Move the tracker into } \\
\text { alignment with the sun. If the } \\
\text { tracker consistently does not } \\
\text { track the sun, contact the } \\
\text { supplier. }\end{array}$ \\
\hline & $\begin{array}{l}\text { Reduced power } \\
\text { from batteries } \\
\text { due to corroded } \\
\text { terminals or low } \\
\text { electrolyte }\end{array}$ & $\begin{array}{l}\text { Inspect terminals and } \\
\text { electrolyte level. }\end{array}$ & $\begin{array}{l}\text { Clean corroded terminals or } \\
\text { replenish electrolyte. }\end{array}$ \\
\hline & $\begin{array}{l}\text { Aged } \text { or } \\
\text { damaged } \\
\text { batteries }\end{array}$ & $\begin{array}{l}\text { Have batteries tested under } \\
\text { load by professional battery } \\
\text { supplier. }\end{array}$ & $\begin{array}{l}\text { If found defective, replace } \\
\text { batteries. }\end{array}$ \\
\hline & $\begin{array}{l}\text { Worn or } \\
\text { damaged pump }\end{array}$ & None & $\begin{array}{l}\text { If the pump still does not } \\
\text { deliver the specified amount of } \\
\text { water, contact the pump } \\
\text { supplier for assistance. }\end{array}$ \\
\hline
\end{tabular}


BIBLIOGRAPHY 
Bibliography

J. Bigger, et al., "Powering T\&D Sectionalizing Switches with Photovoltaics: A Low-Cost Option," Proceedings of IEEE Summer Meeting, July 1992.

J. E. Bigger and E. C. Kern, "Early Applications of Photovoltaics in the Electric Utility Industry," Electric Power Research Institute, Presented at the 21st IEEE PV Specialists Conference, Kissimmee, FL, May 1990.

J. Iannucci and D. Shugar, "Structural Evolution of Utility Systems and Its Implication for PV Applications," IEEE Summer Power Meeting, July 1991.

Idaho Power Company's Solar Photovoltaic Service, Filed with the Idaho Public Utilities Commission, Order Number 24473, September 1992.

C. Jennings, "PG \& E's Cost-Effective PV Installations," Pacific Gas and Electric Co., Report No. 007.3-89.5, August 1989.

On-Site Utility Applications for Photovoltaics, EPRI Journal, March 1991.

A Profile of Stand-Alone Residential Power Systems, Dan Shugar, Pacific Gas and Electric, and Bob Hammond, Alpha Specialties. Solar 90, Annual Conference of the American Solar Energy Society, 1990.

V. Risser, "Working Safely with Photovoltaic Systems," Daystar, Inc., Las Cruces, NM, 1992.

V. Risser, et al., "Stand-Alone PV Systems: A Handbook for Recommended Design Practices," Sandia National Laboratories PV Design Assistance Center, Report No. SAND87-7023, April 1988.

Stand-Alone Remote PV Home - Lessons Learned, Bob Hammond, Alpha Specialties, and Christina Jennings, Pacific Gas and Electric, Solar Engineering 91, ASME, March 1991.

J. Stevens, et al., "Photovoltaic Systems for Utilities," Sandia National Laboratories PV Design Assistance Center, Report No. SAND90-1378, October 1990.

K. Stokes, et al., "Photovoltaic Water Pumping for K. C. Electric Association," NEOS Corporation, Report in support of Western Area Power Administration's Loveland Area Office, January 1991.

K. Stokes and G. Churchill, "Photovoltaic Power as a Utility Service: Lessons Learned for 15 PV Service Programs," Sandia National Laboratories, Interim Report, October 1992. 
K. Stokes and P. Saito, "Reliability, Cost, and Performance of PV-Powered Water Pumping Systems: A Survey for Electric Utilities," Electric Power Research Institute, Report No. RP3258-02, April 1992.

M. Thomas, "Water Pumping: The Solar Alternative," Sandia National Laboratories PV Design Assistance Center, Report No. SAND87-0804, December 1988.

J. Wiles, "Photovoltaic Power Systems and the National Electric Code: Suggested Practices," Southwest Technology Development Institute, Las Cruces, NM, November, 1992. 


\section{GLOSSARY OF TERMS}


Glossary of Terms

Ambient Temperature: The temperature of the surroundings.

Array: A collection of photovoltaic (PV) modules, electrically wired together and mechanically installed in their working environment.

Bypass Diode: A diode connected in parallel with a PV module to provide an alternate current path in case of module shading or failure.

Charge Controller: A device that controls the charging rate and/or state of charge for batteries.

Efficiency: The ratio of output power (or energy) to input power (or energy). Expressed in percent.

Fixed Tilt Array: A PV array set in a fixed position.

Flat-Plate Array: A PV array that consists of non-concentrating PV modules.

Insolation: The solar radiation incident on an area over time. Usually expressed in kilowatthours per square meter. See also Solar Resource.

Inverter: In a PV system, an inverter converts DC power from the PV array to AC power compatible with AC loads.

Irradiance: The solar power incident on a surface. Usually expressed in kilowatts per square meter. Irradiance multiplied by time equals insolation.

I-V Curve: The plot of the current versus voltage characteristics of a photovoltaic cell, module, or array. Three important points on the I-V curve are the open-circuit voltage, short-circuit current, and peak power operating point.

Load: The amount of electric power used by any electrical appliance at any given moment.

Maximum Power Point Tracker: A mode of operation, whereby the PV array operating voltage is controlled to extract maximum power.

Module: The smallest replaceable unit in a PV array. An integral, encapsulated unit containing a number of PV cells.

Open Circuit Voltage (Voc): The maximum voltage produced by a photovoltaic cell, module, or array with no load connected. This value will increase as the temperature of the PV material increases. 
Orientation: Placement with respect to the cardinal directions, N, S, E, W; azimuth is the measure of orientation from north.

Peak Sun Hours: The equivalent number of hours per day when solar irradiance averages 1,000 watts $/ \mathrm{m}^{2}$. For example, six peak sun hours means that the energy received during total daylight hours equals the energy that would have been received had the irradiance for six hours been 1,000 watts $/ \mathrm{m}^{2}$.

Photovoltaic Cell: The treated semiconductor material that converts solar irradiance to electricity.

Pyranometer: An instrument used for measuring solar irradiance.

Short Circuit Current (Isc): The current produced by a PV cell, module, or array when its output terminals are shorted.

Solar Resource: The amount of solar insolation a site receives, usually measured in $\mathrm{kWh} / \mathrm{m}^{2} /$ day, which is equivalent to the number of peak sun hours. See Insolation and Peak Sun Hours.

Stand-Alone PV System: A Photovoltaic system that operates independent of the utility grid.

String: A number of modules interconnected electrically to obtain the operating voltage required by the load.

System Autonomy: The number of consecutive days the stand-alone system will meet a defined load without solar energy input.

Tilt Angle: The angle of inclination of a solar collector measured from the horizontal.

Tracking Array: A PV array that follows the path of the sun. This can mean one axis east to west daily tracking of the sun or two-axis tracking where the sun's elevation is also tracked.

Water Pumping Terminology

Centrifugal Pump:

A class of water pump using a rotating impeller to move water. The faster the rotation, the greater the flow.

Dynamic Head:

The vertical distance from the surface of the water to the point of free discharge of the water. Pipe friction is included. See Friction Head. 
Glossary of Terms

\section{Friction Head:}

The energy that must be overcome by the pump to offset the friction losses of the water moving through a pipe.

\section{Positive Displacement:}

See Volumetric Pump.

\section{Static Water Level:}

The vertical distance from the surface of the water source to ground surface where the pump is located (when the pump is not operating).

\section{Suction Head:}

The vertical distance from the surface of the water source to the center of the pump (when the pump is located above the water level).

\section{Volumetric Pump:}

A type of water pump that utilizes pistons, cylinders, and screws or rotating vanes to move water. 
APPENDIX A

Resource List for PV Information

103 
Carbon Light \& Light

110 E. Spring St.

Box 579

Saratoga, WY 82331

Gary Garber

(307) 326-5206

Electric Power Research Institute 3412 Hillview Ave.

Palo Alto, CA 94303

John Bigger

(415) $855-2178$

Florida Solar Energy Center

300 State Rd. 401

Cape Canaveral, FL 32920

David Block

(407) 783-0300 x111

Idaho Power Company

P.O. Box 70

Boise, ID 83707

John Prescott

(208) 383-2708

KC Electric Association

P.O. Box 8

Hugo, CO 80821

Jim Zabukover

(719) 743-2431

McKenzie Electric Coop., Inc.

P.O. Box 649

Watford City, ND 58854

Tom Miller

(701) 842-2311
National Renewable Energy Lab.

Portal Building, Suite 710

40912 Street, SW

Washington, DC 20024-2188

Roger Taylor

(303) 231-1332

North Carolina Solar Center

Box 7401, NCSU

Raleigh, NC 27695-7401

Bill Brooks

(919) 515-3480

Northwest Rural Public Power District

P.O. Box 249

Hay Springs, NE 69347

Rolland Skinner

(308) 638-4445

Pacific Gas and Electric Co.

3400 Crow Canyon Rd.

San Ramon, CA 94583

Steve Hester

(510) 866-5258

PV for Utilities

15 Haydn St.

Boston, MA 02131-4013

Jane Weissman

(607) 323-7377

San Isabel Electric

P.O. Box 892

Pueblo, CO 81002

Bill Wood

(719) $547-2160$

Sandia National Laboratories

PV System Design Assistance Center

P.O. Box 5800

Albuquerque, NM 87185

John Stevens

(505) $844-7717$ 
Solar Energy Industries Association

777 N. Capitol St., NE

Washington, DC 20002-4226

Rick Sellers

(202) 408-0660

SW Technology Development Institute

P.O. Box 3001

Las Cruces, NM 88003

John Wiles

(505) 646-6105

US Department of Energy

Office of Solar Energy Conservation

1000 Independence Ave., SW

Washington, DC 20585

Bud Annan

(202) $586-1720$

Utility Photovoltaic Group

357 Skyline Dr.

Hamilton, MT 59840

Jeff Serfass

(202) $457-0868$

Western Area Power Adminstration

Loveland Area Office

P.O. Box 3700

Loveland, CO 80539

Peggy Plate

(303) 490-7227 


\section{APPENDIX B}

\section{List of Pump Manufacturers and Equipment Suppliers ${ }^{15}$}

${ }^{15}$ The companies listed in this appendix undoubtedly represent an incomplete list of both pump manufacturers and PV equipment suppliers. For a more complete list, refer to the publication entitled Solar Electric Applications and Directory of the U.S. Photovoltaic Industry prepared by the Solar Energy Industries Association. Solar Energy Industries Association, Suite 805; 777 North Capitol Street NE, Washington D.C., 20002, (202) 408-0660. 
A. Y. McDonald Manufacturing Co.

P.O. Box 508

Dubuque, IA 52004-0508

(319) 583-7311

\section{Altech Energy}

7009 Raywood Rd.

Madison, WI 53713

Apollo Energy Systems, Inc.

200 Louise St.

P.O. Box 238

Navasota, TX 77868-0238

1-800-535-8588

Canadian Agtechnology Partners (CAP)

5037 50th St.

P.O. Box 2457

Olds, Alberta, Canada

TOM 1P0

(403) 556-8779

Cimarron Manufacturing, Inc.

Route 2, Box 55

Selman, OK 73834

(405) 727-4259

Dinh Company, Inc.

P.O. Box 999

Alachua, FL 32615

(904) 462-3464

Electron Connection

P.O. Box 203

Hornbrook, Ca 96044

(916) 475-3401

Flowlight Solar Power, Inc.

Hwy. 285 South

Route 1 Box 216

Espanola, NM 87532

(800) 327-6527
Grundfos Solar Pumps

U.S. Distributor: Solar Engineering 1210 Homann Dr. SE

Lacey, WA 98503

(206) 438-2110

Independent Sun Power

HC 85 Box 21

Tryon, NE 69167

(308) 587-2468

Integrated Power Corporation

7524 Standish Place

Rockville, MD 20855

(301) 294-9133

Muth Drilling

203 Pine St.

Elko, NV 89801

Photocomm, Inc.

Corporate Headquarters

7681 E. Gray Road

Scottsdale, AZ 85260

(602) 948-8003

Photocomm, Inc.

115 S. Summit Ave.

Prescott, AZ 85303

(602) 778-1616

Photocomm, Inc.

4419 E. Broadway

Tucson, AZ 85711

(602) $327-8558$

Photocomm, Inc.

930 Idaho Mary land Rd.

Grass Valley, CA 95945

(916) 477-5121 
Photocomm, Inc.

101 State Pl., Suite P

Escondito, CA 92029

(609) 739-9098

Photocomm, Inc.

9850-A Girton Drive

Lakewood, CO 80227

(303) 988-8208

Photocomm, Inc.

5117D Main St.

Downers Grove, IL 60515

(708) $971-8822$

Photocomm, Inc.

120 S. Redwood Highway

P.O. Box 329

Cave Junction, OR 97523

(503) 592-4357

Photocomm, Inc.

9806 Mula Rd.

Stafford, TX 77477

(713) 933-1578

Photron

77 W Commercial St.

Willits, CA 95490

(707) 459-3211

Remote Power, Inc.

1608 Riverside

Fort Collins, CO 80524

(303) 482-9507

Robison Solar Systems

PO Box 117B

Canton, OK 73724

(405) 886-3539
SHURflo - Headquarters

12650 Westminster Ave.

Santa Ana, CA 92706-2100

(800) 854-3218

SHURflo - East

52748 Park Six Ct.

Elkhart, IN 46514-5427

(800) 762-8094

Solar Electric Specialties Co.

P.O. Box 537

Willits, CA 95490

(707) 459-9496

Solar Engineering Services

1210 Homann Dr. SW

Lacey, WA 98503

(206) 438-2110

Solarjack

325 E. Main St.

Safford, AZ 85546

(602) 428-1092

Sunelco, Inc.

100 Skeels St.

P.O. Box 1499

Hamilton, MT 59840-1499 


\section{APPENDIX C \\ Wiring Sizing Guidelines \\ from PV Stand-Alone Handbook}




\begin{tabular}{|c|c|c|c|c|c|c|c|c|c|c|c|c|c|c|}
\hline \multicolumn{15}{|c|}{$\begin{array}{c}\text { MAXIMUM ONE-WAY WIRE DISTANCE (FT.) } \\
3 \% \text { VOLTAGE DROP-12 VOLT CIRCUITS }\end{array}$} \\
\hline & & & & & & & & & & & & & & \\
\hline \multicolumn{15}{|c|}{ AWG WIRE SIZE } \\
\hline & & & & & & & & & & & & & & \\
\hline & & 14 & 12 & 10 & 8 & 6 & 4 & 3 & 2 & 1 & $1 / 0$ & $2 / 0$ & $3 / 0$ & $4 / 0$ \\
\hline AMPS & WATTS & & & & & & & & & & & & & \\
\hline & & & & & & & & & & & & & & \\
\hline 0.5 & 6 & 110.4 & 175.6 & 279.1 & 445 & 705.9 & 1121.5 & 1417.3 & 1791 & 2250 & 2834.6 & 3564.4 & 4516.9 & 5750.8 \\
\hline 1 & 12 & 55.2 & 87.8 & 139.5 & 222.5 & 352.9 & 560.7 & 708.7 & 895.5 & 1125 & 1417.3 & 1782.2 & 2258.5 & 2875.4 \\
\hline 2 & 24 & 27.6 & 43.9 & 69.8 & 111.2 & 176.5 & 280.4 & 354.3 & 447.8 & 562.5 & 708.7 & 891.1 & 1129.2 & 1437.7 \\
\hline 4 & 48 & 13.8 & 22 & $\overline{34.9}$ & 55.6 & 88.2 & 140.2 & 177.2 & 223.9 & 281.2 & 354.3 & 445.5 & 564.6 & 718.8 \\
\hline 6 & 72 & 9.2 & 14.6 & 23.3 & 37.1 & 58.8 & 93.5 & 118.1 & 149.3 & 187.5 & 236.2 & 297 & 376.4 & 479.2 \\
\hline 8 & 96 & 6.9 & 11 & 17.4 & 27.8 & 44.1 & 70.1 & 88.6 & 111.9 & 140.6 & 177.2 & 222.8 & 282.3 & 359.4 \\
\hline 10 & 120 & 5.5 & 8.8 & 14 & 22.2 & 35.3 & 56.1 & 70.9 & 89.6 & 112.5 & 141.7 & 178.2 & 225.8 & 287.5 \\
\hline 12 & 144 & 4.6 & 7.3 & 11.6 & 18.5 & 29.4 & 46.7 & 59.1 & 74.6 & 93.7 & 118.1 & 148.5 & 188.2 & 239.6 \\
\hline 14 & 168 & 3.9 & 6.3 & 10 & 15.9 & 25.2 & 40.1 & 50.6 & 64 & 80.4 & 101.2 & 127.3 & 161.3 & 205.4 \\
\hline 16 & 192 & & 5.5 & 8.7 & 13.9 & 22.1 & 35 & 44.3 & 56 & 70.3 & 88.6 & 111.4 & 141.2 & 179.7 \\
\hline 18 & 216 & & 4.9 & 7.8 & 12.4 & 19.6 & 31.2 & 39.4 & 49.8 & 62.5 & 78.7 & 99 & 125.5 & 159.7 \\
\hline 20 & 240 & & 4.4 & 7 & 11.1 & 17.6 & 28 & 35.4 & 44.8 & 56.2 & 70.9 & 89.1 & 112.9 & 143.8 \\
\hline 25 & 300 & & & 5.6 & 8.9 & 14.1 & 22.4 & 28.3 & 35.8 & 45 & 56.7 & 71.3 & 90.3 & 115 \\
\hline 30 & 360 & & & 4.7 & 7.4 & 11.8 & 18.7 & 23.6 & 29.9 & 37.5 & 47.2 & 59.4 & 75.3 & 95.8 \\
\hline 35 & 420 & & & & 6.4 & 10.1 & 16 & 20.2 & 25.6 & 32.1 & 40.5 & 50.9 & 64.5 & 82.2 \\
\hline 40 & 480 & & & & 5.6 & 8.8 & 14 & 17.7 & 22.4 & 28.1 & 35.4 & 44.6 & 56.5 & 71.9 \\
\hline 45 & 540 & & & & & 7.8 & 12.5 & 15.7 & 19.9 & 25 & 31.5 & 39.6 & 50.2 & 63.9 \\
\hline 50 & 600 & & & & & 7.1 & 11.2 & 14.2 & 17.9 & 22.5 & 28.3 & 35.6 & 45.2 & 57.5 \\
\hline 60 & 720 & & & & & & 9.3 & 11.8 & 14.9 & 18.7 & 23.6 & 29.7 & 37.6 & $\overline{47.9}$ \\
\hline 70 & 840 & & & & & & 8 & 10.1 & 12.8 & 16.1 & 20.2 & 25.5 & 32.3 & 41.1 \\
\hline 80 & 960 & & & & & & & 8.9 & 11.2 & 14.1 & 17.4 & 22.3 & 28.2 & 35.9 \\
\hline 90 & 1080 & & & & & & & & 10 & 12.5 & 15.7 & 19.8 & 25.1 & 31.9 \\
\hline 100 & 1200 & & & & & & & & & 11.2 & 14.2 & 17.8 & 22.6 & 28.8 \\
\hline 110 & 1320 & & & & & & & & & 10.2 & 12.9 & 16.2 & 20.5 & 26.1 \\
\hline 120 & 1440 & & & & & & & & & & 11.8 & 14.9 & 18.8 & 24 \\
\hline 130 & 1560 & & & & & & & & & & & 13.7 & 17.4 & 22.1 \\
\hline 140 & 1680 & & & & & & & & & & & 12.7 & 16.1 & 20.5 \\
\hline 150 & 1800 & & & & & & & & & & & & 15.1 & 19.2 \\
\hline 160 & 1920 & & & & & & & & & & & & 14.1 & 18 \\
\hline 170 & 2040 & & & & & & & & & & & & & 16.9 \\
\hline 180 & 2160 & & & & & & & & & & & & & 16 \\
\hline 190 & 2280 & & & & & & & & & & & & & 15.1 \\
\hline 200 & 2400 & & & & & & & & & & & & & \\
\hline
\end{tabular}




\begin{tabular}{|c|c|c|c|c|c|c|c|c|c|c|c|c|c|c|}
\hline \multicolumn{15}{|c|}{ MAXIMUM ONE-WAY WIRE DISTANCE (FT.) } \\
\hline \multicolumn{15}{|c|}{$3 \%$ VOLTAGE DROP-120 VOLT CIRCUITS } \\
\hline & & & & & & & & & & & & & & \\
\hline \multicolumn{15}{|c|}{ AWG WIRE SIZE } \\
\hline & & & & & & & & & & & & & & \\
\hline & & 14 & 12 & 10 & 8 & 6 & 4 & 3 & 2 & 1 & $1 / 0$ & $2 / 0$ & $3 / 0$ & $4 / 0$ \\
\hline AMPS & WATTS & & & & & & & & & & & & & \\
\hline & & & & & & & & & & & & & & \\
\hline 0.5 & 60 & 1104.3 & 1756.1 & 2790.1 & 4449.9 & 7058.8 & 11215 & 14173.2 & 17910.4 & 22500 & 28346.5 & 35643.6 & 45169.4 & 57508 \\
\hline 1 & 120 & 552.1 & 878 & 1395.3 & 2225 & 3229.4 & 5607.5 & 7086.6 & 8955.2 & 11250 & 14173.2 & 17821.8 & 22584.7 & 28754 \\
\hline 2 & 240 & 276.1 & 439 & 697.7 & 1112.5 & 1764.7 & 2803.7 & 3543.3 & 4477.6 & 5625 & 7086.6 & 8910.9 & 11292.3 & 14377 \\
\hline 4 & 480 & 138 & 219.5 & 348.8 & 556.2 & 882.4 & 1401.9 & 1771.7 & 2238.8 & 2812.5 & 3543.3 & 4455.4 & 5646.2 & 7188.5 \\
\hline 6 & 720 & 92 & 146.3 & 232.6 & 370.8 & 588.2 & 934.6 & 1181.1 & 1492.5 & 1875 & 2362.2 & 2970.3 & 3764.1 & 4792.3 \\
\hline$\overline{8}$ & 960 & 69 & 109.8 & 174.4 & 278.1 & 441.2 & 700.9 & 885.8 & 1119.4 & 1406.2 & 1771.7 & 2227.7 & 2823.1 & 3594.2 \\
\hline 10 & 1200 & 55.2 & 87.8 & 139.5 & 222.5 & 352.9 & 560.7 & 708.7 & 895.5 & 1125 & 1417.3 & 1782.2 & 2258.5 & 2875.4 \\
\hline 12 & 1440 & 46 & 73.2 & 116.3 & 185.4 & 294.1 & 467.3 & 590.6 & 746.3 & 937.5 & 1181.1 & 1485.1 & 1882.1 & 2396.2 \\
\hline 14 & 1680 & 39.4 & 62.7 & 99.7 & 158.9 & 252.1 & 400.5 & 506.2 & 639.7 & 803.6 & 1012.4 & 1273 & 1613.2 & 2053.9 \\
\hline 16 & 1920 & & 54.9 & 87.2 & 139.1 & 220.6 & 350.5 & 442.9 & 559.7 & 703.1 & 885.8 & 1113.9 & \begin{tabular}{|l|l|}
1411.5 \\
\end{tabular} & 1797.1 \\
\hline 18 & 2160 & & 48.8 & 77.5 & 123.6 & 196.1 & 311.5 & 393.7 & 497.5 & 625 & 787.4 & 990.1 & 1254.7 & 1597.4 \\
\hline 20 & 2400 & & 43.9 & 69.8 & 111.2 & 176.5 & 280.4 & 354.3 & 447.8 & 562.5 & 708.7 & 891.1 & 1129.2 & 1437.7 \\
\hline 25 & 3000 & & & 55.8 & 89 & 141.2 & 224.3 & 283.5 & 358.2 & 450 & 566.9 & 712.9 & 903.4 & 1150.2 \\
\hline 30 & 3600 & & & 46.5 & 74.2 & 117.6 & 186.9 & 236.2 & 298.5 & 375 & 477.2 & 594.1 & $\begin{array}{l}752.8 \\
\end{array}$ & 958.5 \\
\hline 35 & 4200 & & & & 63.6 & 100.8 & 160.2 & 202.5 & 255.9 & 321.4 & 404.9 & 509.2 & 645.3 & 821.5 \\
\hline 40 & 4800 & & & & 55.6 & 88.2 & 140.2 & 177.2 & 223 & 281.2 & 354.3 & 445.5 & 564.6 & 718.8 \\
\hline 45 & 5400 & & & & & 78.4 & 124.6 & \begin{tabular}{ll|}
157.5 \\
\end{tabular} & 199 & 250 & 315 & 396 & 501.9 & 639 \\
\hline 50 & 6000 & & & & & 70.6 & 112.6 & 141.7 & \begin{tabular}{ll|}
179.1 \\
\end{tabular} & 225 & 283.5 & 297 & 451.7 & 575.1 \\
\hline 60 & 7200 & & & & & & 93.5 & $\begin{array}{ll}118.1 \\
\end{array}$ & 149.3 & 187.5 & 236.2 & 254.5 & $\begin{array}{l}376.4 \\
\end{array}$ & 479.2 \\
\hline 70 & 8400 & & & & & & 80.1 & 101.2 & 127.9 & 160.7 & 202.5 & 222.8 & 322.6 & 410.8 \\
\hline 80 & 9600 & & & & & & & 88.6 & 111.9 & 140.6 & 177.2 & 198 & 282.3 & 359.4 \\
\hline 90 & 10800 & & & & & & & & $\begin{array}{l}99.5 \\
\end{array}$ & 125 & 157.5 & 178.2 & 250.9 & 319.5 \\
\hline 100 & 12000 & & & & & & & & & 112.5 & $\begin{array}{ll}141.7 \\
\end{array}$ & 162 & 225.8 & 287.5 \\
\hline 110 & 13200 & & & & & & & & & 102.3 & 128.8 & 148.5 & 205.3 & 261.4 \\
\hline 120 & 14400 & & & & & & & & & & 118.1 & 137.1 & 188.2 & 239.6 \\
\hline 130 & 15600 & & & & & & & & & & & 127.3 & $\begin{array}{l}173.7 \\
\end{array}$ & 221.2 \\
\hline 140 & 16800 & & & & & & & & & & & 12.7 & 161.3 & 205.4 \\
\hline 150 & 18000 & & & & & & & & & & & & 150.6 & 191.7 \\
\hline 160 & 19200 & & & & & & & & & & & & 141.2 & 179.7 \\
\hline 170 & 20400 & & & & & & & & & & & & & 169.1 \\
\hline 180 & 21600 & & & & & & & & & & & & & 159.7 \\
\hline 190 & 22800 & & & & & & & & & & & & & 151.3 \\
\hline 200 & 24000 & & & & & & & & & & & & & \\
\hline
\end{tabular}




\begin{tabular}{|c|c|c|c|c|c|c|c|c|c|c|c|c|c|c|}
\hline \multicolumn{15}{|c|}{ MAXIMUM ONE-WAY WIRE DISTANCE (FT.) } \\
\hline & & & & & & & & & & & & & & \\
\hline \multicolumn{15}{|c|}{ AWG WIRE SIZE } \\
\hline & & & & & & & & & & & & & & \\
\hline & & 14 & 12 & 10 & 8 & 6 & 4 & 3 & 2 & $\mathbf{1}$ & $1 / 0$ & $2 / 0$ & $3 / 0$ & $4 / 0$ \\
\hline AMPS & WATTS & & & & & & & & & & & & & \\
\hline & & & & & & & & & & & & & & \\
\hline 0.5 & 24 & 441.8 & 702.4 & 1116.2 & 1780 & 2823.6 & 4486 & 5669.2 & 7164.2 & 9000 & 11338.6 & 14257.4 & 18067.8 & 23003.2 \\
\hline 1 & 48 & 220.8 & 351.2 & 558.2 & 890 & 1411.8 & 2243 & 2834.6 & 3582 & 4500 & 5669.2 & 7128.8 & $9 \overline{9033.8}$ & 11501.6 \\
\hline 2 & 96 & 110.4 & 175.6 & 279 & 445 & 705.8 & 1121.4 & 1417.4 & 1791 & 2250 & 2834.6 & 3564.4 & 4517 & 5750.8 \\
\hline 4 & 192 & 55.2 & 87.8 & 139.6 & 222.4 & 353 & 560.8 & 708.6 & 895.6 & 1125 & 1417.4 & 1782.2 & 2258.4 & 2875.4 \\
\hline 6 & 288 & 36.8 & 58.6 & 93 & 148.4 & 235.2 & 373.8 & 472.4 & 597 & 750 & 944.8 & 1188.2 & 1505.6 & 1917 \\
\hline 8 & 384 & 27.6 & 44 & 69.8 & 111.2 & 176.4 & 280.4 & 354.4 & 447.8 & 562.4 & 708.6 & 891 & 1129.2 & 1437.6 \\
\hline 10 & 480 & 22 & 35.2 & 55.8 & 89 & 141.2 & 224.2 & 283.4 & 358.2 & 450 & 567 & 712.8 & 903.4 & 1150.2 \\
\hline 12 & 576 & 18.4 & 29.2 & 46.6 & 74.2 & 117.6 & 187 & 236.2 & 298.6 & 375 & 472.4 & 594 & 752.8 & 958.4 \\
\hline 14 & 672 & 15.8 & 25 & $\begin{array}{l}39.8 \\
\end{array}$ & 63.6 & 100.8 & 160.2 & 202.4 & 255.8 & 321.4 & 405 & 509.2 & 645.2 & 821.6 \\
\hline 16 & 768 & & 22 & 34.8 & 55.6 & 88.2 & 140.2 & 177.2 & 223.8 & 281.2 & 354.4 & 445.6 & 564.6 & 718.8 \\
\hline 18 & 864 & & 19.6 & 31 & 49.4 & 78.4 & 124.6 & 157.4 & 199 & 250 & 315 & 396 & 501.8 & 639 \\
\hline 20 & 960 & & 17.6 & 28 & 44.4 & 70.6 & 112.2 & 141.8 & 179.2 & 225 & 283.4 & 356.4 & 451.6 & 575 \\
\hline 25 & 1200 & & & 22.4 & 35.6 & 56.4 & 89.8 & 113.4 & 143.2 & 180 & 226.8 & 285.2 & 361.4 & 460 \\
\hline 30 & 1440 & & & 18.6 & 29.6 & 47 & 74.8 & 94.4 & 119.4 & 150 & 189 & 237.6 & 301.2 & 383.4 \\
\hline 35 & 1680 & & & & 25.4 & 40.4 & 64 & 81 & 102.4 & 128.6 & 162 & 203.6 & 258.2 & 328.6 \\
\hline 40 & 1920 & & & & 22.2 & 35.2 & 56 & 70.8 & 89.6 & 112.4 & 141.8 & 178.2 & 225.8 & 287.6 \\
\hline 45 & 2160 & & & & & 31.4 & 49.8 & 63 & 79.6 & 100 & 126 & 158.4 & 200.8 & 255.6 \\
\hline 50 & 2400 & & & & & 28.2 & 44.8 & 56.6 & 71.6 & 90 & 113.4 & 142.6 & 180.6 & 230 \\
\hline 60 & 2880 & & & & & & 37.4 & 47.2 & 59.8 & 75 & 94.4 & 118.8 & 150.6 & 191.6 \\
\hline 70 & 3360 & & & & & & 32 & 40.4 & 51.2 & 64.2 & 81 & 101.8 & 129 & $\overline{164.4}$ \\
\hline 80 & 3840 & & & & & & & 35.4 & 44.8 & 56.2 & 70.8 & 89.2 & 113 & 143.8 \\
\hline 90 & 4320 & & & & & & & & 39.8 & 50 & 63 & 61.2 & 100.4 & 127.8 \\
\hline 100 & 4800 & & & & & & & & & 45 & 56.6 & 71.2 & 90.4 & 115 \\
\hline 110 & 5280 & & & & & & & & & 41 & 51.6 & 64.8 & 82.2 & 104.6 \\
\hline 120 & 5760 & & & & & & & & & & 47.2 & 59.4 & 75.2 & 95.8 \\
\hline 130 & 6240 & & & & & & & & & & & 54.8 & 69.4 & 88.4 \\
\hline 140 & 6720 & & & & & & & & & & & 51 & 64.6 & 82.2 \\
\hline 150 & 7200 & & & & & & & & & & & & 60.2 & 76.6 \\
\hline 160 & 7680 & & & & & & & & & & & & 56.4 & 71.8 \\
\hline 170 & 8160 & & & & & & & & & & & & & 67.6 \\
\hline 180 & 8640 & & & & & & & & & & & & & 63.8 \\
\hline 190 & 9120 & & & & & & & & & & & & & 60.6 \\
\hline 200 & 9600 & & & & & & & & & & & & & \\
\hline
\end{tabular}




\begin{tabular}{|c|c|c|c|c|c|c|c|c|c|c|c|c|c|c|}
\hline \multicolumn{15}{|c|}{ MAXIMUM ONE-WAY WIRE DISTANCE (FT.) } \\
\hline \multicolumn{15}{|c|}{$3 \%$ VOLTAGE DROP- 24 VOLT CIRCUITS } \\
\hline & & & & & & & & & & & & & & \\
\hline \multicolumn{15}{|c|}{ AWG WIRE SIZE } \\
\hline & & & & & & & & & & & & & & \\
\hline & & 14 . & 12 & 10 & 8 & 6 & 4 & 3 & 2 & 1 & $1 / 0$ & $2 / 0$ & $3 / 0$ & $4 / 0$ \\
\hline AMPS & WATTS & & & & & & & & & & & & & \\
\hline & & & & & & & & & & & & & & \\
\hline 0.5 & 12 & 220.9 & 351.2 & 558.1 & 890 & 1411.8 & 2243 & 2834.6 & 3582.1 & 4500 & 5669.3 & 7128.7 & 9033.9 & 11501.6 \\
\hline 1 & 24 & 110.4 & 175.6 & 279.1 & 445 & 705.9 & 1121.5 & 1417.3 & 1791 & 2250 & 2834.6 & 3564.4 & 4516.9 & 5750.8 \\
\hline 2 & 48 & 55.2 & 87.8 & 139.5 & 222.5 & 352.9 & 560.7 & 708.7 & 895.5 & 1125 & 1417.3 & 1782.2 & 2258.5 & 2875.4 \\
\hline 4 & 96 & 27.6 & 43.9 & 69.8 & 111.2 & 176.5 & 280.4 & 354.3 & 447.8 & 562.5 & 708.7 & 891.1 & 1129.2 & 1437.7 \\
\hline 6 & 144 & 18.4 & 29.3 & 46.5 & 74.2 & 117.6 & 186.9 & 236.2 & 298.5 & 375 & 472.4 & 594.1 & 752.8 & 958.5 \\
\hline 8 & 192 & 13.8 & 22 & 34.9 & 55.6 & 88.2 & 140.2 & 177.2 & 223.9 & 281.2 & 354.3 & 445.5 & 564.6 & 718.8 \\
\hline 10 & 240 & 11 & 17.6 & 27.9 & 44.5 & 70.6 & 112.1 & 141.7 & 179.1 & 225 & 283.5 & 356.4 & 451.7 & 575.1 \\
\hline 12 & 288 & 9.2 & 14.6 & 23.3 & 37.1 & 58.8 & 93.5 & 118.1 & 149.3 & 187.5 & 236.2 & 297 & 376.4 & 479.2 \\
\hline 14 & 336 & 7.9 & 12.5 & 19.9 & 31.8 & 50.4 & 80.1 & 101.2 & 127.9 & 160.7 & 202.5 & 254.6 & 322.6 & 410.8 \\
\hline 16 & 384 & & 11 & $\overline{17.4}$ & 27.8 & 44.1 & 70.1 & 88.6 & 111.9 & 140.6 & 177.2 & 222.8 & 282.3 & 359.4 \\
\hline 18 & 432 & & 9.8 & 15.5 & 24.7 & 39.2 & 62.3 & 78.7 & 99.5 & 125 & 157.5 & 198 & 250.9 & 319.5 \\
\hline 20 & 480 & & 8.8 & 14 & 22.2 & 35.3 & 56.1 & 70.9 & 89.6 & 112.5 & 141.7 & 178.2 & 225.8 & 287.5 \\
\hline 25 & 600 & & & 11.2 & 17.8 & 28.2 & 44.9 & 56.7 & 71.6 & 90 & 113.4 & 142.6 & 180.7 & 230 \\
\hline 30 & 720 & & & 9.3 & 14.8 & 23.5 & 37.4 & 47.2 & 59.7 & 75 & 94.5 & 118.8 & 150.6 & 191.7 \\
\hline 35 & 840 & & & & 12.7 & 20.2 & 32 & 40.5 & 51.2 & 64.3 & 81 & 101.8 & 129.1 & 164.3 \\
\hline 40 & 960 & & & & 11.1 & 17.6 & 28 & 35.4 & 44.8 & 56.2 & 70.9 & 89.1 & 112.9 & 143.8 \\
\hline 45 & 1080 & & & & & 15.7 & 24.9 & 31.5 & 39.8 & 50 & 63 & 79.2 & 100.4 & 127.8 \\
\hline 50 & 1200 & & & & & 14.1 & 22.4 & 28.3 & 35.8 & 45 & 56.7 & 71.3 & 90.3 & 115 \\
\hline 60 & 1440 & & & & & & 18.7 & 23.6 & 29.9 & 37.5 & 47.2 & 59.4 & 75.3 & 95.8 \\
\hline 70 & 1680 & & & & & & 16 & 20.2 & 25.6 & 32.1 & 40.5 & 50.9 & 64.5 & 82.2 \\
\hline 80 & 1920 & & & & & & & 17.7 & 22.4 & 28.1 & 35.4 & 44.6 & 56.5 & 71.9 \\
\hline 90 & 2160 & & & & & & & & 19.9 & 25 & 31.5 & 39.6 & 50.2 & 63.9 \\
\hline 100 & 2400 & & & & & & & & & 22.5 & 28.3 & 35.6 & 45.2 & 57.5 \\
\hline 110 & 2640 & & & & & & & $\therefore$ & & 20.5 & 25.8 & 32.4 & 41.1 & 52.3 \\
\hline 120 & 2880 & & & & & & & & & & 23.6 & 29.7 & 37.6 & 47.9 \\
\hline 130 & 3120 & & & & & & & & & & & 27.4 & 34.7 & 44.2 \\
\hline 140 & 3360 & & & & & & & & & & & 25.5 & 32.3 & 41.1 \\
\hline 150 & 3600 & & & & & & & & & & & & 30.1 & 38.3 \\
\hline 160 & 3840 & & & & & & & & & & & & 28.2 & 35.9 \\
\hline 170 & 4080 & & & & & & & & & & & & & 33.8 \\
\hline 180 & 4320 & & & & & & & & & & & & & 31.9 \\
\hline 190 & 4560 & & & & & & & & & & & & & 30.3 \\
\hline 200 & 4800 & & & & & & & & & & & & & \\
\hline
\end{tabular}


116 


\section{PRINTING HISTORY}

Reprinted June 1993

Reprinted October 1994 